\title{
Techno-Economic Feasibility of Highly Efficient Cost-Effective Thermoelectric-SOFC Hybrid Power Generation Systems
}

Final Technical Report

October 1, 2005 - September 30, 2007

Jifeng Zhang and Jean Yamanis

December 2007

DE-FC26-05NT42626

United Technologies Research Center

411 Silver Lane

East Hartford, CT 06108
BSST LLC

5462 Irwindale Ave., Irwindale, CA 91706 


\section{DISCLAIMER}

This report was prepared as an account of work sponsored by an agency of the United States Government. Neither the United States Government nor any agency thereof, nor any of their employees, makes any warranty, express or implied, or assumes any legal liability or responsibility for the accuracy, completeness, or usefulness of any information, apparatus, product, or process disclosed, or represents that its use would not infringe privately owned rights. Reference herein to any specific commercial product, process, or service by trade name, trademark, manufacturer, or otherwise does not necessarily constitute or imply its endorsement, recommendation, or favoring by the United States Government or any agency thereof. The views and opinions of authors expressed herein do not necessarily state or reflect those of the United States Government or any agency thereof. 


\begin{abstract}
Solid oxide fuel cell (SOFC) systems have the potential to generate exhaust gas streams of high temperature, ranging from 400 to $800^{\circ} \mathrm{C}$. These high temperature gas streams can be used for additional power generation with bottoming cycle technologies to achieve higher system power efficiency. One of the potential candidate bottoming cycles is power generation by means of thermoelectric (TE) devices, which have the inherent advantages of low noise, low maintenance and long life. This study was to analyze the feasibility of combining coal gas based SOFC and TE through system performance and cost techno-economic modeling in the context of multi-MW power plants, with $200 \mathrm{~kW}$ SOFC-TE module as building blocks.

System and component concepts were generated for combining SOFC and TE covering electrothermo-chemical system integration, power conditioning system (PCS) and component designs. SOFC cost and performance models previously developed at United Technologies Research Center were modified and used in overall system analysis. The TE model was validated and provided by BSST. The optimum system in terms of energy conversion efficiency was found to be a pressurized SOFC-TE, with system efficiency of $65.3 \%$ and cost of $\$ 390 / \mathrm{kW}$ of manufacturing cost. The pressurization ratio was approximately 4 and the assumed ZT of the TE was 2.5.

System and component specifications were generated based on the modeling study. The major technology and cost barriers for maturing the system include pressurized SOFC stack using coal gas, the high temperature recycle blowers, and system control design. Finally, a 4-step development roadmap is proposed for future technology development, the first step being a $1 \mathrm{~kW}$ proof-ofconcept demonstration unit.
\end{abstract}




\section{Table of Contents}

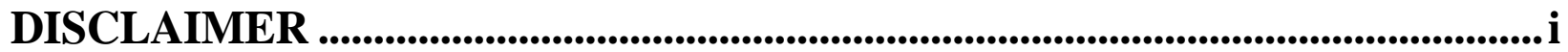

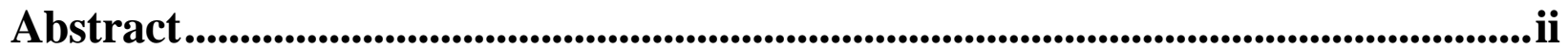

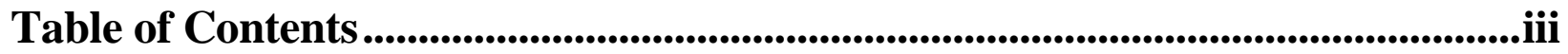

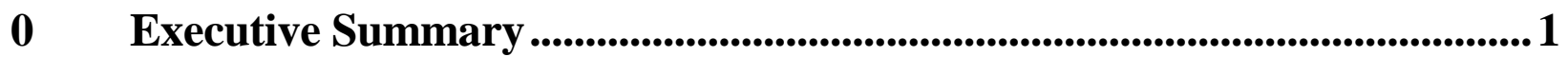

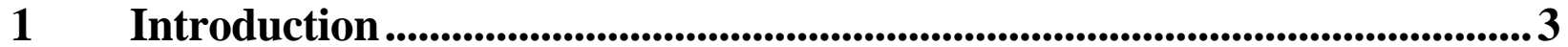

$1.1 \quad$ SOFC and Thermoelectric Technologies .........................................................................................4

1.2 Objectives and Scope...........................................................................................................................5

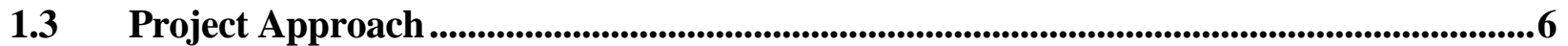

2 Concept Generation and Analysis ..........................................................

2.1 Goal of the CGS and Generation Process ..........................................................................................8

2.2 Description of the Generated Concepts................................................................................................9

2.3 Summary ...................................................................................................................................................... 15

3 TE Material Benchmarking (BSST) ......................................................16

$3.1 \quad$ Approach..............................................................................................................................16

3.2 Results and Discussions.............................................................................................................17

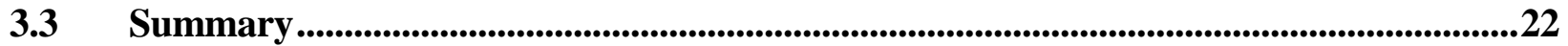

$4 \quad$ System Modeling .......................................................................................................223

4.1 Subsystem Model Development .................................................................................................23

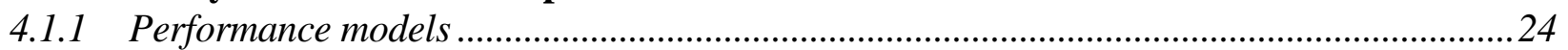

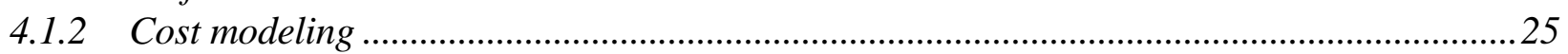

4.2 System Integration ..............................................................................................................................26

5 System Down-Selection .......................................................................................22

$5.1 \quad$ System Results and Characteristics ......................................................................................................27

5.2 System Design Envelope and Sensitivity Analysis ....................................................................28

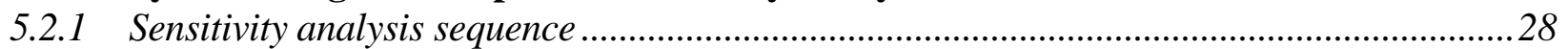

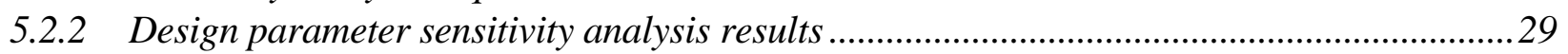

$5.3 \quad$ System Architecture Analysis.................................................................................................31

5.3.1 Architecture A1: Ambient pressure SOFC + ITE with 1 air blower ...................................... 31

5.3.2 Architecture A2: Ambient pressure SOFC + 2TE with 1 shared air blower ..........................32

5.3.3 Architecture A3: Ambient pressure SOFC + 2TE with 2 air blowers.....................................

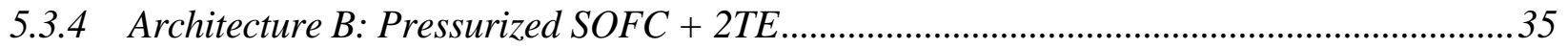

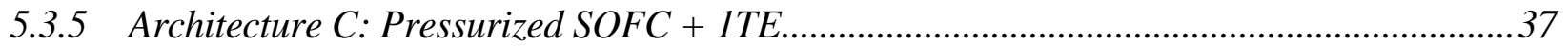

5.4 System Optimization.................................................................................................................37

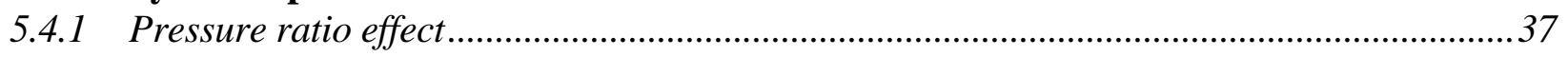

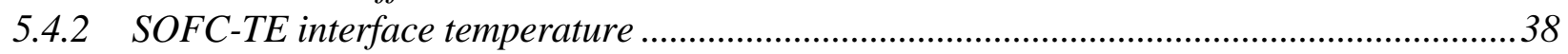

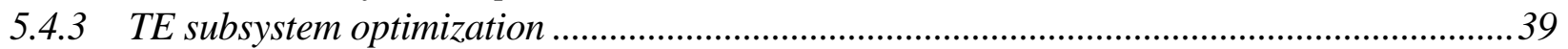

5.5 Optimum System Size................................................................................................................................40

5.6 Summary .............................................................................................................................................4

6 Product and Performance Specifications.....................................................43

6.1 Product Working Principles .......................................................................................................................43 
6.1.1 Working principles of the pressurized SOFC-TE system ..................................................43

6.1.2 Working principles of an ambient pressure SOFC-TE system ...........................................43

6.1.3 Power conditioning system (PCS) diagram and working principle ...................................44

6.1.4 System operation modes and dynamic responses.........................................................45

6.2 System Performance Specifications ...................................................................................................45

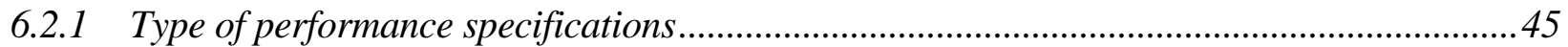

6.2.2 Detailed System and Components Performance Specifications ...........................................45

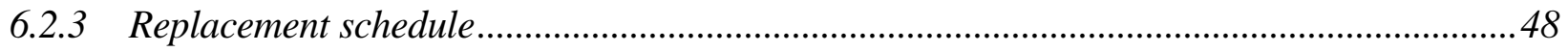

6.3 System Cost Specifications...................................................................................................................49

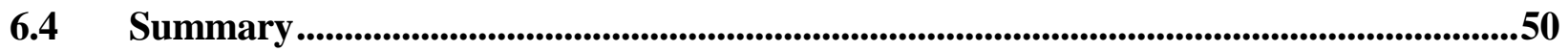

7 Evaluate Barriers and Enablers........................................................................51

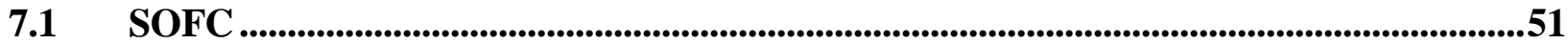

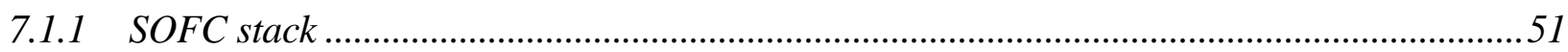

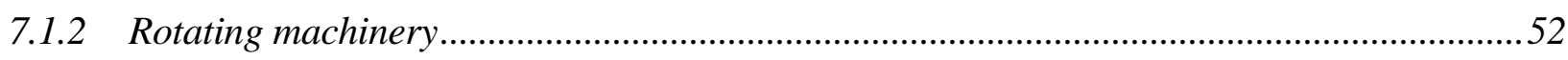

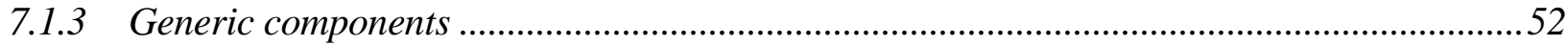

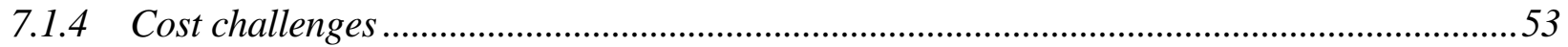

7.2 Thermoelectric Generator ...........................................................................................................53

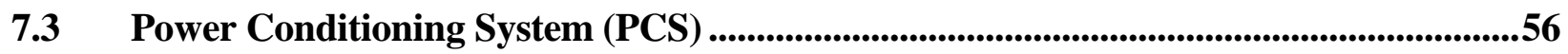

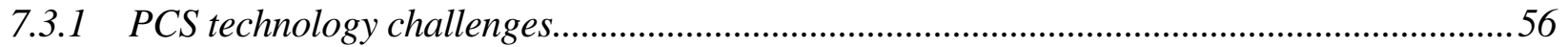

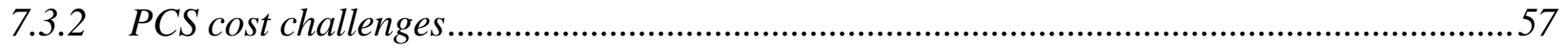

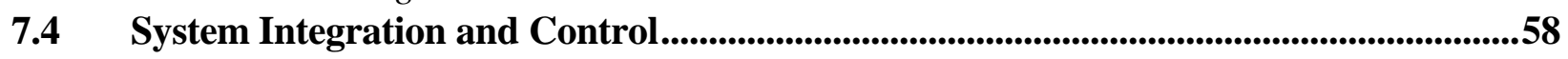

7.5 Summary ........................................................................................................................................................59

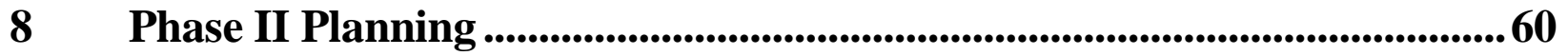

8.1 Roadmap for Technology Maturation ....................................................................................................60

8.2 Phase II Work Proposed ....................................................................................................................................661

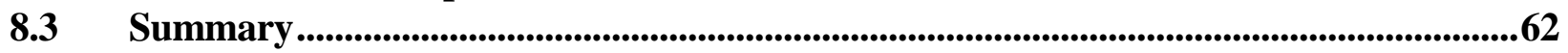

9 Summary and Conclusions .............................................................63

List of Figures..........................................................................................................65

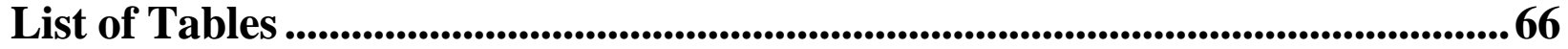

References .................................................................................................................................67

Bibliography ........................................................... Error! Bookmark not defined.

List of Acronyms and Abbreviations ........................................................ 70 


\section{Executive Summary}

Techno-economic feasibility analysis for hybrid solid oxide fuel cell-tThermoelectric (SOFC-TE) systems was conducted in this study. SOFC has the potential to be a competitive technology for power generation due to its inherent high efficiency and near-zero emission. Thermoelectric generators can be used to generate additional power with the SOFC exhaust gas. The goal of this study was to identify the optimal system configuration to reach the overall system thermal to electrical efficiency of $65 \%$ with a manufacturing cost of $\$ 400 / \mathrm{kWe}$ or less. The targeted power plant in the long term is multi-MW coal power plants. For now, the project scope was limited to $200 \mathrm{~kW}$ power plants for the purpose of technology evaluation.

TE generators as heat recovery devices can be put into multiple locations in an SOFC subsystem. There are also different choices for component and power conditioning system design. Following two concept generation sessions using the proprietary concept generation process at United Technologies Research Center (UTRC), experts from inside and outside UTRC gathered to understand the design goal and to brainstorm ideas for the desired system. Ten concepts were generated for system integration and component design. These concepts were first evaluated qualitatively or using back-of-the-envelope quantitative analysis. Three system concepts that deserved detailed modeling studies were identified, including two ambient pressure SOFC systems and one pressurized SOFC system. The component and power conditioning concepts were treated as add-on or subset of the three aforementioned systems.

For the system analysis, previous SOFC-CHP models developed by United Technologies Corporation (UTC) were modified for the SOFC-TE concept evaluation. BSST's TE model was added to the model library and system models were built for each system configuration from the concept generation. The cost library was extrapolated to cover the range of $5-200 \mathrm{~kW}$. The model was validated against publicly available cost data.

To understand system performance characteristics, system sensitivity analysis was conducted for major design variables. Other than the efficiency of power conditioning system (PCS) and cell voltage, which are common to any SOFC system, the heat exchanger size and the efficiency of rotating machinery, including both the turbine and air blowers, affect the system electrical efficiency greatly relative to other balance of plant (BOP) components.

The cost and performance of ambient pressure and pressurized SOFC-TE systems were modeled and some of the systems included several different configurations, the latter being mainly the location of the heat exchangers and the blowers. The best system configuration to reach the project target was identified as a pressurized SOFC with a TE at the downstream of the SOFC air preheater. The optimum pressure ratio is approximately 4 and the system efficiency is $65.3 \%$ with the ZT of TE materials at 2.5. The system manufacturing cost is $\$ 390 / \mathrm{kW}$. The optimum working condition for the TE blowers was found through a performance trade study. If an ambient pressure SOFC system is used, the highest system efficiency is $51 \%$ with TE making $6 \%$ contribution. 
The system technical and cost specifications were generated based on the modeling results. Then, the specifications for major components such as the blower capacity were derived from the system design parameters.

Technology and cost barriers for deploying the SOFC-TE hybrid systems were evaluated. For the SOFC sub-system, major technology barriers include the pressurized stack using coal gas as fuel, reliable blowers for the cathode and anode recycle that work at $700-1000^{\circ} \mathrm{C}$ and the system control design. On the TE sub-system, TE material and heat transfer design still need development. The PCS that handles DC electricity from two subsystems with different voltage and amount of power may require a novel design to get high efficiency. If the DC bus of a central power plant were adopted, the design for interfacing the hybrid SOFC-TE would need to be developed. Significant cost reduction is still needed from today's manufacturing cost of $\$ 800 / \mathrm{kW}$ to the $\$ 400 / \mathrm{kW}$ cost target, which could be achieved through high volume production, combination of certain components, and novel designs such as the power plant DC bus.

A staged SOFC-TE development plan is being proposed from today's feasibility analysis to the ultimate multi-MW power plant application. A proof-of-concept unit is proposed for the next phase, which is likely to help understand the system performance and technical risks in greater detail, as well as model validation. 


\section{Introduction}

Worldwide, total energy use is, according to the International Energy Outlook 2006 reference case [1], expected to grow from 421 quadrillion British thermal units (Btu) in 2003 to 563 quadrillion Btu in 2015 and to 722 quadrillion Btu in 2030. This is an increase of more than 300 quadrillion Btu in less than 30 years, and not far way from a doubling of energy use during the time period.

Total primary energy consumption in the U.S. is, according to the reference case in the Annual Energy Outlook 2006 [2], projected to increase from 99.7 quadrillion Btu in 2004 to 127.0 quadrillion Btu in 2025.

In 1940, 10\% of energy consumption in the U.S. was used to produce electricity. In 1970, that fraction was $25 \%$ and today it is $40 \%$. All this shows electricity's growing importance as a source of energy supply.

Today, the U.S. operates a fleet of about 10,000 power plants. The average thermal efficiency is around 33\%. Efficiency has not changed much since 1960 because of slow turnover of the capital stock and the inherent inefficiency of central power generation that cannot recycle heat. Power plants are generally long-lived investments; the majority of the existing capacity is 30 or more years old [3]. Already by 1965, conventional steam turbine technology had reached roughly $33 \%$ efficiency. Today's advanced combustion turbine technology can produce electricity at over $40 \%$ efficiency when operated alone [2].

Figures for losses in transmission and distribution systems are between 6 and $8 \%$, depending on the geographical location. Transmission and distribution losses depend on how heavily the system is loaded. The average transmission and distribution losses in the U.S. have grown from about 5\% in 1970 to $9.5 \%$ in 2001, due to heavier utilization and more frequent congestion [3]. There is therefore a need for improvements in existing facilities and additional new electric power generation capacity during the coming years.

Coal-fired power plants have a long working life and, with the extensive investments being made in many parts of the world, coal is likely to remain an important source of energy well into this century. The coal share of the U.S. energy portfolio is projected to decline slightly, from $50 \%$ in 2004 to $49 \%$ in 2020, before increasing to $57 \%$ in 2030. Additions to coal-fired generating capacity in the reference case in [2] are projected to $174 \mathrm{GW}$ of new coal-fired generating capacity between 2004 and 2030.

The energy systems of tomorrow will rely on a mix of advanced, clean, efficient technologies for energy supply and use. Hydrogen is considered to have the potential to provide clean energy at the point of use. Fossil fuels, notably coal and natural gas, coupled with $\mathrm{CO}_{2}$ capture and storage, could provide the transitional pathway to the longer-term objective of a hydrogen economy based on renewable energy [4]. 
Technology for fuel flexibility coming from the U.S. DOE fossil energy fuel cell program can provide a bridge to the hydrogen economy. There is need and value for providing energy storage technologies at central power plants; especially coal-based plants. One significant benefit involves enabling central coal plants with load leveling and peak load electricity supply capabilities. Solid oxide fuel cells (SOFCs) could play an important role in providing flexible, highly efficient additions to state-of-the-art central power Integrated Gasification Combined Cycle (IGCC) coal plants.

\subsection{SOFC and Thermoelectric Technologies}

Solid oxide fuel cells are highly efficient, high temperature energy conversion systems that can accommodate a large range of fossil fuels, such as natural gas or coal syngas. Although large scale coal-fired power plants today can reach very high efficiencies above 50\%, SOFCs approach zeroemission due to the physical separation between air and fuel, meanwhile bringing inherent high efficiency. In particular, virtually no NOx is present in the exhaust stream and lower carbon dioxide emissions (i.e., due to high efficiency) are released compared to other technologies such as gasturbines or internal combustion engines.

SOFC technology is rapidly improving and achieving both cost and efficiency targets. Recently, solid-state energy conversion alliance (SECA) reported that prototype fuel cell systems with an efficiency of $38 \%$ at a volume-scaled manufacturing cost of $\$ 746 / \mathrm{kW}$ [5]. This is an important milestone towards the SECA system cost of $\$ 400 / \mathrm{kW}$ for a SOFC system by 2010 . An objective of introducing fuel cell technology in FutureGen, which is a DOE demonstration of coal technology in advanced power systems, is to improve the electric generating efficiency in a power station with near-zero emissions and efficient carbon dioxide sequestration.

Envisioned applications for SOFC include multi-MW hybrid (SOFC-Gas Turbine) power plant systems. For these applications, electrical efficiencies well above 60\% can be achieved [6] (fueled with natural gas). While highly efficient, these power plants rely on complex architectures that do not scale down economically to the small 10kW-range systems as the ones developed under SECA. Because of their high operating temperature and high efficiency, SOFC-based cooling heating and power (CHP) systems are viewed as a possible "Game-Changer" in the commercial market (100500kWel). United Technologies Research Center (UTRC) recently developed and analyzed a large set of proprietary conceptual CHP systems based on natural gas fueled SOFC with electrical efficiencies ranging from 50\% (ambient pressure systems) to 70\% (pressurized systems). Detailed 8760-hr analysis over a large range of building locations, size and types showed very attractive paybacks in areas such as California, with $40 \%$ of the cases having less than 3-year payback [7]. Importantly, the concepts developed provide high SOFC system discharge temperature, ranging from 400 to $700^{\circ} \mathrm{C}$, well above those in conventional system designs with typically 200 to $300^{\circ} \mathrm{C}$ waste heat.

Improved energy conversion efficiency of fossil fuels can be achieved through integration of thermoelectric (TE) conversion devices with the waste heat exhaust streams, such as high temperature fuel cell power generation systems. A notional system is shown in the diagram of Figure 1-1. Thermoelectric modules provide a good candidate to capture waste heat from a SOFC 
system. The TE technology is quiet, simple, scalable, and requires little maintenance. Much work is done today on improving TE technology, in particular their efficiency and cost. A well designed SOFC-TE based power system can achieve approximately $65 \%$ efficiency.

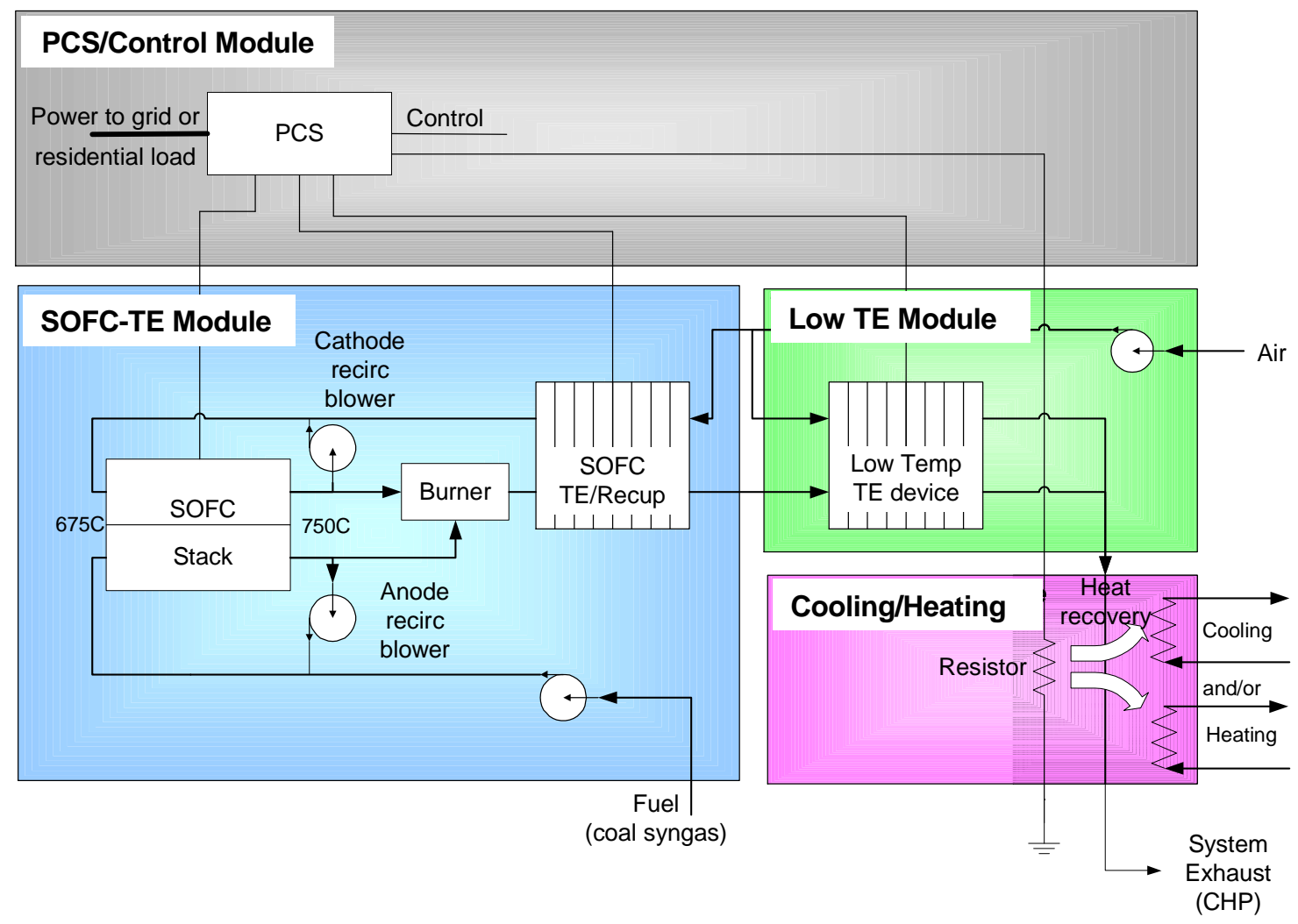

Figure 1-1: Diagram of a notional hybrid SOFC-TE system

These background concepts will be used in this effort to maximize TE-SOFC hybrid system efficiencies.

\subsection{Objectives and Scope}

The overall objective of this work was to assess the feasibility of SOFC-TE concepts and to study a range of trade-offs by applying in-depth techno-economic analysis and integrated concurrent engineering processes developed at UTRC. Design and off-design analysis were aimed at assessing the robustness of the proposed design. Critical cost and technical barriers and enablers to the deployment of this technology were also assessed. Specifically, the present work addressed the following objectives:

1. Create innovative integrated SOFC-TE technical concepts meeting the requirements of $65 \%$ system electric efficiency and $\$ 400 / \mathrm{kW}$ system initial cost 
2. Assess the feasibility of these concepts and to study a range of tradeoffs by applying rigorous in-depth techno-economic analysis

3. Assess the critical cost and technical barriers and enablers to the deployment of this technology

4. Deliver a Phase II Development Plan for SOFC-TE systems

The original scope of this work was the coal-gas fueled 10kW SOFC-TE modules with the prospect of scaling to commercial $(100-500 \mathrm{~kW})$ and large multi-MW power plants. After a discussion with DOE in February 2006, the scope of the work was changed to $200 \mathrm{~kW}$ hybrid SOFC-TE power plants with the SOFC stack size of 5-200 kW. The reason for the plant size reduction from multiMW to $200 \mathrm{~kW}$ is that typical stack size is close to or below $200 \mathrm{~kW}$. For a $200 \mathrm{MW}$ SOFC-TE plant, very large stack at MW scale or above would be needed, which is beyond the performance and cost modeling capability in this study. For now, this study was focused on the fundamental issues of system integration concept and system cost/performance tradeoff while keeping the utility power plant application as the ultimate objective subject to technology maturation. The cost and technical specs are assumed for the year 2011, to be consistent with the SECA timeline [8].

\subsection{Project Approach}

To systematically evaluate the novel hybrid SOFC-TE power generation technology, a set of system integration concepts was generated first. These concepts were analyzed qualitatively or quantitatively using the modeling tool. Based on the performance and cost analysis, the optimal system concept was selected. Finally, the technical barriers or enablers for the identified best concepts will be evaluated.

The analysis was broken down to the following tasks:

Task 1:Problem definition (Section 1.2):

Define customer requirements and define a baseline SOFC power system fueled with syngas.

Task 2: Develop conceptual designs (Chapter 2):

Create a rich set of idea fragments. Cluster these fragments and generate at least two promising concepts.

Task 3: TE-material suppliers benchmarking (Chapter 3)

Benchmark the TE-material technologies in the market place and under development. The emphasis was tailored to the SOFC systems. In particular, cost, performance, durability, manufacturing process, technology readiness level, time to market and ease of mass production were emphasized.

Task 4: System level performance and cost modeling (Chapter 4, Section 5.1)

UTRC: Employ existing SOFC system physics-based performance library and provide power plant system models for the conceptual designs created under Task 2. Extend 
existing (100-50MW) SOFC system parametric cost model library to $10 \mathrm{~kW}$ range power plants.

Subcontractor (BSST): Employ existing high-fidelity TE module models to calibrate reduced-fidelity models for use in techno-economic feasibility study. Employ findings from Task 3 and existing TE device design to provide parametric cost models for the TE module.

Task 5: Explore techno-economic design and operating envelopes (Section 5.2)

Define the key technical and cost tradeoffs.

Assess techno-economic design envelopes (tradeoffs)

Select robust optimal designs for each system analyzed and each tradeoff.

Assess operating performance envelopes for optimal designs in order to verify the robustness of each optimal selected design.

Task 6: Down-select to one integrated system/component concept (Section 5.3 - 5.5)

Using the results from Task 5, select system concept that meets the Phase I goals.

Task 7: Create product cost and performance specifications for selected concept (Chapter 6)

Using the data available from Task 5, flow-down the requirements on the system and the components.

Task 8: Evaluate barriers/enablers (Chapter 7)

Assess the technology and cost barriers and enablers for the deployment of TE-SOFC hybrid systems: SOFC (UTRC); TE (subcontractor).

Task 9: Create development plan for Phase II (Chapter 8) Create a development plan for Phase II that addresses the critical risks identified under Task 8. Propose development and risk-mitigation tasks to advance the science and technology for an insertion in coal-based power plant.

Task 10: Project management and reporting

Project management is in accordance with existing UTRC project management principles and procedures to ensure that all cost, schedule and technical performance are met. 


\section{Concept Generation and Analysis}

The feasibility analysis of the integrated SOFC-TE system starts from exploring the design space as widely as possible so that key technologies that enable achievement of the design targets are not missed. To effectively obtain the concepts as exhaustively as possible leading to optimal designs, we used UTRC's Concept Generation Session (CGS).

\subsection{Goal of the CGS and Generation Process}

The Concept Generation Session is a proprietary process and tool suite used in the concept definition stage in UTRC's standard Project Planning and Execution (PPE) processes. In concept generation sessions, experts with different engineering background sit together, who may or may not be affiliated with the project, to learn about the project scope and challenges, and then contribute conceptual ideas for problem resolution and system enhancement. The ideas are grouped, synthesized and narrowed down for further detailed analysis, either qualitatively or quantitatively. The CGS integrates the following modules: value analysis, problem formulation, idea generation, concept assembly, concept selection and gap or risk analysis. It has been used successfully in previous projects accomplished by UTRC.

For the current SOFC-TE project, since the thermal system is relatively independent of the power conditioning unit, two sessions were held, with the first session on thermal electrochemical aspects and the second one on electrical/power conditioning aspects.

In the first session, a group of 13 participants from UTRC and BSST built upon a base of hundreds of ideas captured in UTC's 2004 TE opportunity audit and generated 30 ideas focused on SOFC-TE thermal integration and performance improvement of stacks. Low cost was also a major consideration in this session.

In the second session, seven participants from UTRC, UTC Power and BSST generated 11 ideas focused on power electronics for SOFC-TE systems.

More than 40 idea fragments were generated spanning areas from thermal to electrical, from component to systems, and from technical to economic. These ideas were then grouped and consolidated to 10 concepts depending on the idea interdependency or reciprocity, as shown in Figure 2-1. Group 1 focuses on system configuration with different thermal integration concepts, Group 2 on the components electrochemical design, and Group 3 is about the power conditioning system (PCS). 


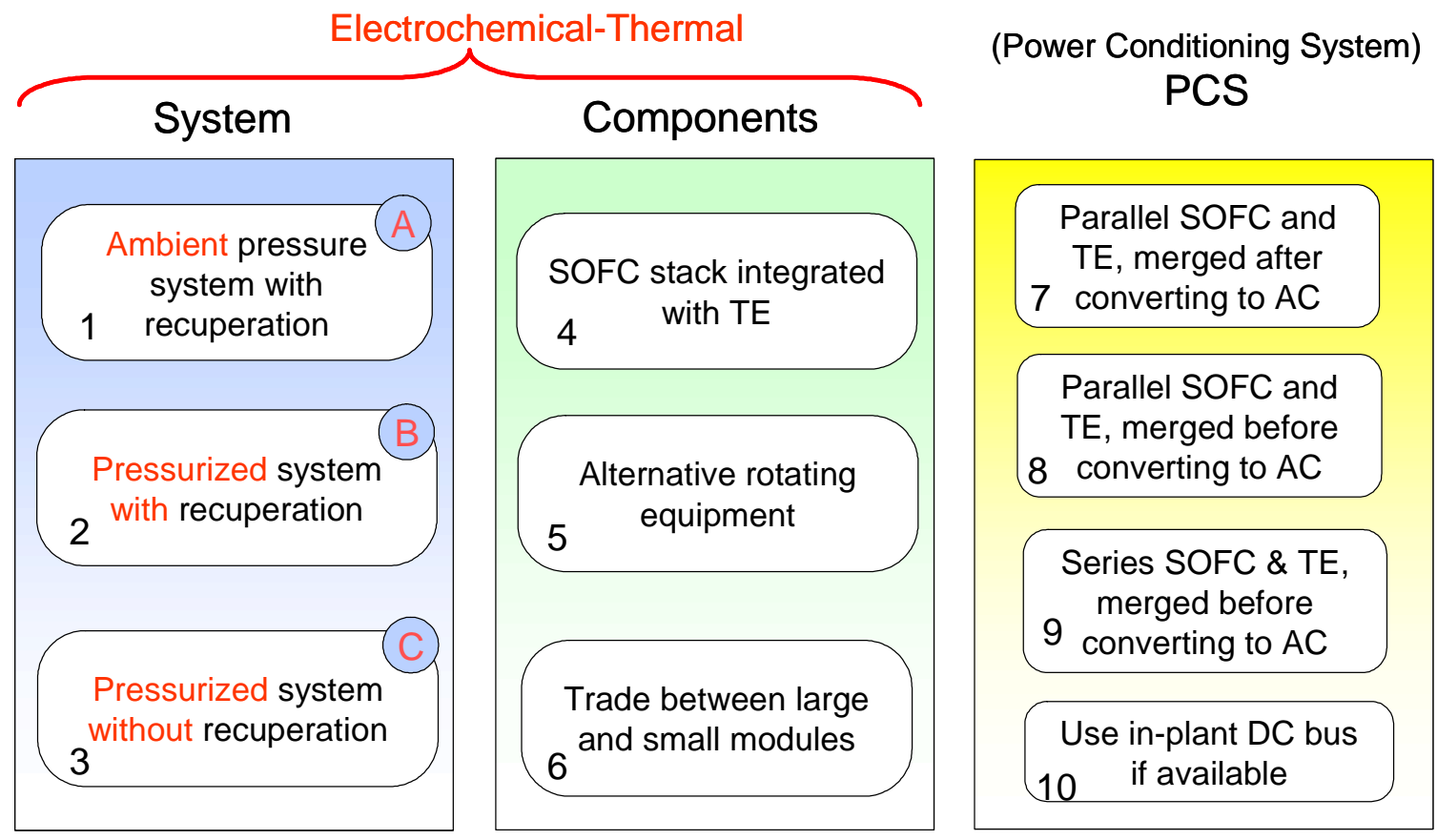

Figure 2-1: Summary of concepts generated during the Concept Generation Sessions

\subsection{Description of the Generated Concepts}

In this section, a more detailed explanation of the generated concepts is provided. Concepts 1-6 are electrochemical or thermal and Concepts 7-10 are electrical.

Concept 1: Ambient-pressure system with recuperation

This concept is the notional system shown in Figure 1-1 in which there is a SOFC stack working at ambient pressure, a high-temperature TE and a low-temperature TE connected in series. The exhaust gas from the SOFC stack enters the high-stage TE first and then the low-stage TE. The two TE generators use the exhaust gas as the hot side for the power generation. For the cold side, one stream of the air from the cold air blower goes to the low stage TE, and then is discharged into the environment. Another stream of the cold air goes to the high stage TE. The preheated air enters the cathode after merging with the cathode recycled gas.

This system has operational flexibility with two TE generators. For example, the low stage TE can be turned off without affecting the rest of the system. In addition, the system is easy to control with recycle blowers instead of ejectors. If ejectors are used, the cost is lower but the gas recycle ratio cannot be controlled at off-design conditions and is limited to low multiples of feed flow, i.e., 4-5.

The exhaust gas leaving the low stage TE can be utilized further for heating with a heat exchanger or cooling with an absorption chiller, in principle. This exhaust stream, however, after leaving two 
stages of TE, can contain only a small amount of heat and is at a low temperature. Quantitative analysis is needed to determine whether the final heating or cooling is worthwhile.

Further evaluation of this system can focus on the TE performance and cost, the cost/performance benefit of the blowers and the optimum temperature at the outlet of the SOFC and at the outlet of the first TE.

\section{Concept 2: Pressurized system with two TE generators}

This system is similar to similar to Concept 1 , with the only difference that a pressurized SOFC stack is used for higher stack efficiency. As a result, the region enclosed within the red line in Figure 2-2 now works at higher pressure. An air compressor has to be used to raise the pressure. A gas turbine can generate more power with the stack exhaust. The gas turbine is usually on the same shaft as the air compressor.

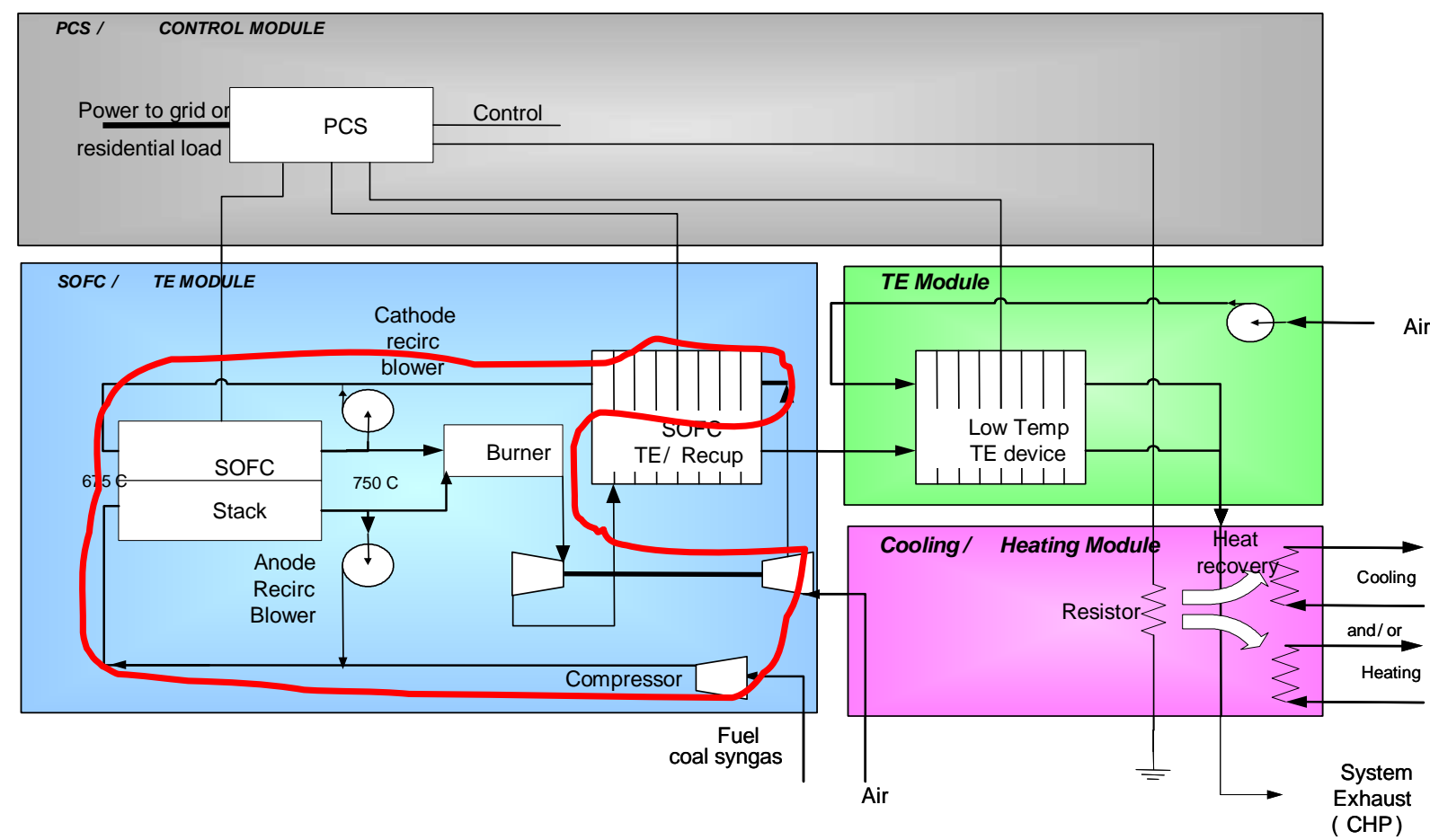

Figure 2-2: A pressurized SOFC-TE system with two TE generators

The major advantage of this system is that it has a higher system electric efficiency. However, the system is more complex with the pressurization-related components. Cross-leakage of air and fuel is possible from the pressurized part, a potential hazard for the plant.

Analysis to be done for the system is mainly determining the optimum pressurization ratio for the highest system efficiency.

Concept 3: Pressurized system with one TE generator 
If the temperature of the gas leaving the turbine in Concept 2 is too low, or the temperature of the gas leaving the compressor is too high, the high-stage TE in Figure 2-2 may provide only marginal electric benefit. In such cases, a pressurized SOFC system with only one TE generator may be more cost-effective. Detailed thermo-economic analysis is needed in making the final conclusions. Quantitative analysis for this system includes finding the optimal pressurization ratio of the system.

Concept 4: TE integrated into the SOFC stack

With this concept, the TE is integrated into the SOFC stack. As shown in Figure 2-3, the hot side of the TE generator is in contact with the interconnect of the original stack, which has a high temperature close to $750 \mathrm{C}$. The cold side of the TE generator is connected to a cooling channel in which the ambient air is fed.

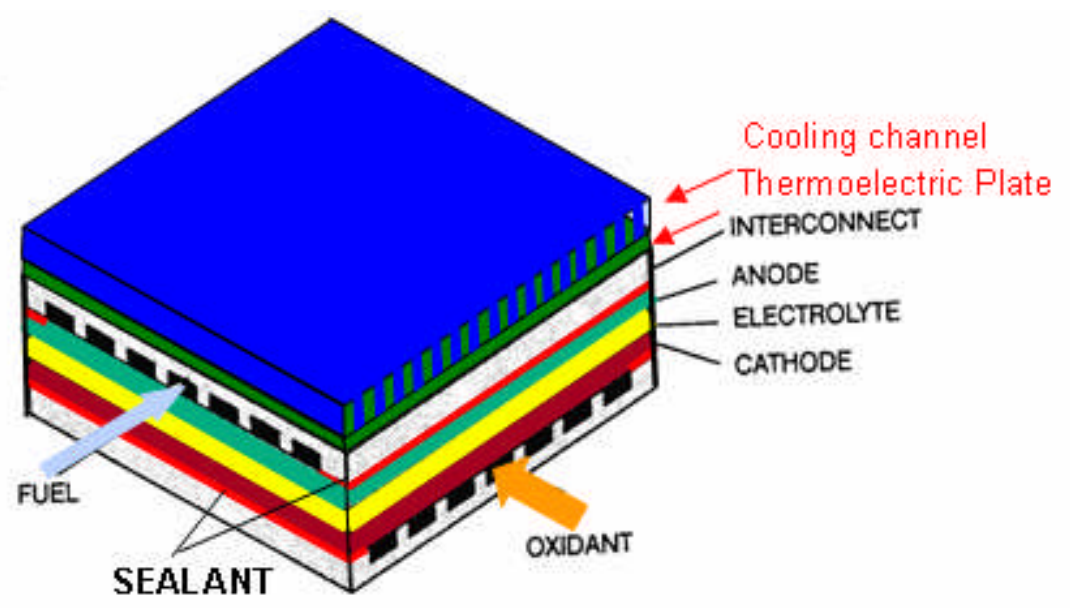

Figure 2-3: Concept of TE integrated into SOFC stacks

The major advantage of this concept is that the TE generator has access to the high stack temperature. The TE can also serve as an electric heating device when working in the heating mode to heat the stack during start-up. During transient changes, local stack in-plane temperature can be controlled.

After the concept generation, an Excel-based simple model was made for this concept. It was found that TE inside the stack can produce only a small amount of power. The power produced is limited by two factors: 1) The cold air flow will be sent to the cathode after being heated. It is at a smaller flow rate compared to that in a separate TE for which the cold air flow rate can be up to 20 times higher than the hot flow rate. 2) The TE heat transfer area is essentially the stack surface area. Today's high SOFC energy density means a smaller surface area. These two factors together greatly limit the power that can be obtained from the TE inside the stack. Applying the efficiency of a high performance TE at the given stack cold and hot inlet temperature and the stack surface area, the incremental electric efficiency by TE was found to be $0.7 \%$. 
Although there is benefit of utilizing the heat in the stack directly, integrating the TE materials into the stack is a great challenge for the stack design. The material contact, expansion and sealing issues all need to be considered. Considering that even the SOFC and TE designs by themselves are still under development, integrating the two is not considered achievable in the next a few years.

Concept 5: Alternative rotating equipment design

Several types of rotating equipment are being considered in SOFC-TE systems, e.g., anode and cathode recycle blowers and TE cold air blowers. A pressurized system also needs a turbine expander, and air and, possibly, fuel compressors. Except turbines, all other rotating equipment consume electricity. This proposed concept considers using rotating equipment with higher efficiency to increase the system efficiency. However, machines with higher performance typically involve higher cost. Other factors to consider in choosing different types of rotating equipment are mainly the type, total power consumption, efficiency, pressure drop and temperature allowed for blowers. The goal with this concept is to find the optimal system in terms of the trade-off between performance and cost.

Concept 6: Trade between large and small SOFC modules

Today's typical SOFC stack size is below $200 \mathrm{~kW}$. The proposed SOFC-TE system is originally intended to use coal gas as the fuel for large scale power plants, so that a large number of SOFC-TE units would be needed for those plants.

For the plant, there is a choice between using large SOFC stacks vs. using small ones. This will have several impacts. First, large stacks are likely to have lower unit cost, or $\$ / \mathrm{kW}$ of electricity. Second, for a plant with given total capacity, using large stacks means a smaller number of units to be serviced, leading to a reduction in piping, electrical ancillaries and control elements, etc. Third, large stacks require longer startup time, which is not desired. Finally, the performance and lifetime cost can be different. For example, to get $60 \mathrm{~kW}$ of electricity, we can have a $120 \mathrm{~kW}$ of stack running at $50 \%$ part-load ratio; or we can have $3 \times 20 \mathrm{~kW}$ of stacks running at full power from a bank of 6 stacks. The efficiency of $50 \%$ part load of a large stack can be different from the overall efficiency of 3 smaller stacks running at $100 \%$ of load. On the other hand, the life of a component may change running at $100 \%$ of load relative to running at $50 \%$ of load.

The approach to evaluate this concept is to get the efficiency, cost, number of stacks of different capacities for a given plant and then to conduct a sensitivity analysis. For the purpose of this project, only the first cost is considered. However, in practice, the lifetime cost and the system reliability information must also be considered.

Concept 7: SOFC and TE power in parallel, merged after DC/AC conversion

In this concept, the SOFC and TE each have an independent inverter, as shown in Figure 2-4. This can be treated as the baseline power conditioning system (PCS) for the integrated system. Each 
individual branch is mature and commercially available today. The DC/DC conversion has a typical efficiency of $97 \%$ and DC/AC of $95 \%$. The overall efficiency is approximately $92 \%$.

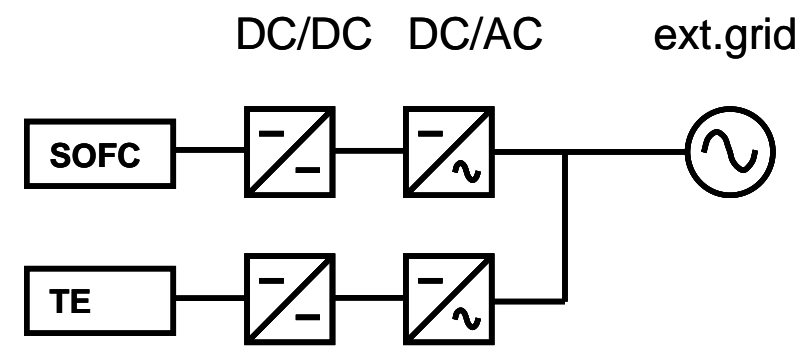

Figure 2-4: SOFC-TE power in parallel, merged after DC/AC conversion

During operation, each subsystem can run or discontinue without affecting the other. Since SOFC and TE are producing power with different magnitudes, DC/AC inverters can be optimized for SOFC and TE separately. The disadvantage of the system is that two sets of DC/AC inverters are needed and the interconnection with the grid is complex.

Concept 8: SOFC and TE power in parallel, merged before DC/AC conversion

Compared to Concept 7, this concept of SOFC and TE power merging before DC/AC conversion has only one DC/AC converter and one point of interconnection with the grid, as shown in Figure 2-5. However, such a PCS system needs voltage control of internal DC bus since the SOFC and TE produce power at different voltage, $\mathrm{kW}$ and timing.

This type of configuration may need some development work that is tailored to individual plants. The initial cost and the development cost should be evaluated, but may not be available until more detailed specifications of the plants are obtained.

DC/DC DC/AC ext.grid

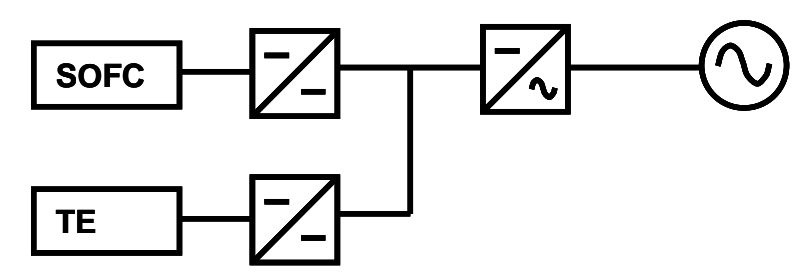

Figure 2-5: SOFC-TE power in parallel, merged before DC/AC conversion

Concept 9: SOFC and TE power in series connection

Another possible connection method is to have SOFC and TE power in series connection, as shown in Figure 2-6. An optional DC/DC converter may be required to adjust voltage before DC/AC inverter. With less conversion, the PCS efficiency should be higher. As in Concept 8, only one inverter is needed so the interconnection with the grid is simple. 
Still, development cost will be needed for this system. The first cost of the system, however, can be lower with a smaller number of components, once developed.

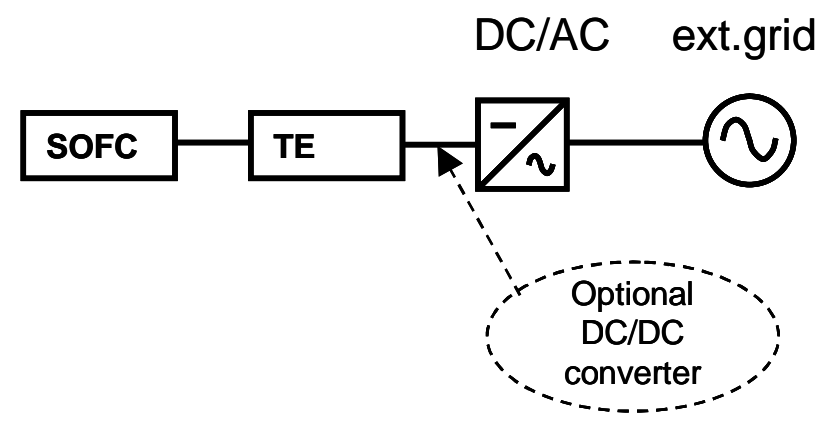

Figure 2-6: SOFC-TE power in series connection

Concept 10: SOFC and TE Common DC bus - For plant internal loads

In power plants, certain equipment run on DC power, such as DC motors. If the SOFC-TE power is used for the DC loads through the plant common DC bus, the loss on the DC/AC inverter can be avoided. The connection diagram is shown in Figure 2-7 below.

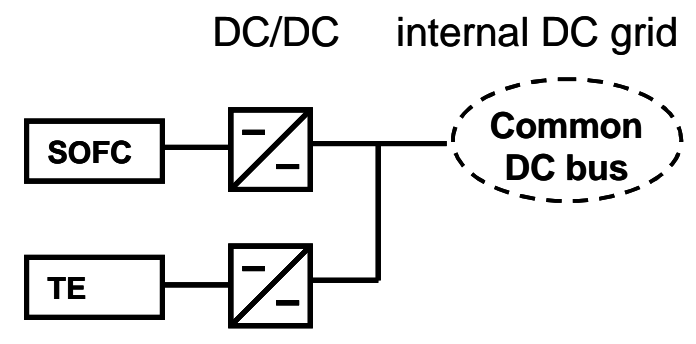

Figure 2-7: SOFC-TE power in parallel connection

This connection is simple and there are fewer parts. The cost is likely to be low. One disadvantage is the building of a DC bus, if it is not available in the current plant. In addition, the SOFC and TE should have high reliability to ensure that the DC driven equipment can run with little interruption. An AC/DC backup system to use grid AC power may be needed, therefore to some extent counteracting the low cost of this system.

The PCS concepts are summarized in Table 2-1. The efficiency and cost data are based on UTC's estimation in the notional amount for comparison purposes. Recent progress in PCS research enabled PCS efficiency of 95\% [40]. However, the most common referred data are used here. The cost is rounded to the hundred dollar magnitude. 
Table 2-1: Summary of the power conditioning system (PCS) concepts

\begin{tabular}{|c||c||c||c||c|}
\hline & $\begin{array}{c}\text { 7: SOFC \& TE in } \\
\text { parallel, merged } \\
\text { after DC/AC } \\
\text { conversion }\end{array}$ & $\begin{array}{c}\text { 8: SOFC \& TE in } \\
\text { parallel, merged } \\
\text { before DC/AC } \\
\text { conversion }\end{array}$ & $\begin{array}{c}\text { 9: SOFC \& TE } \\
\text { matching - series } \\
\text { configuration }\end{array}$ & $\begin{array}{c}10 \text { : Use in-plant DC } \\
\text { bus if available }\end{array}$ \\
\hline Efficiency & $92 \%$ & $92 \%$ & $95 \%$ & $97 \%$ \\
\hline Cost & $\$ 400 / \mathrm{kW}$ & $\$ 400 / \mathrm{kW}$ & $\$ 300 / \mathrm{kW}$ & $\$ 200 / \mathrm{kW}$ \\
\hline $\begin{array}{c}\text { Technology } \\
\text { Readiness }\end{array}$ & $\begin{array}{c}\text { Commercially } \\
\text { available }\end{array}$ & $\begin{array}{c}\text { Commercially } \\
\text { available }\end{array}$ & Never tried & Needs development \\
\hline $\begin{array}{c}\text { Other Major } \\
\text { Disadvantages }\end{array}$ & $\begin{array}{c}\text { Separate DC } \rightarrow \mathrm{AC} \\
\text { converters needed }\end{array}$ & $\begin{array}{c}\text { Voltage control of } \\
\text { DC bus }\end{array}$ & $\begin{array}{c}\text { Unproven current } \\
\text { and VI matching } \\
\text { technologies }\end{array}$ & Reliability; need DC \\
bus built
\end{tabular}

\subsection{Summary}

The concepts generated above span from system integration to component designs and from electrochemical-thermal to electrical. The factors affecting the concept down-selection include:

- Stack pressurization and the optimal pressure ratio

- Stack size selection

- Stack design, e.g., whether to integrate TE into the stack or not

- Stack optimization such as the anode and cathode recycle ratio

- Thermal system configuration, e.g., putting turbine before or after the recuperator

- Number of stages of TE and the TE specification selection, e.g., TE material or ZT (figure of merit)

- Fan, blower and compressor efficiency

- PCS efficiency and technology readiness level

- Part-load operation strategy

- Cost

The ideas that were explored and the thoughts behind the concepts provide a basis for more detailed qualitative and quantitative analysis in future tasks. 


\section{TE Material Benchmarking (BSST)}

Thermoelectric (TE) material technologies in the marketplace today as well as the important ones under development were benchmarked. This involved the compilation of thermoelectric (TE) material supplier information and resources. No additional experimentation or modeling was done in order to complete this task. Potential material suppliers range from large chemical companies to startup nano-tech houses to academic institutions. These organizations are located in the US, Europe, and Asia. The benchmarking task involved identifying and compiling the following information regarding the organizations:

$\begin{array}{ll}\text { 1. } & \text { Location } \\ \text { 2. } & \text { Material(s) } \\ \text { 3. } & \text { Material Structure } \\ \text { 4. } & \text { Material type (p- or } \mathrm{n}-\text { ) } \\ \text { 5. } & \text { Material Figure of Merit }- \text { ZT at different temperature ranges } \\ \text { 6. } & \text { Cost } \\ \text { 7. } & \text { Durability } \\ \text { 8. } & \text { Manufacturing Process } \\ \text { 9. } & \text { Technology Readiness Level } \\ \text { 10. } & \text { Time to Market } \\ \text { 11. } & \text { Ease of Mass Production }\end{array}$

\subsection{Approach}

The above information was listed in three tables shown later in this chapter. In order to be listed in the table, a company, organization, or institution must have demonstrated some potential in their technology beyond theoretical calculations. This could be achieved either through published experimental data or independent, non-biased validation. Information on the organizations has been gathered from conference papers, journal articles, websites, and personal business communications. The materials range from standard $\mathrm{Bi}_{2} \mathrm{Te}_{3}$ to PbTe and TAGS [ $(\mathrm{AgSbTe})_{1-}$ $\left.{ }_{\mathrm{x}}(\mathrm{GeTe})_{\mathrm{x}}\right]$ to skutterudites $\left(\mathrm{CoSb}_{3}\right)$ to high temperature oxides. Certain columns in the table have more subjective values. Any subjective values are based on available information and determined by BSST and confirmed by the rest of the team. The scale for the Technology Readiness Level is a government-accepted scale similar to that used by NASA [9]. This benchmarking study should be used as a snapshot of where TE material development is today. Due to the changing nature of the information of the TE benchmarking study, the compiled set of organizations and associated information is subject to change.

It is extremely important to monitor the progress of these organizations. Being aware of all the entities that are working on developing new and improved TE materials reduces the risk associated with this program. Improvements in TE material performance greatly enable the success of creating an economically feasible, highly efficient SOFC-TE hybrid power generating system. It is not only important to understand whether an organization can create a high-performing material, but whether that material is cost-effectively manufacturable in large quantities in some reasonable timeframe. 


\subsection{Results and Discussions}

The overall material list has been organized into three separate lists classified by temperature range. The first list, shown in Table 3-1, has suppliers of materials that provide optimum performance when operated with hot-side temperatures up to $250^{\circ} \mathrm{C}$. Most of this table is made up of suppliers of different forms of $\mathrm{Bi}_{2} \mathrm{Te}_{3}$, both $\mathrm{p}$ - and $\mathrm{n}$ - type. $\mathrm{Bi}_{2} \mathrm{Te}_{3}$ has been the material of choice for heating and cooling and low temperature power generation applications for close to 50 years. Today, there are suppliers of standard $\mathrm{Bi}_{2} \mathrm{Te}_{3}$, such as Ferrotec/SCTB Nord, Kyocera, and Yamaha.

Micropelt/Fraunhofer Institute is making $\mathrm{a} \mathrm{Bi}_{2} \mathrm{Te}_{3}$ with standard thermoelectric properties, but of a much smaller size. Marlow makes a $\mathrm{Bi}_{2} \mathrm{Te}_{3}$ that can be made in high power density configurations. Nextreme/Research Triangle Institute (RTI) is working on developing $\mathrm{Bi}_{2} \mathrm{Te}_{3}$ with a superlattice structure, which helps reduce the thermal conductivity of the material, increasing the ZT up to 2.4. This material is still under development and is not commercially available yet. However, it does show the promise of a technique that can boost the thermoelectric performance of an existing material.

The second list of materials, shown in Table 3-2, is comprised of suppliers of materials with optimum ZT at hot side temperatures between $250^{\circ} \mathrm{C}-500^{\circ} \mathrm{C}$. This group includes manufacturers of p- and n-type PbTe, p-type TAGS, p-type $\mathrm{Zn}$-Sb, n-type LAST ( $\mathrm{AgPb}_{\mathrm{m}} \mathrm{SbTe}_{2+\mathrm{m}}$ ), and some lower temperature skutterudites. Lincoln Labs is making the most promising material in this group. ZT for their PbTe material peaks at 3.0 for p-type and 3.2 for n-type at $300^{\circ} \mathrm{C}$. The $\mathrm{PbTe}$ is enhanced by quantum dot superlattice (QDSL) structures. These are different superlattice structures than those being developed by RTI, but also provide significant improvement to material performance. Although this material has shown great promise, it still needs significant development. It is manufactured by a molecular beam epitaxy (MBE) process that takes far too long and is far too costly. In addition, there are also significant concerns about contact resistance with this material, which will reduce performance significantly due to the thin nature of the material. RTI has similar concerns in this area of contact resistance.

BASF is also working on a promising n-type $\mathrm{PbTe}$ material that has expected performance above that of standard PbTe. BSST continues to evaluate this material with no hard numbers to report yet.

Teledyne has made the standard for TAGS and PbTe for decades for space applications. TAGS material has the best ZT for p-type material in this temperature range. Despite Teledyne's experience with this material, there is still some concern in using it in geometries other than what Teledyne has used before. BSST is currently working with Marlow and JPL, among others, to develop mechanically stable TAGS that can be effectively metallized in form factors desirable for applications other than space. 
Table 3-1: Materials for applications with hot-side temperatures up to $250^{\circ} \mathrm{C}$

\begin{tabular}{|c|c|c|c|c|c|c|c|c|c|c|c|c|c|c|c|}
\hline Organization & Location & Material(s) & $\begin{array}{c}\text { Material } \\
\text { Structure }\end{array}$ & $\begin{array}{c}\mathrm{p} \text { - or } \mathrm{n} \\
\text { type }\end{array}$ & $\begin{array}{l}\text { Low Temp - } \\
\text { ZT (Temp) }\end{array}$ & \begin{tabular}{|l} 
Medium or \\
Peak Temp \\
ZT (Temp) \\
\end{tabular} & $\begin{array}{c}\text { High Temp - } \\
\text { ZT (Temp) }\end{array}$ & Cost (1) & Durability & $\begin{array}{c}\text { Manufacturing } \\
\text { Process }\end{array}$ & $\begin{array}{c}\text { TRL } \\
(2)\end{array}$ & $\begin{array}{c}\text { TTM } \\
(3)\end{array}$ & \begin{tabular}{|c|} 
EMP \\
$(4)$
\end{tabular} & Comments & Sources \\
\hline $\begin{array}{c}\text { Ferrotec / SCTB } \\
\text { Nord } \\
\end{array}$ & $\begin{array}{l}\text { China / } \\
\text { Russia } \\
\end{array}$ & $\mathrm{Bi}-\mathrm{Te}$ & bulk & $\mathrm{p}-, \mathrm{n}-$ & $\begin{array}{c}0.3(175 \mathrm{~K}) \\
\text { effective }\end{array}$ & $\begin{array}{c}0.68 \text { (300K) } \\
\text { effective } \\
\end{array}$ & $\begin{array}{l}0.25 \text { (425K) } \\
\text { effective }\end{array}$ & low & high & $\begin{array}{c}\text { bridgeman } \\
\text { growth }\end{array}$ & 9 & 10 & 10 & & 1 \\
\hline II-VI / Marlow & $\mathrm{PA} / \mathrm{TX}$ & $\mathrm{Bi}-\mathrm{Te}$ & $\begin{array}{c}\text { bulk, HPD, } \\
\text { nanowires } \\
\text { (UCB) }\end{array}$ & $\mathrm{p}-, \mathrm{n}-$ & $\begin{array}{c}1.00(300 \mathrm{~K}) / \\
0.91(300 \mathrm{~K}) \\
\end{array}$ & \begin{tabular}{|c|}
$1.03(325 \mathrm{~K})$ \\
$/ 0.98$ \\
$(350 \mathrm{~K})$ \\
\end{tabular} & \begin{tabular}{|c|}
$0.65(450 \mathrm{~K}) /$ \\
$0.6(500 \mathrm{~K})$ \\
\end{tabular} & low & high & $\begin{array}{c}\text { microalloyed, } \\
\text { sintered (MAM), } \\
\text { electrochemical } \\
\text { (UCB) }\end{array}$ & 9 & 10 & 9 & & 2 \\
\hline Kyocera & Japan & $\mathrm{Bi}-\mathrm{Te}$ & bulk & p-, n- & & $0.9-0.95$ & & low & high & $\begin{array}{c}\text { bridgeman } \\
\text { growth }\end{array}$ & 7 & 7 & 10 & & \\
\hline $\begin{array}{c}\text { Micropelt / Infineon } \\
\text { Franhofer Inst. } \\
\end{array}$ & Germany & $\mathrm{Bi}-\mathrm{Te}$ & $\begin{array}{c}\text { thick film / } \\
\text { wafer }\end{array}$ & $\mathrm{p}-, \mathrm{n}-$ & & $0.8-1.0$ & & high & medium & sputtering & 7 & 8 & 7 & $\begin{array}{c}\text { targeting low } \\
\text { wattage } \\
\text { application } \\
\end{array}$ & 3 \\
\hline Nextreme / RTI & $\mathrm{NC}$ & $\begin{array}{c}\mathrm{Bi}-\mathrm{Te} \\
\text { Nanostructure }\end{array}$ & superlattice & $\mathrm{p}-$ & $1.6(200 \mathrm{~K})$ & $2.0(250 \mathrm{~K})$ & $2.4(300 \mathrm{~K})$ & high & NA & $\begin{array}{c}\text { metallorganic } \\
\text { CVD }\end{array}$ & 4 & 6 & 4 & $\begin{array}{c}\text { targeting low } \\
\text { wattage } \\
\text { application } \\
\end{array}$ & 4 \\
\hline Yamaha & Japan & $\mathrm{Bi}-\mathrm{Te}$ & $\begin{array}{c}\text { fine grains, } \\
\text { unidirectional } \\
\text { crystal } \\
\text { structure } \\
\end{array}$ & $\mathrm{p}-, \mathrm{n}-$ & $" 1.3 \times$ con & ventional" (32 & $3 \mathrm{~K}-473 \mathrm{~K})$ & medium & high & $\begin{array}{c}\text { fine grains, } \\
\text { unidirectional } \\
\text { crystal structure }\end{array}$ & 7 & 9 & 7 & & 5 \\
\hline
\end{tabular}

(1) Cost low $\quad<\$ 200 / \mathrm{kg}$

(2) high $>\$ 500 / \mathrm{kg}$

(2) TRL $\quad 1 \quad$ basic principles observed and reported

(Technology 5 component and/or bench configured subsystem validation in relevant environment

Readiness Level) $\quad 9$ actual system proven through successful operations

(3) TTM (Time to $\quad \begin{array}{lll}1 & \text { no recognized path } \\ \text { Market) } & 5 & 3-4 \text { years out to low volume production }\end{array}$

Market)

(4) EMP (Ease of

$\begin{array}{ccl}\text { Mass Production) } & 5 & \text { unproven mass process identified that ent } \\ & 10 & \text { proven, reliable mass production process }\end{array}$

3-4 years out to low volume production
currently in mass production

no known viable production process

no known viable production process

Sources:

$1 \mathrm{http}: / /$ www.ferrotec.com/usa/thermoelectric/ref/3refappendA127.htm

2 Marlow provided data; BSST testing

3 Bottner, "Micropelt Miniaturized Thermoelectric Devices: Small Size, High Cooling Power Densities, Short Response Time", ICT 2005, Clemson, SC

4 Venkatasubramanian et al., Nature, Vol. 413, pp. 597-602, Oct. 11, 2001

5 Kajikawa et al., "Progress of Development for Advanced Thermoelectric Conversion Systems", ICT 2005, Clemson, SC 
Table 3-2: Materials for applications with hot-side temperature between 250 and $500^{\circ} \mathrm{C}$

\begin{tabular}{|c|c|c|c|c|c|c|c|c|c|c|c|c|c|c|c|}
\hline Organization & Location & Material(s) & $\begin{array}{l}\text { Material } \\
\text { Structure }\end{array}$ & $\begin{array}{c}\text { p- or } n \\
\text { type }\end{array}$ & $\begin{array}{l}\text { Low Temp - } \\
\text { ZT (Temp) }\end{array}$ & $\begin{array}{c}\text { Medium or } \\
\text { Peak Temp - } \\
\text { ZT (Temp) } \\
\end{array}$ & $\begin{array}{l}\text { High Temp - } \\
\text { ZT (Temp) }\end{array}$ & Cost (1) & Durability & $\begin{array}{c}\text { Manufacturing } \\
\text { Process }\end{array}$ & $\begin{array}{c}\text { TRL } \\
(2)\end{array}$ & $\begin{array}{c}\text { TTM } \\
(3)\end{array}$ & $\begin{array}{c}\text { EMP } \\
(4)\end{array}$ & Comments & Sources \\
\hline BASF & Germany & Ge doped $\mathrm{PbTe}$ & $\begin{array}{l}\text { nanoenhanced } \\
\text { bulk }\end{array}$ & NA & NA & NA & NA & medium & medium - high & $\begin{array}{l}\text { bulk (melt quench } \\
\text { annel- MQA) }\end{array}$ & 2 & 5 & 8 & & 2 \\
\hline DuPont & DE & $\ln \mathrm{CoSb}$ & bulk & $n-$ & $0.5(300 \mathrm{~K})$ & $0.9(450 \mathrm{~K})$ & $1.2(575 \mathrm{~K})$ & low & medium - high & $\begin{array}{c}\text { synthesis / hot } \\
\text { press } \\
\end{array}$ & 3 & 5 & 8 & & 3 \\
\hline JPL & $\mathrm{CA}$ & $\mathrm{Zn}-\mathrm{Sb}$ & bulk & p- & $0.2(300 \mathrm{~K})$ & $1.0(575 \mathrm{~K})$ & $1.4(675 \mathrm{~K})$ & high & high & $\begin{array}{c}\text { hot press, } \\
\text { sintering }\end{array}$ & 4 & $N / A$ & 8 & & 4 \\
\hline Lincoln Labs & MA & $\mathrm{PbTe}$ & $\operatorname{QDSL}(p, n)$ & $\mathrm{p}-, \mathrm{n}-$ & $\begin{array}{l}1.5(300 \mathrm{~K}) / \\
1.6(300 \mathrm{~K}) \\
\end{array}$ & $\begin{array}{l}2.4(475 \mathrm{~K}) / \\
2.6(475 \mathrm{~K}) \\
\end{array}$ & $\begin{array}{l}3.0(575 \mathrm{~K}) / \\
3.2(575 \mathrm{~K})\end{array}$ & high & medium & $\begin{array}{l}\text { molecular beam } \\
\text { epitaxy (MBE) }\end{array}$ & 4 & 4 & 2 & $\begin{array}{c}\text { marketing } \\
\text { plans } \\
\text { uncertain }\end{array}$ & 5 \\
\hline $\begin{array}{c}\text { Nanodynamics / } \\
\text { MetaMateria }\end{array}$ & $\mathrm{OH}$ & $\mathrm{PbTe} / \mathrm{PbSe}$ & $\begin{array}{c}\text { QW bulk } \\
\text { nanocomposite }\end{array}$ & $\mathrm{p}-, \mathrm{n}-$ & NA & NA & NA & medium & medium & $\begin{array}{l}\text { solution based, } \\
\text { core-shell, } \\
\text { densification }\end{array}$ & 2 & 4 & 7 & $\begin{array}{l}\text { Funded for } \\
\text { Phase } 2\end{array}$ & 6 \\
\hline NanoLabs & MA & $\begin{array}{c}\mathrm{Bi}-\mathrm{Te} / \mathrm{PbTe} / \mathrm{Si} \\
\mathrm{Ge}\end{array}$ & $\begin{array}{c}\text { Nanocomposite } \\
\text { or nanowire - } \\
\text { nanocomposite }\end{array}$ & $\mathrm{p}-, \mathrm{n}-$ & $1<Z$ & $T<2(300 \mathrm{~K}-4$ & $75 \mathrm{~K})$ & medium & medium & $\begin{array}{l}\text { blend, mix, } \\
\text { consolidation } \\
\text { (processing) }\end{array}$ & 2 & 4 & 6 & $\begin{array}{c}\mathrm{PbTe} \\
\text { funded; } \mathrm{Si}- \\
\text { Ge not } \\
\text { funded; } \mathrm{Bi} \text { - } \\
\text { Te not active }\end{array}$ & 7 \\
\hline Teledyne & MD & TAGS / PbTe & bulk (p) / (n) & $\mathrm{p}-, \mathrm{n}-$ & $\begin{array}{c}0.25(300 \mathrm{~K}) / \\
0.1(275 \mathrm{~K})\end{array}$ & \begin{tabular}{|c|}
$1.4(700 \mathrm{~K}) /$ \\
$1.0(725 \mathrm{~K})$ \\
\end{tabular} & $\begin{array}{c}1.25(850 \mathrm{~K}) / \\
0.7(875 \mathrm{~K}) \\
\end{array}$ & high & high & hot press & 9 & 10 & 8 & & 8 \\
\hline Tellurex / MSU & $\mathrm{MI}$ & LAST & $\begin{array}{c}\text { bulk } \\
\text { nanocomposite }\end{array}$ & $n-$ & $0.4(300 \mathrm{~K})$ & $1.5(650 \mathrm{~K})$ & $2.2(800 \mathrm{~K})$ & low & medium - high & $\begin{array}{c}\text { high temp sinter } / \\
\text { press } \& \text { sinter }\end{array}$ & 4 & 8 & 8 & $\begin{array}{l}\text { Funded for } \\
\text { Phase } 2\end{array}$ & 9 \\
\hline Ube Industries & Japan & $\mathrm{Zn}-\mathrm{Sb} / \mathrm{Co}-\mathrm{Sb}$ & cascaded & $\mathrm{p}-, \mathrm{n}-$ & $\sim 0.7$ & 5 avg $(503 \mathrm{~K}-7$ & $23 \mathrm{~K})$ & low & low & $\begin{array}{l}\text { high temperature } \\
\text { sintering }\end{array}$ & 4 & 8 & 8 & & 1 \\
\hline
\end{tabular}

\footnotetext{
$\begin{array}{ccc} & \text { low } & < \\ \text { (1) Cost } & \$ 200 / \mathrm{kg} \\ \text { medium } & \$ 200 / \mathrm{kg}-\$ 500 / \mathrm{kg}\end{array}$

high $>\$ 500 / \mathrm{kg}$

(Technology $\quad 1 \quad$ basic principles observed and reported

Readiness Level) $\quad 9 \quad$ component and/or bench configured subsystem validation in relevant environment

$\begin{array}{lll}\text { (3) TTM (Time to } & 1 & \text { no recognized path } \\ & 5 & 3-4 \text { years out to low volume production }\end{array}$

Market) $\quad 10 \quad$ currently in mass production

(4) EMP (Ease of 1 no known viable production process

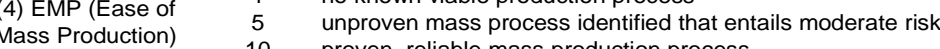

10 proven, reliable mass production process
}

Sources:

1 Kajikawa et al., "Progress of Development for Advanced Thermoelectric Conversion Systems", ICT 2005, Clemson, SC

2 communications with Lon Bell

Properties of Indium-Filled Skutterudites", Chem. Mater., 18 (3), 759 -762, 2006

$4 \mathrm{http}: / /$ www.its.caltech.edu/ jsnyder/thermoelectrics/

6 Suvankar Sengupta com

7 Suvankar Sengupta communication

7 David Carnahan communication

9 Hsu et al., Science, Vol. 303, pp. 818-821, Feb. 6, 2004

\section{United Technologies Research Center}


$\mathrm{Zn}-\mathrm{Sb}$ is another promising p-type material in this temperature range that both Jet Propulsion Laboratory (JPL) and Ube Industries have been working on. This material has a very narrow operating range and is still very much in the research phase.

The LAST material, which has been developed by Michigan State University (MSU) and licensed by Tellurex is a promising n-type material in this temperature range, but still has some need for development before it can be available commercially. In production, performance metrics for this material may be lower than originally published.

The third list of materials, shown in Table 3-3, is for hot side temperatures greater than $500^{\circ} \mathrm{C}$. Historically, this temperature range has been dominated by SiGe. SiGe has been used in space applications for several decades. SiGe, however, does not particularly have exceptional performance. Neither p- nor n-type has ZT greater than 1. Traditional p-type only has a peak ZT of 0.4. Progress has been made on these materials by Ames Lab and JPL.

Caltech/JPL has also been working on several other materials in this temperature range. Most of these other materials still need significant development prior to being ready for commercialization. JPL has developed skutterudites that can be utilized up to $700^{\circ} \mathrm{C}$. Marlow has licensed this technology and is currently working with BSST to create elements out of these materials that are of a suitable size and shape for use in applications other than space.

Ioffe Institute in Russia has been working on silicide materials. They have made both p-and n-type materials with the n-type materials having reasonably good performance. This material could be a good alternative to $\mathrm{Pb}$-based materials, but it again is not ready for commercialization yet.

Meanwhile, several Japanese institutes and universities have been developing oxide materials that can be successfully used as thermoelectrics.

HiZ is another company that has been reporting on materials with very high ZT. Unfortunately, this material has not been successfully proven in independent labs, is still at low technical maturity and requires significant further development. 
Table 3-3 Materials for applications with hot-side temperature above $500^{\circ} \mathrm{C}$

\begin{tabular}{|c|c|c|c|c|c|c|c|c|c|c|c|c|c|c|c|}
\hline Organization & Location & Material(s) & $\begin{array}{c}\text { Material } \\
\text { Structure } \\
\end{array}$ & $\begin{array}{c}\text { p-or } n \\
\text { type }\end{array}$ & $\begin{array}{l}\text { Low Temp - } \\
\text { ZT (Temp) }\end{array}$ & $\begin{array}{l}\text { Medium or } \\
\text { Peak Temp - } \\
\text { ZT (Temp) } \\
\end{array}$ & \begin{tabular}{|c|} 
High Temp - \\
ZT (Temp)
\end{tabular} & Cost (1) & Durability & $\begin{array}{c}\text { Manufacturing } \\
\text { Process }\end{array}$ & $\begin{array}{c}\text { TRL } \\
(2)\end{array}$ & $\begin{array}{c}\text { TTM } \\
(3)\end{array}$ & $\begin{array}{c}\text { EMP } \\
(4)\end{array}$ & Comments & Sources \\
\hline Ames Lab & $\mathrm{IA}$ & $\mathrm{Si}-\mathrm{Ge}$ & bulk & $\mathrm{p}-, \mathrm{n}-$ & $\begin{array}{l}0.4(500 \mathrm{~K}) / \\
0.2(400 \mathrm{~K}) \\
\end{array}$ & $\begin{array}{l}0.7(900 \mathrm{~K}) / \\
0.9(1150 \mathrm{~K})\end{array}$ & $\begin{array}{l}0.4(1300 \mathrm{~K}) / \\
0.8(1250 \mathrm{~K}) \\
\end{array}$ & medium & high & hot press & 9 & 9 & 8 & & 10 \\
\hline Caltech & $\mathrm{CA}$ & CaYbZnSb & bulk & $\mathrm{p}-$ & & & $0.8(875 \mathrm{~K})$ & medium & medium & $\begin{array}{l}\text { high temperature } \\
\text { Sn-flux methods }\end{array}$ & 1 & 4 & 6 & & 2 \\
\hline Caltech & $\mathrm{CA}$ & MoSbTe & bulk & $\mathrm{n}-$ & & & $0.75(975 \mathrm{~K})$ & medium & medium & $\begin{array}{l}\text { high temperature } \\
\text { Sn-flux methods }\end{array}$ & 1 & 4 & 6 & & 2 \\
\hline Caltech & $\mathrm{CA}$ & YbAMSb & bulk & $\mathrm{p}-$ & \multicolumn{3}{|c|}{0.95 avg $(975 \mathrm{~K}-1275 \mathrm{~K})$} & medium & medium & $\begin{array}{l}\text { high temperature } \\
\text { Sn-flux methods }\end{array}$ & 2 & 4 & 6 & & 2 \\
\hline $\begin{array}{c}\text { CREST (Japan } \\
\text { Science and } \\
\text { Technology Agency) }\end{array}$ & Japan & $\begin{array}{c}\mathrm{Co}-349 /(\mathrm{Ni}-113) \\
\text { oxides }\end{array}$ & bulk & $\mathrm{p}-, \mathrm{n}-$ & $\begin{array}{c}0.1(475 K)- \\
\text { Co-349 }\end{array}$ & $\begin{array}{c}0.4(800 \mathrm{~K}) \text { - } \\
\text { Co-349 }\end{array}$ & $\begin{array}{c}0.6(1000 \mathrm{~K})- \\
\text { Co-349 }\end{array}$ & low & medium & $\begin{array}{l}\text { hot pressing, solid- } \\
\text { state reaction, sol- } \\
\text { gel method }\end{array}$ & 3 & 3 & 8 & & 3 \\
\hline eco21 & Japan & $\begin{array}{c}\text { CexFe3CoSb12/ } \\
\text { YbxCo4Sb12 } \\
\end{array}$ & $\begin{array}{c}\text { skutterudites / } \\
\text { cascaded }\end{array}$ & $\mathrm{p}-, \mathrm{n}-$ & \multicolumn{3}{|c|}{$\sim 0.8$ avg $(300 \mathrm{~K}-700 \mathrm{~K})$} & medium & medium & $\begin{array}{c}\text { process, spark } \\
\text { plasma sintering }\end{array}$ & 3-4 & $5-6$ & 7 & & 1 \\
\hline $\mathrm{Hi}-\mathrm{Z}$ & $\mathrm{CA}$ & $\mathrm{B} 4 \mathrm{C} / \mathrm{BgC} / \mathrm{Si} / \mathrm{SiGe}$ & QW films & $\mathrm{p}-, \mathrm{n}-$ & & $3.0(525 \mathrm{~K})$ & $4.0(875 \mathrm{~K})$ & medium & high & sputtering & 3 & 4 & 8 & & 4 \\
\hline Hokkaido University & Japan & TiO1.1 & bulk & $\mathrm{p}-$ & $0.4(575 \mathrm{~K})$ & $1.64(1075 \mathrm{~K})$ & $1.5(1225 \mathrm{~K})$ & low & medium & $\begin{array}{c}\text { reacted } \mathrm{Ti} \& \\
\mathrm{NaClO} 4 \text { powders }\end{array}$ & 4 & 6 & 8 & & 5 \\
\hline II-VI / Marlow & $\mathrm{PA} / \mathrm{TX}$ & $\mathrm{Co}-\mathrm{Sb}$ & $\begin{array}{c}\text { skutterudites, } \\
\text { segmented }\end{array}$ & $\mathrm{p}-, \mathrm{n}-$ & \multicolumn{3}{|c|}{$\sim 0.85 \mathrm{avg}(300 \mathrm{~K}-975 \mathrm{~K})$} & medium & medium & $\begin{array}{c}\text { sintered (MAM), } \\
\text { hot press }\end{array}$ & 4 & 6 & 8 & & $\frac{6}{7}$ \\
\hline IOFFE Institute & Russia & MgSiSn & bulk & $\mathrm{p}-, \mathrm{n}-$ & $0.15(300 \mathrm{~K})$ & $0.6(800 \mathrm{~K})$ & $0.95(775 \mathrm{~K})$ & low & high & sintered & 0 & $2-3$ & 8 & & 7 \\
\hline JPL & $\mathrm{CA}$ & $\begin{array}{c}\text { CeFe3RuSb12 } \\
/ \text { Co-Sb }\end{array}$ & $\begin{array}{c}\text { bulk/ } \\
\text { skutterudites, } \\
\text { segmented }\end{array}$ & $\mathrm{p}-, \mathrm{n}-$ & $\begin{array}{l}0.1(300 \mathrm{~K}) / \\
0.17(300 \mathrm{~K})\end{array}$ & $\begin{array}{l}0.86(825 \mathrm{~K}) / \\
0.87(875 \mathrm{~K})\end{array}$ & \begin{tabular}{|l}
$0.76(1000 \mathrm{~K}) \prime$ \\
$0.83(1000 \mathrm{~K})$ \\
\end{tabular} & high & high & hot press, sintering & 4 & N/A & 8 & $\begin{array}{l}\text { skutterudite } \\
\text { license to } \\
\text { Marlow } \\
\end{array}$ & 2 \\
\hline Komatsu LTD & Japan & $\begin{array}{c}\mathrm{Bi}-\mathrm{Te} / \mathrm{Mn}-\mathrm{Si} / \mathrm{Mg} \\
\mathrm{Si}\end{array}$ & $\begin{array}{l}\text { silicides / } \\
\text { cascaded }\end{array}$ & $\mathrm{p}-, \mathrm{n}-$ & \multicolumn{3}{|c|}{$\sim 0.75$ avg $(300-800 \mathrm{~K})$} & low & high & $\begin{array}{c}\begin{array}{c}\text { sintering (SPS), } \\
\text { specially } \\
\text { developed sintering }\end{array} \\
\end{array}$ & 4 & 5 & 8 & & 8 \\
\hline Lutronics & $\mathrm{CO}, \mathrm{MA}$ & oxides & $\begin{array}{l}\text { nanoscale, } \\
\text { multiple QW } \\
\text { structure }\end{array}$ & NA & NA & NA & NA & NA & NA & special processing & NA & NA & NA & & \\
\hline Osaka University & Japan & AgTITe & polycrystalline & $\mathrm{p}-, \mathrm{n}-$ & $\begin{array}{l}0.1(300 \mathrm{~K}) / \\
0.01(300 \mathrm{~K})\end{array}$ & $\begin{array}{l}0.5(575 \mathrm{~K}) / \\
0.25(475 \mathrm{~K})\end{array}$ & $\begin{array}{c}1.23(700 \mathrm{~K}) / \\
0.6(600 \mathrm{~K}) \\
\end{array}$ & high & NA & $\begin{array}{c}\text { crushed, pressed, } \\
\& \text { sintered }\end{array}$ & 4 & 7 & 8 & & 9 \\
\hline
\end{tabular}

\footnotetext{
$\begin{array}{llc} & \text { low } & <\$ 200 / \mathrm{kg} \\ \text { (1) Cost } & \text { medium } & \$ 200 / \mathrm{kg}-\$ 500 / \mathrm{kg}\end{array}$

(2) TRL high $>\$ 500 / \mathrm{kg}$

(Technology $\quad 5 \quad$ component and/or bench configured subsystem validation in relevant environment

Readiness Level) $\quad 9 \quad$ actual system proven through successful operations

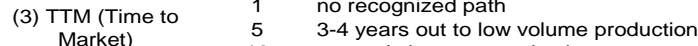

1 currently in mass production

(4) EMP (Ease of 5 no knoven mass process identified that entails moderate risk

Mass Production) $\quad 10 \quad$ proven, reliable mass production process
}

Sources:

1 Kajikawa et al., "Progress of Development for Advanced Thermoelectric Conversion Systems", ICT 2005, Clemson, SC tion/data

3 Funahashi et al., "Power Generation of Thermoelectric Oxide Modules", ICT 2005, Clemson, SC

5 Okinaka et al., "Thermoelectric Properties of Nonstoichiometric TiO as a Promising Oxide Material for High-temperature Thermoelectric Conversion", ICT 2005, Clemson, SC

6 BSST calculations

8 Kaibe et al. "Development of thermoelectric generating cascade modules using silicide and Bi - TE", ICT 2004, Adelaide, Austrailia

9 Kurosaki et al., "Ag9TITe5 and AgTITe: High ZT Materials With Extremely Low Thermal Conductivity", ICT 2005, Clemson, SC

10 Bruce Cook communication 


\subsection{Summary}

In summary, there are existing commercially-ready materials as well as promising developmental materials in all three temperature ranges. The low-temperature material group has the most mature technology, which can be improved further. Nextreme/RTI has the most promising material in this temperature range, but it also requires the most development in cost, technology readiness level, and ease of mass production. In the medium temperature range, Lincoln Laboratories has the most promising material, but it also requires significant development work. Currently available TAGS and $\mathrm{PbTe}$ materials are adequate, but still could be improved upon from a ZT standpoint. They also may require some further development, especially TAGS, for applications other than space. The high temperature materials are the least developed and have lower ZT than materials from the other two ranges. It is not clear what the most promising material is from this group. SiGe is the most mature, but is not as compatible with other low temperature materials. Skutterudites from JPL and Marlow are further along than many of the other materials and do not have the compatibility issues that $\mathrm{SiGe}$ has with other lower temperature materials. A combination of materials from each of the three temperature ranges is required to create the most effective device over the temperature range for the whole application. In short, reasonable cost and performance materials are available today with much more promising materials on the horizon that still require development work. 


\section{$4 \quad$ System Modeling}

The objective of the modeling task is to down-select the optimum SOFC-TE system for the scope defined in Task 1. It involves both performance and cost modeling. The models are assumed to be valid for the year 2011, in accordance with the DOE's SECA program target timeline.

The candidate systems to be modeled are those identified during the concept generation in Task 2 . The model development can be broken down to two steps:

- $\quad$ Subsystem model development for SOFC and TE

- System integration

In this section, the discussion and analysis focus on "cleaned" gas from an oxygen-blown, dry feed, slagging gasifier using bituminous coal. Further, it is assumed that the gas will be provided at pressures from 400 - 1200 psig. The composition of cleaned coal gas is, on a volume or mole basis:

- $\mathrm{H}_{2}: 34 \%$

- $\mathrm{CO}: 61 \%$

- $\mathrm{CO}_{2}: 2 \%$

- $\mathrm{N}_{2}: 3 \%$

- $\mathrm{LHV}=13.07 \mathrm{MJ} / \mathrm{kg}$

- $\mathrm{HHV}=13.8 \mathrm{MJ} / \mathrm{kg}$

Inert gas with $15 \mathrm{ppm}$ up to about $200 \mathrm{ppm} \mathrm{H}_{2} \mathrm{~S}$ and occasional upset periods of $\mathrm{HCl}$ level at about $500 \mathrm{ppm}$ could be present in the gas [13]. For the present analysis, the syngas is assumed to be free of $\mathrm{H}_{2} \mathrm{~S}$ and $\mathrm{HCl}$.

\subsection{Subsystem Model Development}

Subsystem models for the current project are based on SOFC models previously developed at UTRC for SOFC-CHP systems. For those power plant applications the SOFC stack size was above $100 \mathrm{kWe}$. We extended that model to the current analysis in which the SOFC stack size ranges from $5 \mathrm{kWe}$ to $200 \mathrm{kWe}$.

The models are physics-based, as opposed to map-based or performance-curve based. The physics modeled includes energy balance, mass balance, fluid dynamics, heat transfer and chemical reactions.

Only steady state modeling was conducted because dynamic simulation is more appropriate for control or detailed product design in later stages for the SOFC-TE development. The models were implemented using an equation-based solver gPROMs [10]. 


\subsubsection{Performance models}

The component models include:

- Blower: To supply air for the TE and the ambient pressure SOFC stack

- Burner: To burn the remaining fuel in the exhaust gas of the stack

- Compressor: To feed air to a pressurized SOFC

- Heat exchanger: To recover the heat in the SOFC exhaust, if there is no TE

- Insulation: To reduce the heat loss to the environment

- PCS: To convert the SOFC-TE DC power into desired AC voltage and current

- Pipe: To connect different components

- SOFC Stack: To generate power as the major power generation device

- TE generator: To generate power using the SOFC exhaust

- Turbine: To generate power in the pressurized SOFC by driving an electricity generator

To illustrate the level of the model details used for this work, the major equations and variables used in the turbine model are shown in Figure 4-1:

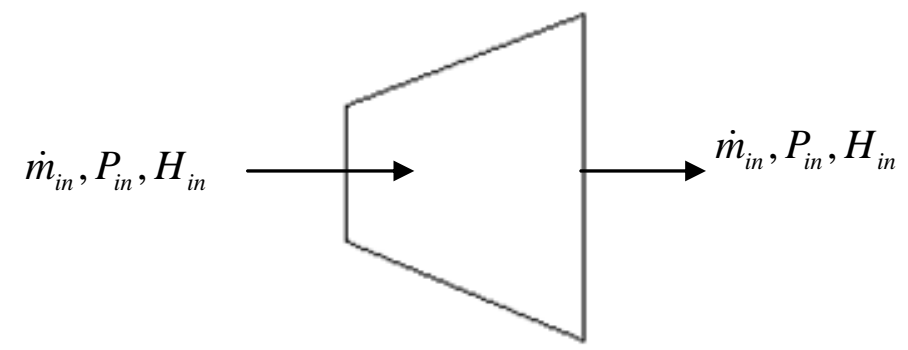

$$
\begin{array}{cl}
\dot{m}_{\text {in }}=\dot{m}_{\text {out }} & H_{\text {out }}=(1-\eta) \cdot H_{\text {in }}+\eta \cdot H_{\text {out }}^{\text {isentropic }} \\
\Delta P=P_{\text {in }}-P_{\text {out }} & P W=\eta_{\text {mech }}\left(\dot{m}_{\text {in }}\left(H_{\text {in }}-H_{\text {out }}\right)-Q_{\text {loss }}\right) \\
P R=P_{\text {in }} / P_{\text {out }} & Q_{\text {loss }}=\dot{m}_{\text {in }} \cdot C_{p}^{\text {out }} \cdot \Delta T \\
\dot{v} \cdot d_{\text {in }}=\dot{m}_{\text {in }} &
\end{array}
$$

Figure 4-1: Major equations and variables used in the turbine model

As can be seen, the model mainly considers mass balance and energy balance between the inlet and the outlet. Other aspects of the turbine operation, such as the isentropic efficiency, are also considered.

The SOFC system performance varies with the unit size. The size of the component is reflected in the component heat transfer area, length, and equipment volume or capacity. The performance of the PCS is modeled using a nominal efficiency for different concepts in Task 5.

The TE generator contains an array of TE elements. The TE model considers heat transfer and power generation at each element. The effect of geometry, such as the TE connector thickness, area 
and the contact resistance between TE materials and the interconnect, was also modeled. The factors affecting power generation include the effect of material figure of merit (ZT), TE material electric resistance and the load resistance. The TE elements are linked together both in parallel and in series where the detailed connection depends on the voltage and current requirements.

\subsubsection{Cost modeling}

Since this study is concerned with the initial cost of the hybrid system, only the equipment manufacturing cost is modeled. Shipping, installation and maintenance cost, etc., have not been considered. For generic components such as heat exchangers or low temperature blowers, the cost is a function of size, capacity or flow rate. For non-generic components such as the turbine, the influence of the sales volume is also included.

The SOFC component cost models are available corresponding to UTRC's databank on SOFCCHP thermodynamic and cost models. Those cost models were reviewed and updated as necessary considering the changes such as the size in the SOFC-TE hybrid system application. The cost models are shown in Table 4-1 below.

Table 4-1: Cost models in SOFC-TE modeling

\begin{tabular}{|c|c|c|c|c|c|}
\hline Component & Equation & Scale Var & Unit & Life & Production Volume \\
\hline Stack (SOFC) & $\begin{array}{l}\$=0.35 \mathrm{P}\left(28.18(\mathrm{~N} \text { cell/P)+120.4 })^{*}((290.94-\right. \\
\left.\left.30.198^{*} \mathrm{LOG}(\mathrm{P})\right) / 130\right)^{*}(\mathrm{Vol} / \mathrm{Vol} 0)^{\wedge}(-0.1278)\end{array}$ & DC pow & $\mathrm{kW}$ & 5 & 2.5GW total capacity \\
\hline Turbine & $\$=272^{\star}(\mathrm{P} / 1.3)^{\wedge} 0.95^{\star}(\mathrm{Vol} / \mathrm{Vol} 0)^{\wedge}(-0.1278)$ & Shaft pow & $\mathrm{kW}$ & 5 & 50000 for $5 \mathrm{~kW}$ SOFC \\
\hline Air compressor & $\$=60^{*}(\text { vdot } / 27.75)^{\wedge} 0.703$ & vdot & CFM & 3 & \\
\hline Cathode Blower & $\$=100^{\star}(\mathrm{vdot} / 27.75)^{\wedge} 0.703$ & vdot & CFM & 2.5 & \\
\hline Anode Blower & $\$=100^{*}(\text { vdot } / 27.75)^{\wedge} 0.703$ & vdot & CFM & 2.5 & \\
\hline Pressure vessel & $\begin{array}{l}\$=5 \mathrm{P}(\mathrm{P} / 200)^{\wedge}(-.25)^{\star}(\mathrm{Vol} / \mathrm{Vol} 0)^{\wedge}(-0.1278)^{\star}((\mathrm{PR}- \\
1)^{\wedge} 0.5\end{array}$ & P, PR & $\mathrm{kW} / 1$ & 3 & 50000 for $5 \mathrm{~kW}$ SOFC \\
\hline Air preheater & $\$=158^{*}(\mathrm{Mdot} / 0.028)$ & Mdot & $\mathrm{kg} / \mathrm{s}$ & 5 & \\
\hline PCS & $\$=(290.94-30.198 *$ LOG(P)) *P & AC pow & $\mathrm{kW}$ & 5 & \\
\hline BOP & $\$=85^{*} \mathrm{P} / 5.6$ & DC pow & $\mathrm{kW}$ & 10 & 50000 for $5 \mathrm{~kW}$ SOFC \\
\hline Insulation & $\$=54^{*} \mathrm{P} / 5.6$ & DC pow & $\mathrm{kW}$ & 10 & 50000 for $5 \mathrm{~kW}$ SOFC \\
\hline Burner & $\$=42^{\star}(\mathrm{Mdot} / 0.028)^{\wedge} 0.55$ & Mdot & $\mathrm{kg} / \mathrm{s}$ & 5 & 50000 for $5 \mathrm{~kW}$ SOFC \\
\hline TE blower & $\$=60^{*}(\mathrm{vdot} / 27.75)^{\wedge} 0.703$ & & & & \\
\hline TE & $\begin{array}{l}\$=\left(\$ T E \_ \text {mat+\$TE_hot+\$TE_cold+\$TE_ass }\right)^{*}(1 \\
\text { +overhead_ratio })\end{array}$ & weight & $\mathrm{kg}$ & 20 & \\
\hline
\end{tabular}

The PCS cost is a regression based on the data for solar photovoltaic system cost and size. As a result, approximately $\$ 150 / \mathrm{kW}$ for $100 \mathrm{~kW}$ PCS with the UTRC model and $\$ 240 / \mathrm{kW}$ for $5 \mathrm{~kW}$ PCS were predicted. Another study with the University of Wisconsin Madison (UWM) model [12] showed that the cost for PCS is $\$ 250 / \mathrm{kW}$, in agreement with our model.

The TE cost model is provided by BSST and is mainly a function of the amount of TE material used. The model has been validated against available experimental data and cost data obtained by BSST. 
The SOFC systems cost data from A. D. Little [11], which were for a 5-kW SOFC system, were used. These data were compared with the UTRC modeled cost, as shown in Table 4-2.

Table 4-2: Comparison of cost with the A. D. Little data (Unit: \$)

\begin{tabular}{|l|r|r|}
\hline \multicolumn{1}{|c|}{ Component } & This Study & \multicolumn{1}{c|}{ ADL } \\
\hline Stack_cost & 1176 & 1184 \\
\hline Burner_cost & 42 & 42 \\
\hline PreheatAir_Cost & 155 & 158 \\
\hline BlowAnode_cost & 103 & 12 \\
\hline BlowCathode_cost & 103 & 78 \\
\hline PreheatGas_cost & 49 & 62 \\
\hline CompAir_cost & 89 & 272 \\
\hline Ins_cost & 53 & 54 \\
\hline BOP_cost & 84 & 85 \\
\hline Pressure_vessel_cost & 7 & 0 \\
\hline Total Without PCS & $\mathbf{1 8 6 0}$ & $\mathbf{1 9 4 7}$ \\
\hline PCS_cost & 1212 & 203 \\
\hline Total & $\mathbf{3 0 7 2}$ & $\mathbf{2 1 5 0}$ \\
\hline
\end{tabular}

The comparison shows that when the UTRC stack cost model, which was originally used for the stack at $100 \mathrm{~kW}$ scale, is extrapolated linearly to small sizes at $5 \mathrm{~kW}$ the stack cost is close to the ADL stack cost. The UTRC system model makes higher prediction than A. D. Little. The PCS in the A. D. Little model does not include sophisticated ready-for-grid-connection capability as in the UTRC system. If the advanced PCS cost is one third of the system cost and is added to the ADL system cost, the ADL model would yield similar system cost as the UTRC model.

\subsection{System Integration}

The TE and the SOFC can be integrated in several ways. The simplest connection is to just connect the SOFC's exhaust to the TE's hot inlet. Using TE to replace the heat recuperator in the original SOFC subsystems may limit the heat recuperation, thus impairing the SOFC performance. In the case of pressurized SOFC, there is an option of sending the SOFC exhaust gas to the TE first and then the turbine. Not all configurations may be physically feasible.

For system integration in the modeling, it is typical to start with an SOFC model and connect the TE's cold and hot streams to appropriate SOFC ports. If the TE is supposed to replace an existing heat exchanger, the TE heat transfer rate is set to that heat exchanger at the start of the modeling. If the TE is a new component, TE heat transfer rate is set to be very small initially. After the system is executable, the TE size is gradually changed to conduct the sensitivity analysis and optimization. 


\section{System Down-Selection}

The system down-selection follows the procedure below:

- Understand the system results and characteristics

- Determine the system performance envelopes and conduct system performance sensitivity analysis

- Compare different system architectures or integration concepts

- Find the optimal size for the best system configuration

- Determine the optimal design parameters for the identified best system

\subsection{System Results and Characteristics}

To understand the system characteristics, a simple hybrid ambient pressure SOFC stack in which the TE serves as a second heat recuperator or air preheater, as shown in Figure 5-1 is used.

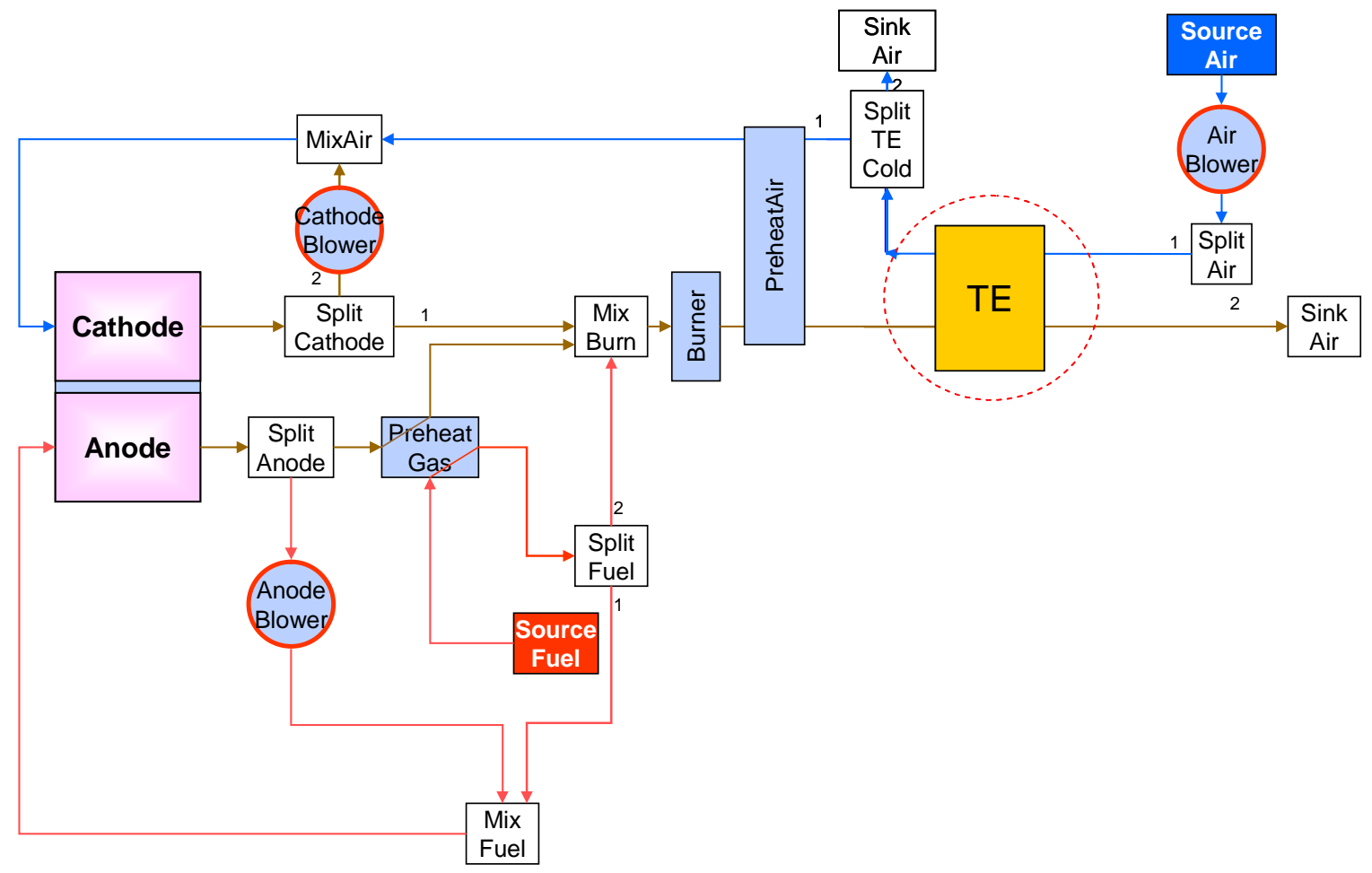

Figure 5-1: Diagram of a simple ambient pressure SOFC-TE hybrid system

This system uses pressurized coal gas as the fuel, which mixes with the anode exhaust and then the mixture is sent to the anode inlet. On the air side, an air blower feeds the air to the cold side of the TE. Part of the TE cold outlet is further heated in an air preheater, and then mixes with the recycle stream of the cathode exhaust. The mixed gas is sent to the cathode inlet. The unrecycled cathode 
outlet and the anode outlet gases come to a burner to burn any unused fuel. The burned exhaust gas enters the air preheater and then the TE. Finally the exhaust gas is released into the ambient.

The major interest of this study is the overall system power generation of the system, which includes the power generated by the SOFC stack and the TE. In this particular ambient pressure system, with $100 \mathrm{~kW}$ of fuel heat input (low heating value), the SOFC and TE generate approximately $45 \mathrm{~kW}$ and $3 \mathrm{~kW}$ of electricity, respectively. The exhaust temperature at the burner outlet is $790^{\circ} \mathrm{C}$ and the TE hot gas inlet temperature is $450^{\circ} \mathrm{C}$. The TE efficiency is close to $8 \%$.

Major control parameters include the stack outlet temperature, stack fuel utilization, air preheater size, TE size and TE cold outlet split ratio. The stack outlet temperature is set depending on the material requirement. It can be adjusted by changing the cathode recycle ratio through the cathode blower. The fuel utilization affects the stack efficiency and can be adjusted through the anode blower.

An optimal air preheater size exists. When the air preheater is large, it will leave less heat for the TE power generation. If the air preheater is too small, the stack air inlet temperature may be too low and adversely affects the SOFC stack performance.

When the TE is large, it tends to recover more heat from the air preheater exhaust and produces more power. However, if the TE is too large, the TE cost will be higher with more TE materials used.

To make the use of TE more effective, a higher air flow rate can be used for the cold side of the TE. However, only a certain amount of the air is needed by the stack. The excess air from the TE cold side has to be dumped into the environment. From the system energy standpoint, even though TE produces more power at higher cold side flow rate, more heat in this case would have to be released into the environment instead of being re-utilized by the stack. This could be detrimental to the system efficiency. Another disadvantage with larger TE cold air flow rate is that the TE fan power consumption will increase. A system evaluation will be conducted in Section 5.4.3 to see whether the incremental power generated by the TE outweighs the additional power consumption for the blower.

\subsection{System Design Envelope and Sensitivity Analysis}

Sensitivity analyses were conducted to identify the possible range of the parameters as well as the impact on the system performance.

\subsubsection{Sensitivity analysis sequence}

First the system sensitivity analyses for the Concept 1-3, or System A, B and C in the tables below, were conducted with typical rotating machinery efficiency, PCS efficiency and cost. These variables are listed in Table 5-1. Concept 4 is about a component design in which TE is integrated into the stack. This concept was analyzed separately at a higher level in Chapter 2. Concept 5, the rotating machinery efficiency, was applied to System A, B and C, as shown in Table 5-2. Concept 
6 , trade between large and small modules, was applied to the best system configuration identified and will be shown later in this chapter. Concept 7-10 are about the PCS, and have been applied to Systems A, B and C in the sensitivity analysis, as shown in Table 5-3.

Table 5-1: System sensitivity analysis variables and ranges

\begin{tabular}{|l|c|c|c|c|c|c|}
\hline & Unit & Low & High & A & B & C \\
\hline Fuel utilization ratio & & 0.75 & 0.93 & $\mathrm{X}$ & $\mathrm{X}$ & $\mathrm{X}$ \\
\hline Air preheater effectiveness & & 0.01 & 0.9 & & & $\mathrm{X}$ \\
\hline Cell voltage & $\mathrm{V}$ & 0.65 & 0.8 & $\mathrm{X}$ & $\mathrm{X}$ & $\mathrm{X}$ \\
\hline TE exhaust outlet temperature & $\mathrm{C}$ & 100 & 200 & $\mathrm{X}$ & $\mathrm{X}$ & $\mathrm{X}$ \\
\hline Stack heat loss HTC & $\mathrm{W} / \mathrm{m}^{2} \mathrm{~K}$ & 5 & 50 & $\mathrm{X}$ & $\mathrm{X}$ & $\mathrm{X}$ \\
\hline Stack inlet air temperature & $\mathrm{C}$ & 650 & 710 & $\mathrm{X}$ & $\mathrm{X}$ & $\mathrm{X}$ \\
\hline Stack outlet gas temperature & $\mathrm{C}$ & 700 & 750 & $\mathrm{X}$ & $\mathrm{X}$ & $\mathrm{X}$ \\
\hline Turbine/Recuperator position & & $\mathrm{T}-->\mathrm{R}^{*}$ & $\mathrm{R}-->\mathrm{T}^{*}$ & & $\mathrm{X}$ & $\mathrm{X}$ \\
\hline
\end{tabular}

*: $\mathrm{T}$ - Turbine, $\mathrm{R}$ - Recuperator

Systems A: Ambient pressure SOFC-TE system

B: Pressurized SOFC-TE with recuperation

C: Pressurized SOFC-TE w/o recuperation

Table 5-2: Rotating machinery sensitivity analysis variables and ranges

\begin{tabular}{|l|c|c|c|c|c|c|}
\hline & Unit & Low & High & A & B & C \\
\hline Turbine efficiency & & 0.75 & 0.95 & & X & X \\
\hline Anode blower efficiency & & 0.5 & 0.77 & X & X & X \\
\hline Cathode blower efficiency & & 0.5 & 0.77 & X & X & X \\
\hline TE air blower efficiency & & 0.5 & 0.77 & X & X & X \\
\hline Air compressor efficiency & & 0.5 & 0.77 & X & X & X \\
\hline
\end{tabular}

Table 5-3: PCS concepts tested

\begin{tabular}{|l|c|c|c|}
\hline & A & $B$ & C \\
\hline 7: SOFC TE in parallel, merged after DC/AC conversion & $X$ & $X$ & $X$ \\
\hline 8: SOFC TE in parallel, merged before DC/AC conversion & $X$ & $X$ & $X$ \\
\hline 9: SOFC TE in series, merged before DC/AC conversion & $X$ & $X$ & $X$ \\
\hline 10: Use in-plant DC bus if available & $X$ & $X$ & $X$ \\
\hline
\end{tabular}

\subsubsection{Design parameter sensitivity analysis results}

The sensitivity analysis shown below in Figure 5-2 was based on a pressurized SOFC-TE system with an air preheater, which has a baseline efficiency of $65 \%$. 


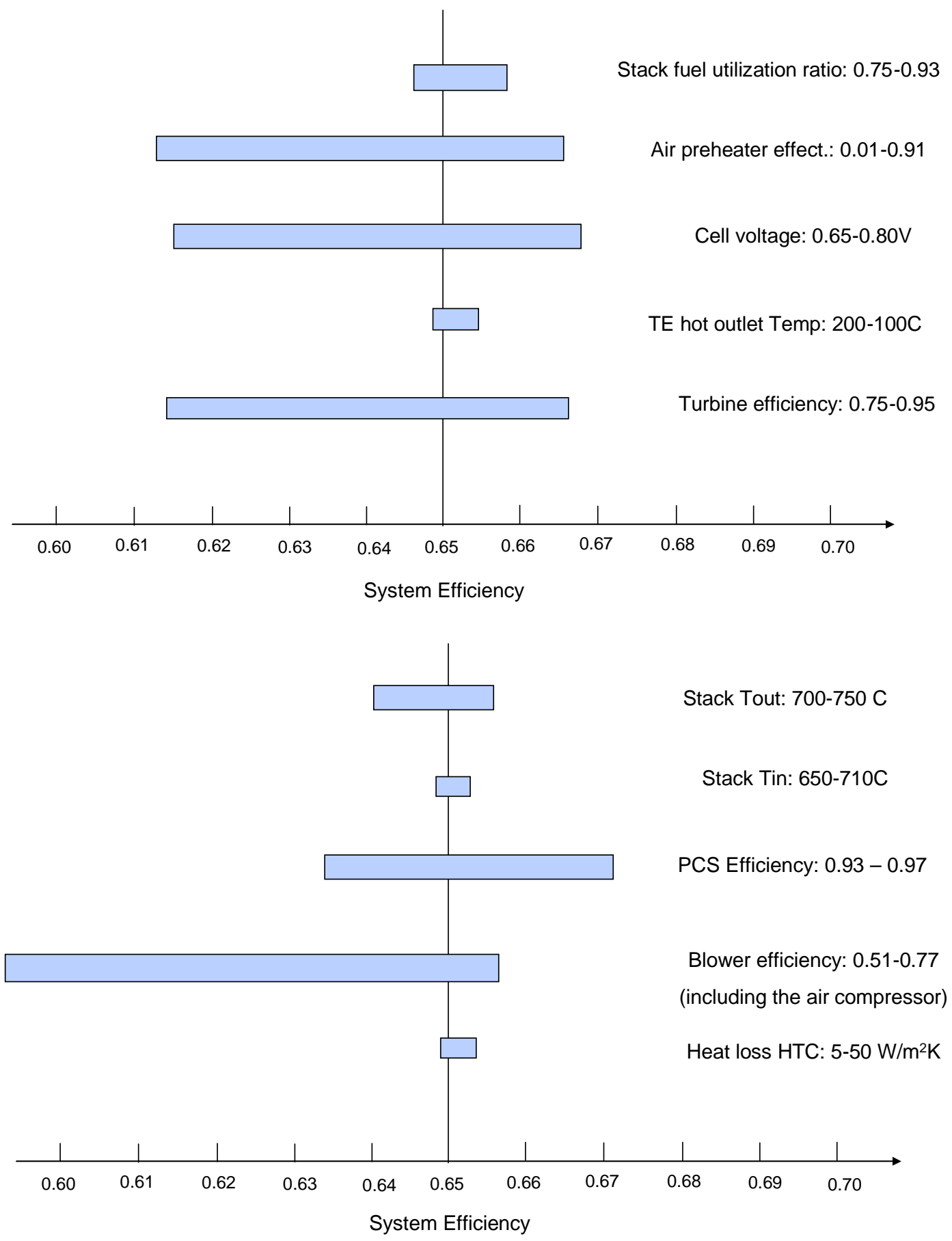

Figure 5-2: Sensitivity analysis results

Each individual design parameter was varied separately and the change of system efficiency, defined as the system power generation divided by the fuel heat input (LHV basis), was recorded. The range of a design parameter covers the typical values found in practice.

The results show that the air preheater size or effectiveness, cell voltage, turbine efficiency, PCS efficiency and blower efficiency are among the most influential design parameters. Cell voltage is 
directly related to the amount of electricity generated by the stack. Turbine power constitutes a significant portion of the power generation in a pressurized SOFC-TE system, thus the turbine efficiency affects the system efficiency strongly. The PCS efficiency is defined as the amount of AC power output vs. the DC power generated by the system. It is essentially a multiplication factor for the system efficiency.

Blowers/air-compressor efficiencies are related to the system power consumption. In a pressurized SOFC-TE system, the air compressor power consumption can be up to $23 \%$ of the gross system power generation. Therefore the air compressor efficiency is important for the system efficiency. The blowers for anode recycle, cathode recycle and for TE cold air all have small pressure drops on the order of a few hundred $\mathrm{Pa}$. The power consumption for those blowers together is less than $2 \%$ of the gross system power generation, thus playing a less significant role.

\subsection{System Architecture Analysis}

For a particular architecture, the major factors affecting the system performance were identified. Then the system efficiency was maximized. Finally, the best system based on the performance was selected. Unless otherwise specified, the system nominal capacity is $100 \mathrm{~kW}$ or below.

\subsubsection{Architecture A1: Ambient pressure SOFC + 1TE with 1 air blower}

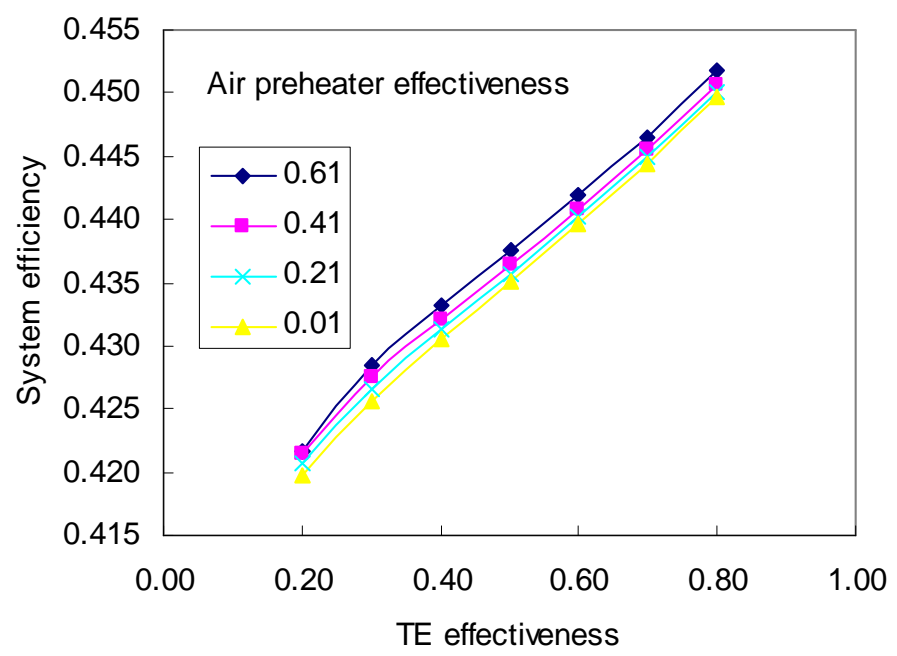

Figure 5-3: System performance of Architecture A1

The system is shown previously in Figure 5-1. The most important design parameters for this system are the TE size and the air preheater size. Since the TE serves as a heat recovery device in addition to a power generation device, the TE size can be directly related to its heat transfer effectiveness. Similar logic applies to the size of the air preheater. The system efficiency vs. the TE and air preheater effectiveness is shown Figure 5-3. 
When the TE effectiveness increases, the system efficiency increases almost linearly. Note that when the effectiveness of a heat exchanger increases linearly, the heat transfer area increases exponentially. Therefore, the results suggest that the efficiency increases with the TE heat transfer area, but to a lesser degree when the TE heat transfer area becomes larger. A larger air preheater can increase the system efficiency by reducing the power of the cathode recycle blower. But this effect is small since the cathode blower power consumption is less than $1 \%$ in the system.

More cold, i.e., ambient temperature, air can be supplied to the cold side of the TE to increase the TE efficiency while the stack only needs a limited amount of cold air to get the best performance. The excess cold air carrying part of the exhaust heat is released to the atmosphere without being recuperated by the system, thus leading to a smaller system efficiency or system power, as shown in Figure 5-4. The best scenario is that there is no excess air.

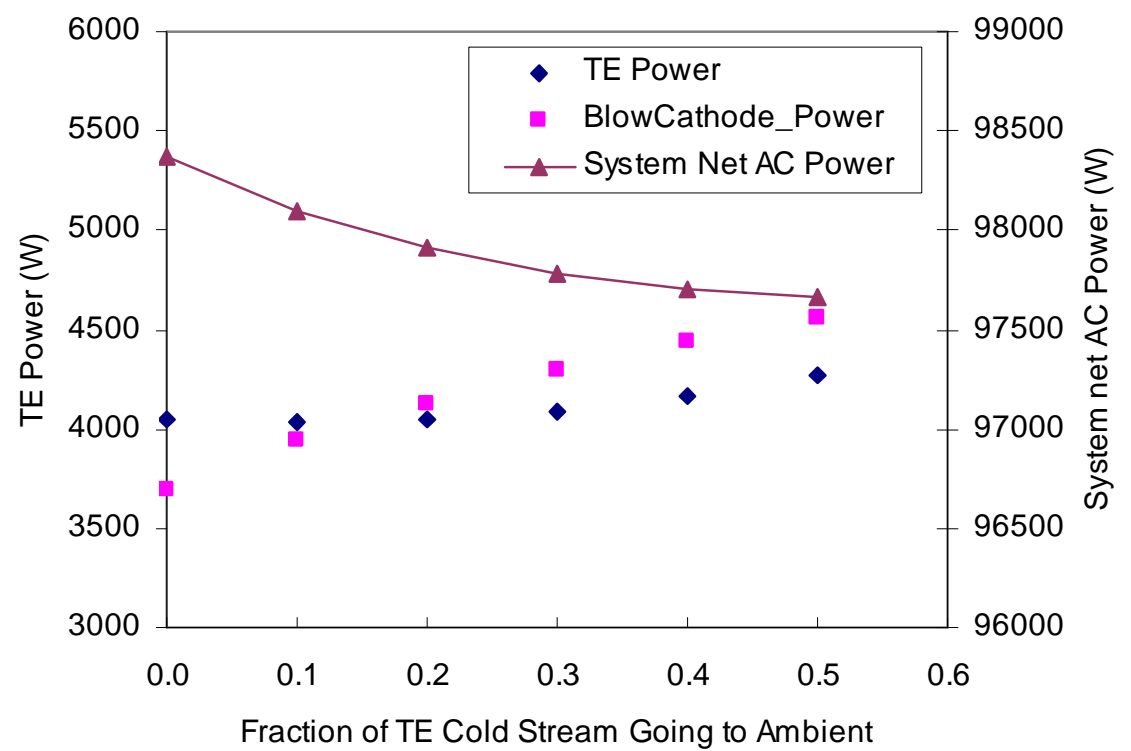

Figure 5-4: TE power and system power of Architecture A1 at different cold air split ratios

\subsubsection{Architecture A2: Ambient pressure SOFC + 2TE with 1 shared air blower}

To generate more power with the exhaust heat, two TEs are employed in this architecture, as shown in Figure 5-5. TE2 in the figure now serves as both an air preheater in the previous Architecture A1 and also a power generator. The two TEs share one air blower. More cold air can be sent to the TE on the right hand side so that TE1 can generate more power. 


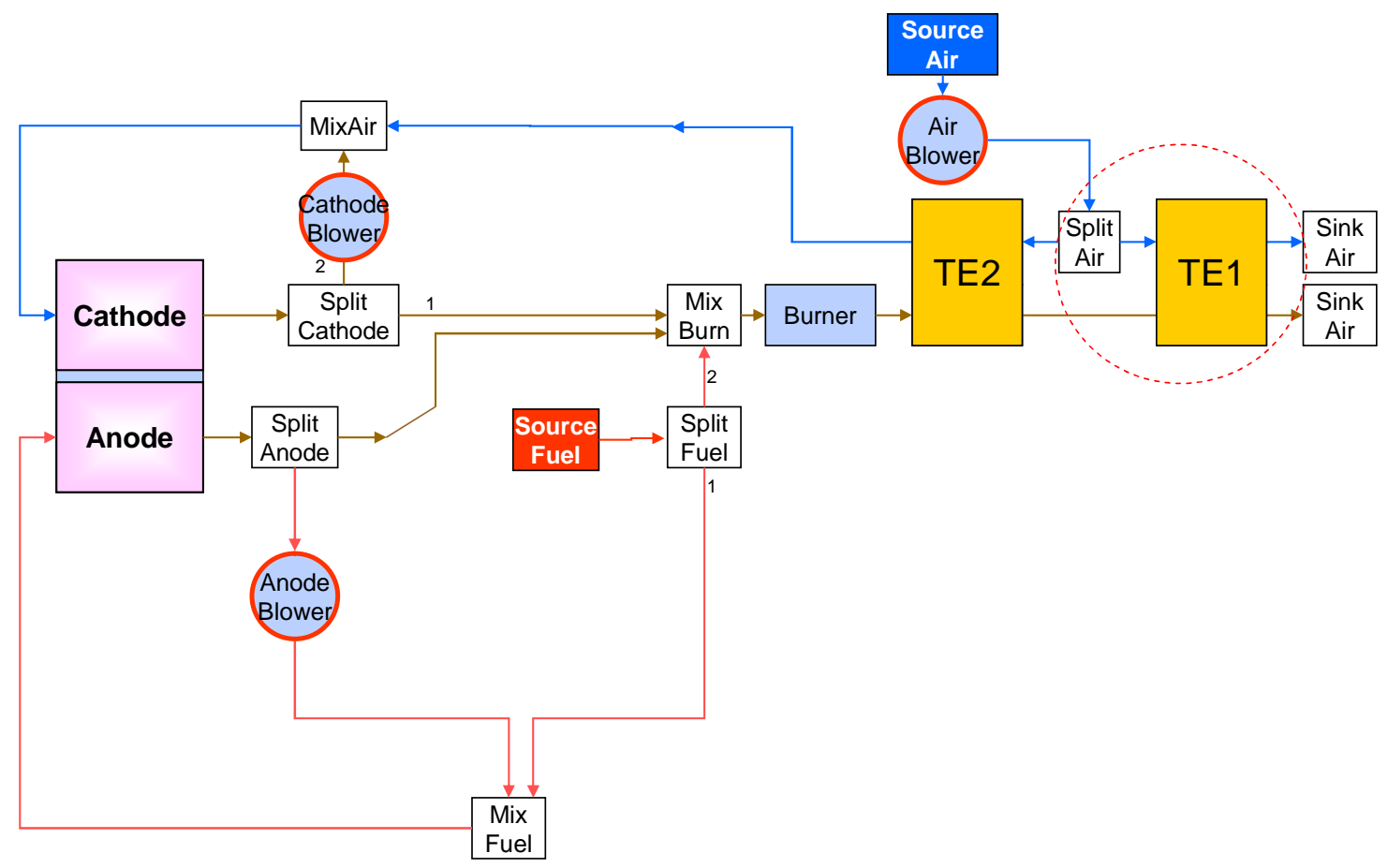

Figure 5-5: Diagram of system Architecture A2

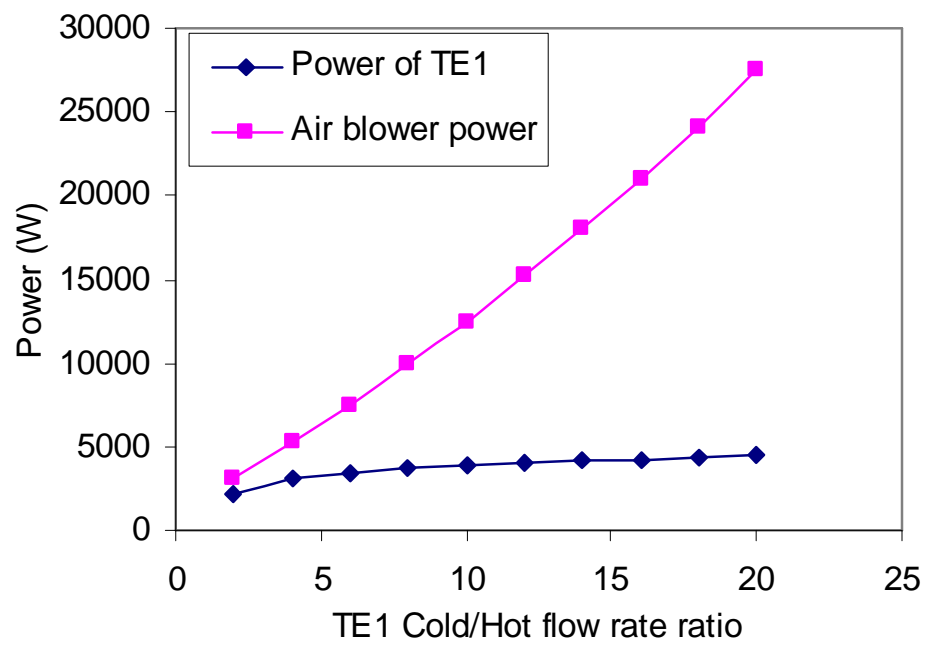

Figure 5-6: TE power and the power consumed by the shared air blower in Architecture A2

The disadvantage with this configuration is the shared air blower. The air blower supplies air to both the SOFC and TE1. The air to the SOFC needs to overcome a higher pressure drop than to the TE1 only, which are of the order of $3000 \mathrm{~Pa}$ and $300 \mathrm{~Pa}$, respectively. The shared blower here has to have high head to meet the pressure requirement for SOFC, and has to provide a large volume flow rate to TE1. As a result, the shared air blower consumes more power than the power generated by TE1 at larger cold air flow rates, as shown in Figure 5-6. For an efficient two TE ambient SOFC-TE system, the shared blower should be avoided. 


\subsubsection{Architecture A3: Ambient pressure SOFC + 2TE with 2 air blowers}

To overcome the unacceptable parasitic power problem in Architecture A2, two air blowers were used in architecture A3, one with a higher head but lower volume flow rate and the other with a smaller head but larger volume flow rate, as shown in Figure 5-7.

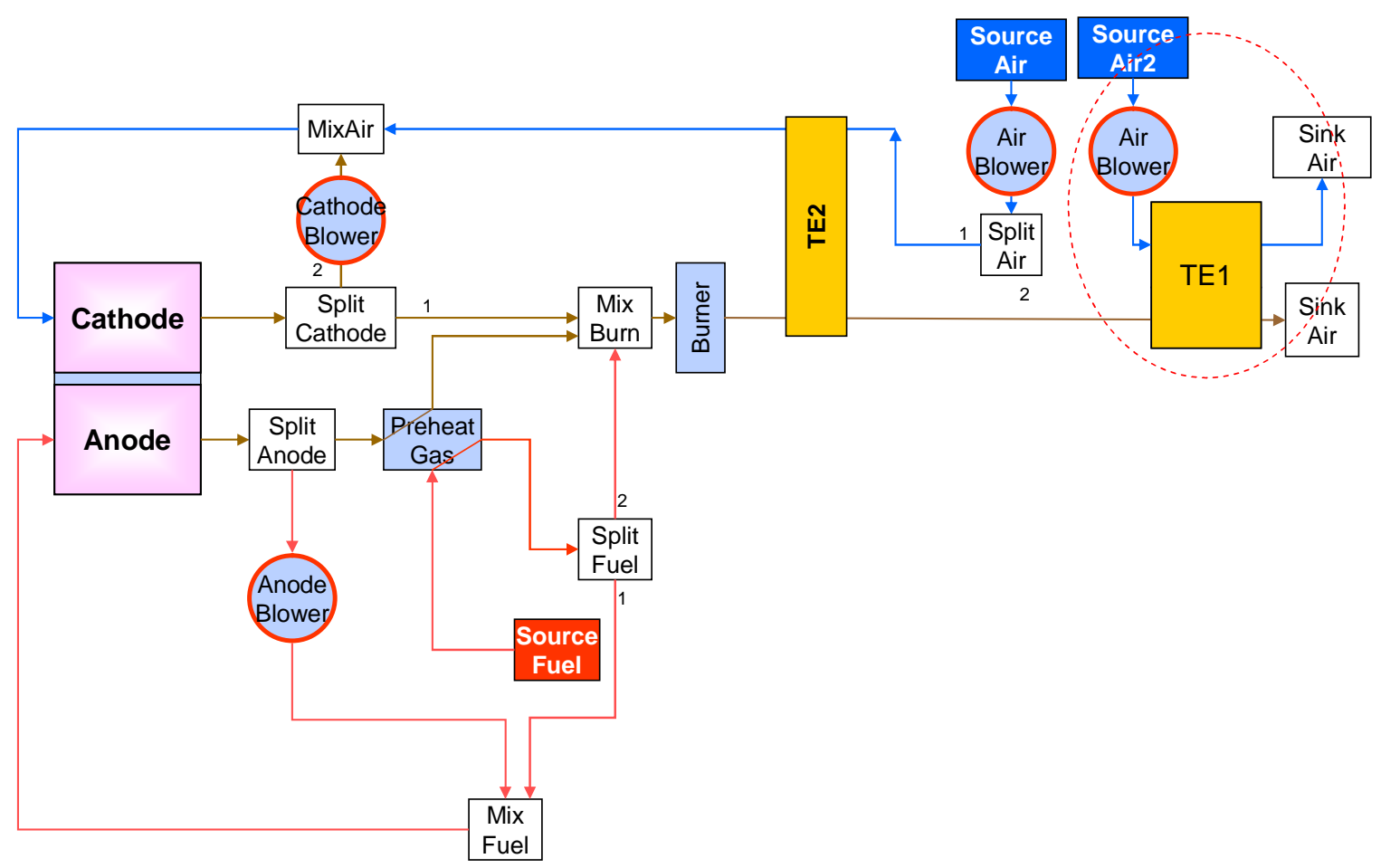

Figure 5-7: Diagram of system Architecture A3

The power generated by TE1, the blower power and the net power between the two are plotted in Figure 5-8(a). The power needed for the TE1 blower is around $1 \mathrm{~kW}$, even at the high cold/hot flow rate ratio of 20 for TE1. With more cold air, TE1's power generation increases. The net power of TE1 and TE1 blower shows a peak when the cold/hot flow ratio is near 10.

Architecture A3 with two TEs and two air blowers is the best ambient pressure SOFC-TE system among what we studied. The performance of this system was further analyzed with respect to ZT, or the figure of merit of the TE generators. The results are shown in Figure 5-8(b). The system efficiency is relatively flat with respect to the change of the cold/hot flow rate ratio of TE1. Note that the cold/hot flow rate ratio for TE2 cannot be changed arbitrarily as it is limited by the SOFC flow requirements. The system has a peak efficiency of $48 \%$ when the ratio is around 6-10 at today's ZT of 0.85 . This is far from the project goal of $65 \%$ system efficiency. If it is assumed that a ZT of 2.5 can be achieved around the year 2011, TE contributes approximately $6 \%$ points for the total system efficiency $51 \%$. This is the highest efficiency achievable for the ambient SOFC-TE. 


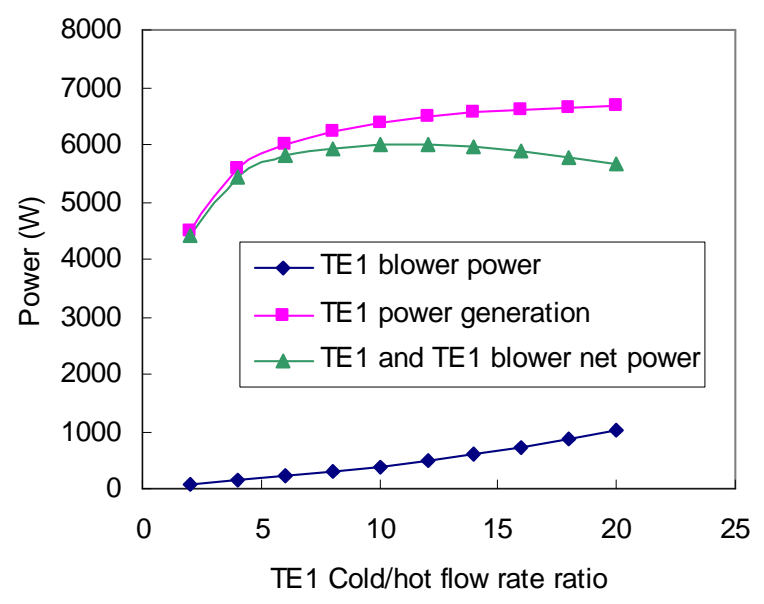

(a)

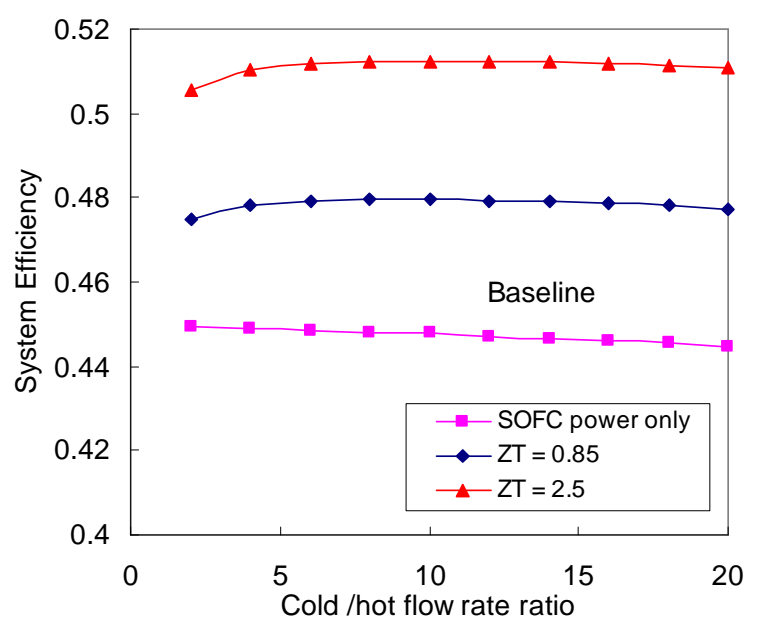

(b)

Figure 5-8: The performance of Architecture A3

\subsubsection{Architecture B: Pressurized SOFC + 2TE}

Figure 5-9 shows a pressurized SOFC with two TEs. This system is similar to Architecture A3 except that the air blower for SOFC is now an air compressor and a gas turbine is added after the burner. The air compressor sends the pressurized air into TE2, a high stage TE generator. The low stage TE, or TE1, is similar to the previous configuration. The turbine and the air compressor are usually put on the same shaft. They can be connected to a generator to produce AC power directly. It is assumed that the fuel source pressure is high enough so that no fuel compressor is needed.

When pressurized SOFC is used, the stack performance is increased and the expander, or turbine, can generate additional power with the high temperature, high pressure exhaust gas. In a typical pressurized SOFC-TE (PSOFC-TE) system, the turbine-compressor, or the turbo generator, can boost the SOFC efficiency from $45 \%$ at ambient pressure to approximately $60 \%$ or above at the pressure ratio of 4 [39].

The cost and performance of TE2 against the TE2 size, as indicated by the parallel number of elements in TE2, are plotted in Figure 5-10. The system efficiency increases slightly with the TE2 size, from 0.61 to 0.63 when the number of TE2 elements increases from 0 to 18,000 . However, the system cost increases substantially from $\$ 400 / \mathrm{kW}$ to $\$ 630 / \mathrm{kW}$ with the TE2 size. 


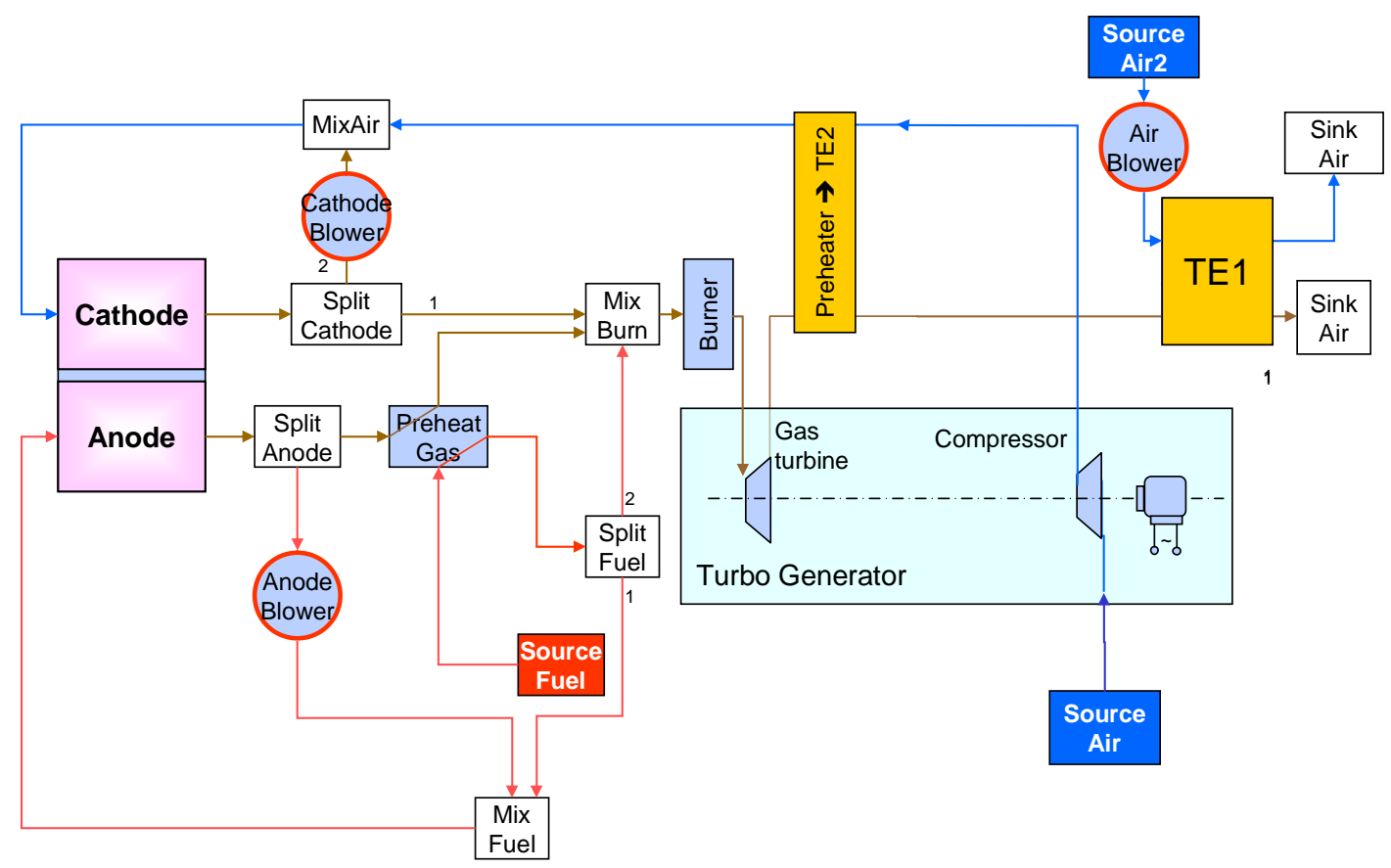

Figure 5-9: Diagram of pressurized SOFC with two TEs

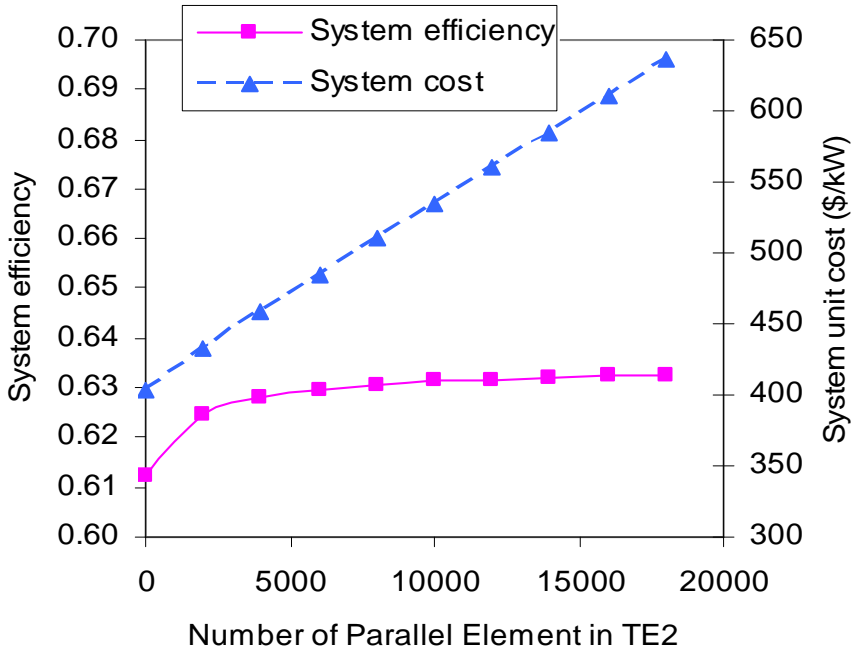

Figure 5-10: Performance and cost variation with TE2 size

TE2 in a pressurized SOFC does not generate as much power as in an ambient pressure system because the exhaust gas leaving the turbine has lower temperature after expansion. On the other hand, the TE2 cold inlet temperature has higher temperature after the compressor. That reduces the temperature difference between the cold and the hot stream across TE2.

Since TE2 adds little benefit but incurs significant cost, it is more cost effective not to use the TE2 in a pressurized SOFC. A simple recuperator can be used instead. 


\subsubsection{Architecture C: Pressurized SOFC + 1TE}

This architecture is the same as Architecture B except that the TE2 is replaced with a simple heat recuperator, as shown in Figure 5-11. This is the best system configuration among all the system concepts analyzed in this study.

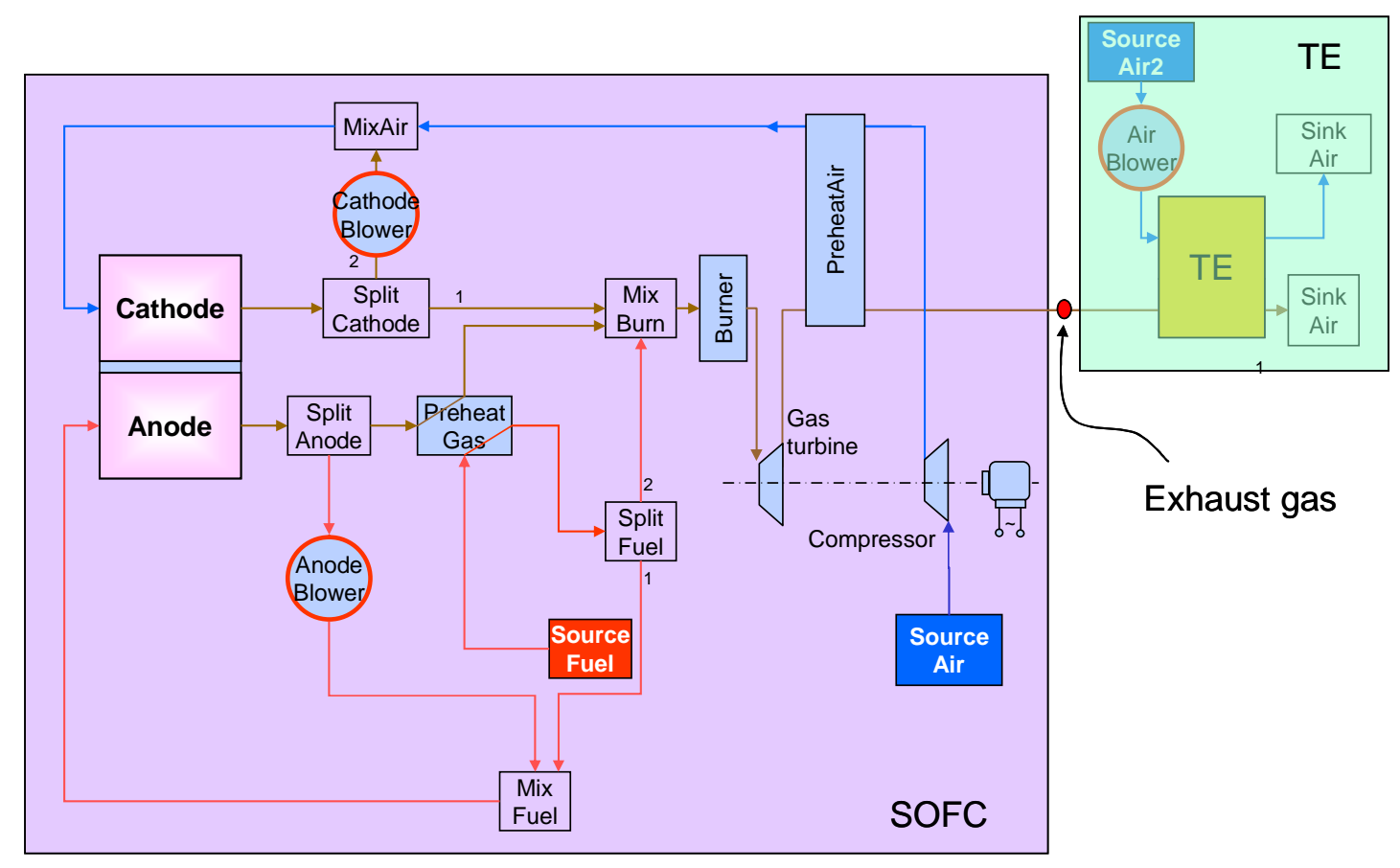

Figure 5-11: Diagram of the optimal system: Architecture C

\subsection{System Optimization}

Next, the optimum working parameters such as the pressure ratio (PR), the gas temperature at the connection point, the TE size, the stack size, the system cost and efficiency need to be determined. Figure 5-11 shows that the TE and the SOFC are essentially connected at one point on the exhaust gas stream, which makes the system optimization between SOFC and TE relatively easy because SOFC and TE can be optimized separately, just leaving the connection point to be optimized. In addition, any previous standalone SOFC optimization results will remain valid here.

\subsubsection{Pressure ratio effect}

System efficiency as a function of the PR is shown in Figure 5-12. Pressurization first increases the SOFC stack performance. The SOFC efficiency increases from $46 \%$ to $48 \%$ when the PR changes from 1 to 10. The turbo generator, or the combination of the gas turbine and the compressor together, increases the system efficiency substantially to above $60 \%$ when the pressure ration (PR) 
is $>2$, as the green line indicates. The turbo generator has a peak efficiency around $\mathrm{PR}=4$, when the system efficiency is close to $63 \%$. When the pressure ratio is higher than 4 , the incremental benefit of the turbo-generator is reduced because of the higher compressor power consumption.

After adding a TE at $\mathrm{PR}=4$, the system efficiency increases by $0.4 \%$ point at $\mathrm{ZT}=0.85$, as the red line shows, and by $1.6 \%$ if ZT is 2.5 in the dark blue line. The highest system efficiency achieved is $65.3 \%$, which corresponds to $\mathrm{PR}=4$ and $\mathrm{ZT}=2.5$.

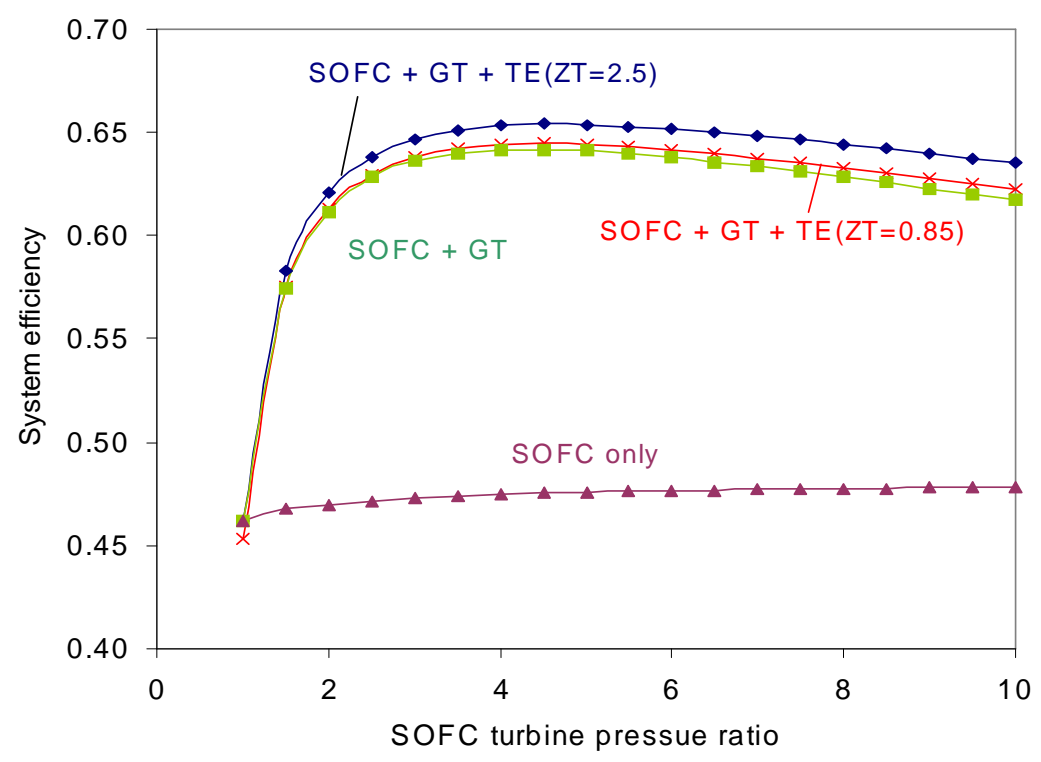

Figure 5-12: System efficiency as a function of turbine pressure ratio

\subsubsection{SOFC-TE interface temperature}

To optimize the SOFC and the TE as a system, only the connection point in the exhaust stream needs to be considered, as shown in Figure 5-11. The flow rate of the exhaust is determined by the system power generation, and it cannot be changed arbitrarily. This leaves only the temperature of the connection point to be optimized. This can be realized by changing the air preheater size. The system efficiency as a function of the SOFC-TE interface temperature is shown in Figure 5-13. 


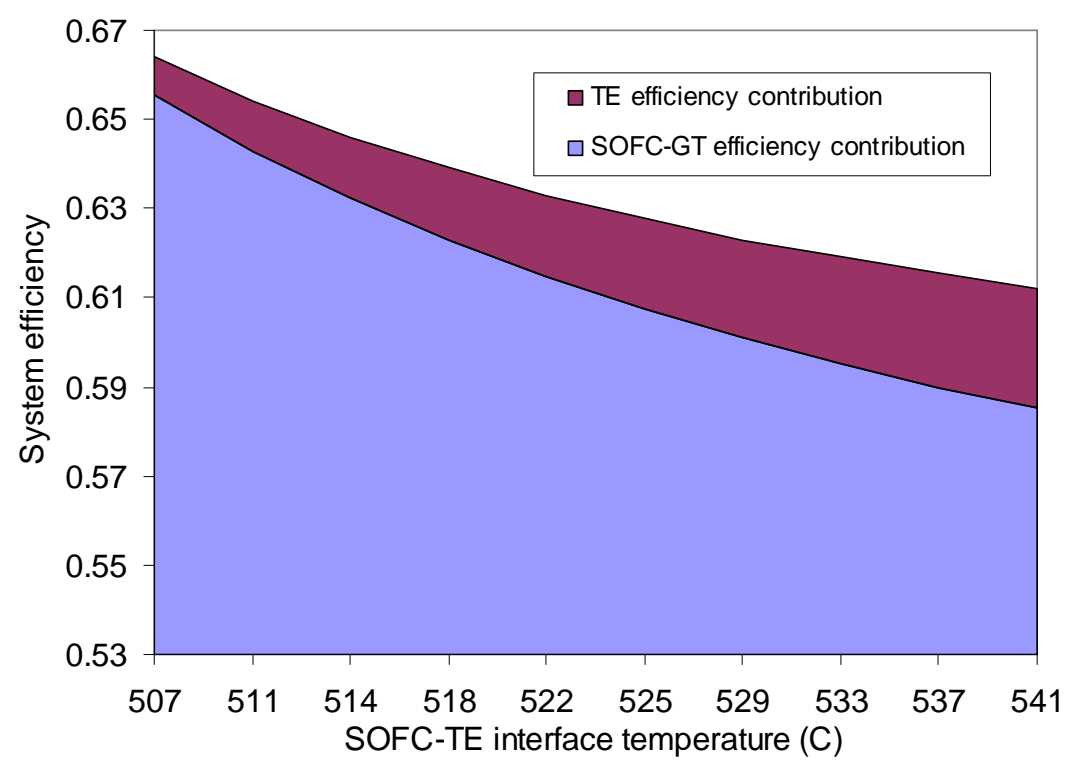

Figure 5-13: System efficiency as a function of the SOFC-TE interface temperature

When the interface temperature increases, more exhaust heat is available for TE power generation, as the dark red zone shows in the figure. However, the SOFC-gas turbine assembly efficiency decreases faster than the TE efficiency increase. This suggests that SOFC-gas turbine can utilize the exhaust heat more efficiently than the TE. As a result, having lower interface temperature and allocating more energy for SOFC leads to higher system performance.

There is a lower limit to the SOFC-TE interface temperature, which is determined by the heat transfer in the SOFC air preheater. The air preheater cold inlet in fact is the compressor outlet, with a temperature of $\sim 200-400 \mathrm{C}$ depending on the pressure ratio. When the air preheater hot outlet temperature, or the SOFC-TE interface temperature, approaches the cold inlet temperature, it becomes difficult to lower the exhaust outlet temperature by increasing the air preheater size. At that point, the lowest interface temperature is achieved.

TE performance improvement in the future may change the optimization picture above. ZT is not the only factor affecting the TE efficiency. When the TE performance is improved through other means such as innovative thermal or geometry design, the system could be made more efficient by increasing the interface temperature. In that case, using higher interface temperature may lead to higher system efficiency.

\subsubsection{TE subsystem optimization}

With a given SOFC-TE interface temperature, the TE performance is mainly affected by the material ZT and the cold/hot flow rate ratio. 


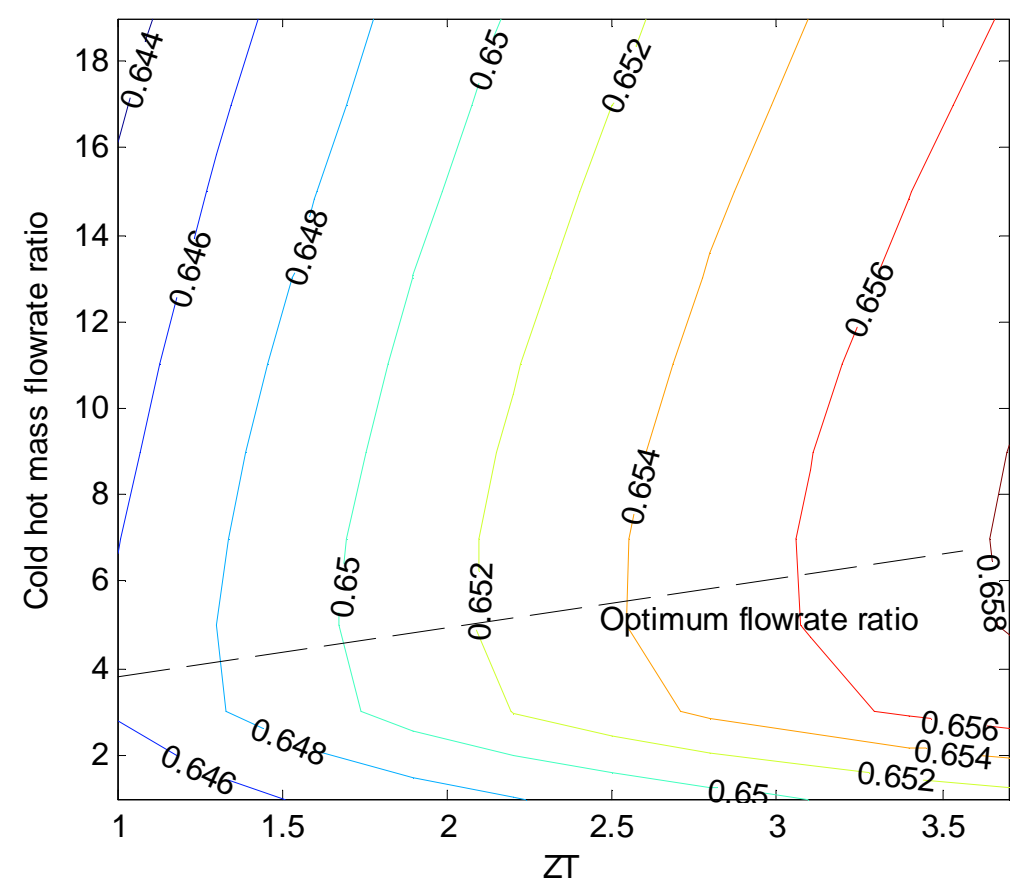

Figure 5-14: TE efficiency as a function of the ZT and the cold flow rate for the TE

The data plotted in Figure 5-14 show that, for a given cold hot flow rate ratio, higher ZT leads to higher efficiency. For a given ZT, increasing the cold flow rate or the cold hot flow rate ratio first increases the system efficiency, because more cold air flow leads to higher cold-hot temperature difference and higher heat transfer rate.

When the cold flow rate increases further, the blower consumes more power, which outweighs the TE incremental power generation so that the system overall efficiency starts to drop. The optimum flow rate ratio increases from 4 to 7 when ZT increases from 1 to 3.5. For ZT $=2.5$, the optimum ratio is approximately 5 .

\subsection{Optimum System Size}

In addition to the performance target, the capital cost target of $\$ 400 / \mathrm{kW}$ electricity for the overall SOFC-TE system was achieved. The system cost is a function of the system capacity, as shown in Figure 5-15. For the 5kW system, the unit capital cost is more than $\$ 600 / \mathrm{kWe}$. When the system capacity increases, the costs of several major components drop including the PCS, the turbine and the air compressor. The stack cost, which is about one third of the total cost, does not drop substantially because we assumed a fixed market size of $2.5 \mathrm{GW} /$ year. Larger system size means a smaller sales volume. The combined effect is that the unit cost does not vary greatly with the unit size.

At the system capacity of $200 \mathrm{kWe}$, the cost of $\$ 390 / \mathrm{kW}$ is achieved, slightly lower than the present SECA goal of $\$ 400 / \mathrm{kWe}$. TE blower and TE generator together cost about $\$ 13 / \mathrm{kWe}$, or $4 \%$ of the 
system cost. The TE contributes $2.4 \%$ of the system power generation (1.6\% out of a total efficiency of $65 \%$ ). Compared to the SOFC assembly, the TE is less cost effective, but still makes a non-trivial contribution to the system capability.

Figure 5-15 suggests that larger size of the system than $200 \mathrm{~kW}$ could lead to even lower system cost. Therefore, if allowed by the technology maturation, larger SOFC units should be used.

\subsection{Summary}

With the models developed in Chapter 4, SOFC-TE sensitivity analysis and comprehensive evaluation of the SOFC-TE system concepts in terms of the system performance and cost were conducted. The best system architecture is a pressurized SOFC with a down stream TE. The optimum design has system efficiency of $65.3 \%$, at a pressure ratio of 4, ZT of 2.5 and cold/hot mass flow rate of 6 . In this optimum system, TE makes approximately a $1.6 \%$ efficiency points contribution. The system cost is $\$ 390 / \mathrm{kWe}$ at the optimum system size of $200 \mathrm{~kW}$. Systems with capacity higher than $200 \mathrm{~kW}$ should be used, if available. 


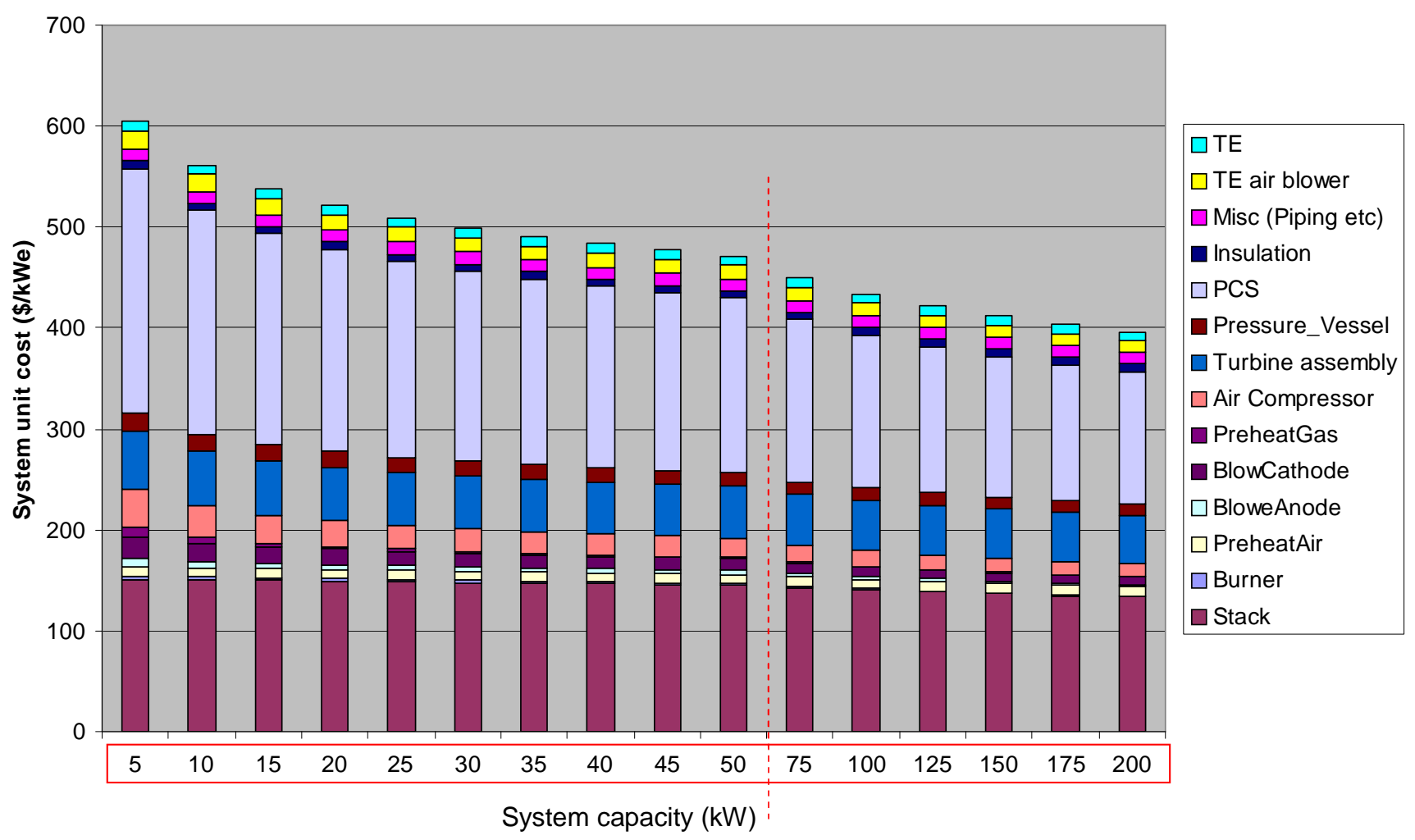

Figure 5-15: SOFC-TE system cost as a function of the system capacity in $\mathrm{kW}$ 


\section{Product and Performance Specifications}

In Chapter 5, the best system configuration was identified as a pressurized SOFC at the pressurization ratio of 4 integrated with a TE that has separate cold (ambient) air supply. The system performance and cost specifications are described below for the best concept based on the modeling results.

Two systems will be covered in this section: a pressurized SOFC-TE system and an ambient pressure SOFC-TE system. The pressurized SOFC-TE is the overall optimal system configuration identified in Section 5.3.5. The pressurized system is likely to have higher development complexity and risks. In comparison, an ambient pressure SOFC-TE system, without turbine, air compressor and pressurized chamber, is simpler and can serve as an intermediate step toward the pressurized system. The ambient pressure system is recommended for the prototype in Phase II of this project, as will be discussed in Chapter 8. The specifications in this chapter cover both the ambient and pressurized systems.

\subsection{Product Working Principles}

\subsubsection{Working principles of the pressurized SOFC-TE system}

The flow diagram of the optimal pressurized system configuration is shown in Figure 5-11. In this system, coal gas is supplied from a pressurized gas source. In utility power plants that the SOFC-TE system is designed for, the coal gas is assumed to be from a pressurized source such as a tank with pressure higher than the required 4 bar for the system, thus the gas compressor is not needed. The coal gas mixes with a stream of stack anode exhaust. The mixed stream is fed into the anode of the stack. In the oxidant stream, the ambient air is compressed, preheated and then mixed with a stream of cathode exhaust. The mixed air is supplied to the stack csathode. The exhaust from the stack cathode and anode are mixed in a burner so that the unused fuel is burnt and the exhaust temperature is increased. The exhaust leaving the burner is expanded through a turbine, producing work that is partially used by the air compressor on the same shaft. Any excess work from the shaft is converted to power with a generator. The exhaust gas leaving the turbine is used to preheat the cold air and then sent to a TE generator for additional power generation. The TE is cooled using the ambient air supplied by a fan.

The pressurized section, including the components that are linked from the air compressor inlet to the turbine outlet, is enclosed in a pressurized vessel.

\subsubsection{Working principles of an ambient pressure SOFC-TE system}

The flow diagram of the optimal ambient SOFC-TE system is shown in Figure 5-7. There are two major differences between an ambient pressure SOFC-TE and a pressurized one: 1) The SOFC stack is designed to work under ambient pressure so that there are no turbine and air compressors in the ambient system; and 2) There are two TE generators in the optimal ambient system configuration. 
The fuel supply is the same as that in the pressurized system. Since the stack works at ambient pressure, the pressure drop through the valve will be larger than in a pressurized system. The air preheater in the pressurized system now is used as a high stage thermoelectric generator. It receives the exhaust gas from the burner directly, without passing through a turbine or expander. The air compressor now consumes much less power than in a pressurized system since it only needs to overcome friction losses in the piping and the system components. A low pressure air blower can be used in place of a compressor.

\subsubsection{Power conditioning system (PCS) diagram and working principle}

The PCS system discussed here converts the DC power generated by the SOFC and the TE into stable AC power that can be supplied to the utility power grid.

Four PCS concepts were generated previously in the conceptual design stage in Chapter 2. For the down-selected system, the basic AC version is chosen, i.e., SOFC DC and TE DC are inverted to AC first and then merged before sending to the grid. The flow diagram of the selected PCS system is shown in Figure 6-1. This concept is advantageous in that it is mature and reliable. If the TE is not used temporarily, the SOFC branch can still work independently. More detailed discussion of the PCS concept selection is shown in Chapter 5.4

The DC power produced by the SOFC and the TE is likely to be at different voltage and different current. In addition, the power generation is dynamic for both the SOFC and the TE during operation depending on the capacity and load requirement. A DC to DC booster is needed in each branch to generate smooth and stable DC current before DC to AC conversion.

Similar integration scheme has been widely used in the solar PV industry. This study is concerned with the form of connection and the system efficiency.

\section{DC/DC DC/AC ext. grid}

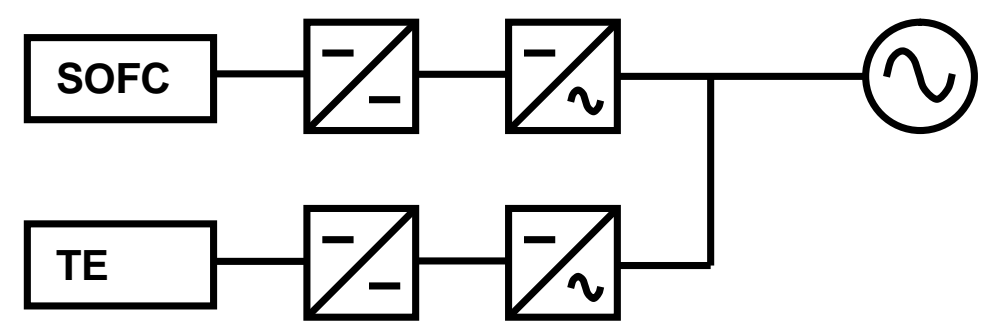

Figure 6-1: Diagram for the parallel connection between SOFC and TE in PCS 


\subsubsection{System operation modes and dynamic responses}

The system has five operation modes: starting-up, steady operation, load transition, shutting-down and being idle.

The start-up procedure can be further divided into four stages: initial heat up, stack temperature gradient control, initial power generation and steady state power generation [14]. Detailed SOFC start-up procedure can be found elsewhere [15] [16]. In a pressurized system, the stack pressure and temperature are increased simultaneously. During start-up, the system needs to be heated up to the operating temperature of the cell stack and this can be achieved by using thermal and/or electrical energy available from other sources, such as on-site power plant. Typical SOFC start-up time is approximately 3 hours [14] while TE start-up time is in the order of a few minutes. During load transition period, it takes less time to reach the new steady state than from a cold start.

To shut down the system, the PCS is disconnected first. The system power is converted to heat through the electric heater in the exhaust stream. The fuel input is reduced gradually. To avoid large thermal stress, the system should be cooled gradually and fuel supply is still needed at the early stage of the shutdown.

In any operation mode, the TE generator has faster response than the SOFC stack. Therefore the integrated system dynamic characteristics are set by the SOFC.

\subsection{System Performance Specifications}

In this section, the performance specifications are presented for both the system and the components.

\subsubsection{Type of performance specifications}

Major system performance specifications include:

- Design specifications, including system efficiency, overall capacity, power allocation to the SOFC stack, the turbine and the TE, the number of operation hours per year and the life span, the minimum and maximum load fraction

- Transient requirement: time for start-up, load transition and shut-down

- System control: allowing the system to operate in different modes with proper transition and logic control of the fuel and air supply as well as the electric power loads

- Subsystem or replacement requirements: time to replace a component or subsystem

Based on the system specifications, the components specifications are determined. Major component specifications are component performance or size characteristics such as heat exchanger capacity and the fan efficiency.

\subsubsection{Detailed System and Components Performance Specifications}

The major design performance specifications or requirements of the selected pressurized and ambient pressure systems are listed in Table 6-1 and Table 6-2, respectively. These specifications 
represent the desired or projected state of the identified optimal configurations, e.g., the ZT value of 2.5 , and may not represent the achievable performance with today's technologies. 
Table 6-1: Major design specifications for the 200kWe pressurized SOFC-TE system

\begin{tabular}{|c|c|c|c|}
\hline Specifications & Value & Unit & Remarks \\
\hline Fuel type & coal gas & & $\begin{array}{r}\text { Composition H2:CO:CO2:N2= } \\
0.34: 0.61: 0.02: 0.03\end{array}$ \\
\hline Fuel pressure & 10 & Bar & \\
\hline Fuel mass flow rate & 0.0234 & $\mathrm{~kg} / \mathrm{s}$ & \\
\hline Fuel low heating value & 13070 & $\mathrm{~kJ} / \mathrm{kg}$ & \\
\hline Air compressor mass flow rate & 0.303 & $\mathrm{~kg} / \mathrm{s}$ & Efficiency: $77 \%$ \\
\hline System power output & 200 & $\mathrm{~kW}$ & \\
\hline Turbine compression ratio & 4.0 & & \\
\hline System efficiency & $65.3 \%$ & & \\
\hline Fuel heat input & 308 & $\mathrm{~kW}$ & \\
\hline Turbine efficiency & $90 \%$ & & Excluding air compressor power \\
\hline PCS conversion efficiency & $93 \%$ & & \\
\hline SOFC/GT/TE PCS connection type & & & Merge after DC/AC \\
\hline SOFC stack efficiency & $45 \%$ & & @ 25C air temperature \\
\hline SOFC power from stack & 146 & $\mathrm{~kW}$ & Not considering the fan power \\
\hline SOFC stack pressure & 400 & $\mathrm{kPa}$ & \\
\hline SOFC stack inlet temperature & 675 & $\mathrm{C}$ & \\
\hline SOFC stack outlet temperature & 725 & $\mathrm{C}$ & \\
\hline Turbocharger power & 54.9 & $\mathrm{~kW}$ & \\
\hline Thermoelectric net power & 4.56 & $\mathrm{~kW}$ & \\
\hline Thermoelectric efficiency & $8 \%$ & & \\
\hline ZT of thermoelectric & 2.5 & & \\
\hline Cathode blower working temperature & 750 & $\mathrm{C}$ & \\
\hline Cathode blower volume flowrate & 1318 & CFM & \\
\hline Cathode blower efficiency & $74 \%$ & & \\
\hline Anode blower working temperature & 750 & $\mathrm{C}$ & \\
\hline Anode blower volume flowrate & 290 & CFM & \\
\hline Anode blower efficiency & $74 \%$ & & \\
\hline Afterburner material & Alloy & & Ni-based alloy \\
\hline Afterburner mass flow rate & 0.327 & $\mathrm{~kg} / \mathrm{s}$ & \\
\hline Afterburner operation temperature & $<1200$ & $\mathrm{C}$ & \\
\hline Air preheater hot inlet temperature & $<900$ & $\mathrm{C}$ & \\
\hline Air preheater cold inlet temperature & $<400$ & $\mathrm{C}$ & \\
\hline Air preheater capacity & 78.6 & $\mathrm{~kW}$ & \\
\hline Air preheater material & SST & & \\
\hline TE air blower power & 772 & $\mathrm{~W}$ & \\
\hline TE air blower efficiency & $74 \%$ & & \\
\hline System startup time (0 full power) & 3 & hours & \\
\hline System shut-down time & 1 & hour & \\
\hline Minimum system load ratio & $15 \%$ & & \\
\hline System load transition rate $(15-100 \%)$ & $\% 1$ & $/ \min$ & \\
\hline Design operating time per year & 8000 & hours & \\
\hline System load transition time & 10 & $\min / 10 \%$ & \\
\hline System shut-down time & 1 & hour & \\
\hline
\end{tabular}

Table 6-2: Major design specifications for the 200kWe ambient pressure SOFC-TE system 


\begin{tabular}{|c|c|c|c|}
\hline Specifications & Value & Unit & Remarks \\
\hline Fuel type & coal gas & & $\begin{array}{r}\text { Composition H2:CO:CO2:N2 = } \\
0.34: 0.61: 0.02: 0.03\end{array}$ \\
\hline Fuel pressure & 10 & Bar & \\
\hline Fuel mass flow rate & 0.0309 & $\mathrm{~kg} / \mathrm{s}$ & \\
\hline Fuel low heating value (LHV) & 13076 & $\mathrm{~kJ} / \mathrm{kg}$ & \\
\hline Air compressor mass flow rate & 0.240 & $\mathrm{~kg} / \mathrm{s}$ & Efficiency: $77 \%$ \\
\hline System power output & 200 & $\mathrm{~kW}$ & \\
\hline System efficiency & $49.6 \%$ & & \\
\hline Fuel heat input & 403 & $\mathrm{~kW}$ & \\
\hline PCS conversion efficiency & $93 \%$ & & \\
\hline SOFC/GT/TE PCS connection type & & & Merge after DC/AC \\
\hline SOFC stack efficiency & $44.4 \%$ & & @ 25C air temperature \\
\hline SOFC power from stack & 178 & $\mathrm{~kW}$ & Not considering the fan power \\
\hline SOFC stack pressure & 101 & $\mathrm{kPa}$ & \\
\hline SOFC stack inlet temperature & 675 & $\mathrm{C}$ & \\
\hline SOFC stack outlet temperature & 725 & $\mathrm{C}$ & \\
\hline Thermoelectric power (high/low) & $5.6 / 18.9$ & $\mathrm{~kW}$ & \\
\hline Thermoelectric efficiency & $10.4 / 10.8 \%$ & & \\
\hline ZT of thermoelectric & 2.5 & & \\
\hline Cathode blower working temperature & 750 & $\mathrm{C}$ & \\
\hline Cathode blower volume flowrate & 7979 & CFM & \\
\hline Cathode blower efficiency & $74 \%$ & & \\
\hline Anode blower working temperature & 750 & $\mathrm{C}$ & \\
\hline Anode blower volume flowrate & 1433 & CFM & \\
\hline Anode blower efficiency & $74 \%$ & & \\
\hline Afterburner material & Alloy & & Ni-based alloy \\
\hline Afterburner mass flow rate & 0.327 & $\mathrm{~kg} / \mathrm{s}$ & \\
\hline Afterburner operation temperature & $<1200$ & $\mathrm{C}$ & \\
\hline High stage TE hot inlet/outlet temperature & $826 / 665$ & $\mathrm{C}$ & \\
\hline High stage TE cold inlet/outlet temperature & $23 / 218$ & $\mathrm{C}$ & \\
\hline Low stage TE hot inlet/outlet temperature & $665 / 85$ & $\mathrm{C}$ & \\
\hline Low stage TE cold inlet/outlet temperature & $23 / 62$ & $\mathrm{C}$ & \\
\hline TE air blower power & 938 & $\mathrm{~W}$ & \\
\hline TE air blower efficiency & $74 \%$ & & \\
\hline System startup time (0 full power) & 3 & hours & \\
\hline System shut-down time & 1 & hour & \\
\hline Minimum system load ratio & $15 \%$ & & \\
\hline System load transition rate $(15-100 \%)$ & $\% 1$ & $/ \min$ & \\
\hline Design operating time per year & 8000 & hours & \\
\hline System load transition time & 10 & $\min / 10 \%$ & \\
\hline System shut-down time & 1 & hour & \\
\hline
\end{tabular}

\subsubsection{Replacement schedule}

The life of a component varies. The life of subsystem or a component in the model is based on the typical equipment data collected and used in another modeling study at UTRC. Generally rotating 
equipment tends to have shorter life than the static or electrical components. The table below lists the life of major components and the replacement requirement.

Table 6-3: SOFC-TE component life and replacement schedule

\begin{tabular}{|c|c|c|c|c|c|c|c|c|c|c|c|c|c|c|c|c|c|c|c|}
\hline Component & Life & & & & & & & pl & $\mathrm{ac}$ & $\mathrm{em}$ & ent & Sc & he & $\mathrm{du}$ & & & & & \\
\hline & Years & 0 & 1 & 2 & 14 & 5 & 6 & 7 & 8 & 9 & $\begin{array}{ll}0 & 1 \\
\end{array}$ & 2 & 3 & 4 & 5 & 6 & $\begin{array}{l}7 \\
\end{array}$ & & 0 \\
\hline SOFC stack & \begin{tabular}{l|l}
5 & \\
\end{tabular} & & & & & & & & & & & & & & & & & & \\
\hline Cathode Blower & 2.5 & & & & & & & & & & & & & & & & & & \\
\hline Anode Blower & 2.5 & & & & & & & & & & & & & & & & & & \\
\hline Turbine & 5 & & & & & & & & & & & & & & & & & & \\
\hline Air compressor & 3 & & & & & & & & & & & & & & & & & & \\
\hline Pressure vessel & 3 & & & & & & & & & & & & & & & & & & \\
\hline Air preheater & 5 & & & & & & & & & & & & & & & & & & \\
\hline PCS & 5 & & & & & & & & & & & & & & & & & & \\
\hline $\mathrm{BOP}$ & 10 & & & & & & & & & & & & & & & & & & \\
\hline Control & 10 & & & & & & & & & & & & & & & & & & \\
\hline Insulation & 10 & & & & & & & & & & & & & & & & & & \\
\hline TE blower & 5 & & & & & & & & & & & & & & & & & & \\
\hline TE & 20 & & & & & & & & & & & & & & & & & & \\
\hline
\end{tabular}

Table 6-3 suggests that the desired system life expectancy should be 10 years or 15 years since a majority of the components or subsystems need to be replaced during those years.

\subsection{System Cost Specifications}

Based on the modeling analysis, the factory manufacturing cost specifications of the best system configurations are outlined, as shown in

Table 6-4. The cost considers the market size or production volume effect and is assumed to be in the year of 2011, corresponding to the SECA program timeline.

The SOFC stack and the PCS cost is approximately one third of the system cost each. The ambient pressure system has higher cost/kW than the pressurized system because a larger stack is needed in an ambient pressure system.

Table 6-4: SOFC-TE cost specifications 


\begin{tabular}{|c|c|c|c|c|}
\hline \multirow[b]{2}{*}{ Equipment cost } & \multicolumn{2}{|c|}{ Pressurized System } & \multicolumn{2}{|c|}{ Ambient Pressure SOFC-TE } \\
\hline & Total $(\$)$ & Unit $(\$ / k W e)$ & Total $(\$)$ & Unit $(\$ / k W e)$ \\
\hline Stack & 26674 & 133 & 39441 & 197 \\
\hline Burner & 162 & 1 & 146 & 1 \\
\hline Air preheater & 1844 & 9 & 0 & 0 \\
\hline Anode blower & 521 & 3 & 1600 & 8 \\
\hline Cathode blower & 1508 & 8 & 5351 & 27 \\
\hline Gas Preheater & 78 & 0 & 78 & 0 \\
\hline Air Compressor & 2551 & 13 & 2976 & 15 \\
\hline Turbine & 9523 & 48 & 0 & 0 \\
\hline PCS & 26188 & 131 & 26188 & 131 \\
\hline Insulation & 1493 & 7 & 1963 & 10 \\
\hline Balance of plant & 2349 & 12 & 3090 & 15 \\
\hline Pressure vessel & 2290 & 11 & 0 & 0 \\
\hline SOFC subtotal & 75181 & 376 & 80833 & 404 \\
\hline TE Air Blower & 850 & 4 & 2976 & 15 \\
\hline TE generator & 2203 & 11 & 5222 & 26 \\
\hline Total system equipment & 78234 & 391 & 89031 & 445 \\
\hline
\end{tabular}

\subsection{Summary}

Based on the system modeling analysis, the system specifications and major design requirements were created for the optimized pressurized and ambient SOFC-TE integrated systems. The working principles of the two systems are outlined. The major system performance specifications were listed such as the system efficiency, size and the replacement schedule. The cost of major components is a function of the size and volume, based on the typical industrial data collected. 


\section{$7 \quad$ Evaluate Barriers and Enablers}

This chapter outlines the technology and cost barriers and enablers for the deployment of SOFC-TE hybrid systems. They are put into four categories: SOFC, TE, PCS and System integration. In each category, both the technology and the cost challenges are discussed.

\subsection{SOFC}

The best system configuration identified in Chapter 5 includes a pressurized SOFC stack with a gas turbine (GT). The SOFC/GT assembly provides $63.5 \%$ efficiency out of a total of $65 \%$ system efficiency based on coal gas fuel. The SOFC/GT is estimated to deliver more than $75 \%$ efficiency with natural gas fuel. To bridge the gap, both the stack and the balance of the SOFC plant, including the turbine, the blowers and other generic components, need to be improved.

\subsubsection{SOFC stack}

The stack is the center piece of the SOFC-TE hybrid system. Improvements on the stack for the goal in this project should address three issues:

1) Using coal gas as the fuel. While SOFC stacks were developed for coal gas since 1950s' [16], stacks using coal gas are still not widely used today. Coal gas, typically with a lower heating value than natural gas, leads to lower power efficiency. The key factors in improving the SOFC stack efficiency are reduction in cathode polarization losses and ohmic resistances. Reduction in the cathode polarization losses will require the discovery and development of higher activity cathode electrodes through composition and microstructure. Reduction of ohmic losses requires primarily the reduction of interface resistances as well as the reduction of the ohmic resistance of the protective scale that forms on metallic interconnects, either through the development of more oxidation resistant alloys or through the development of protective scale compositions having higher electronic conductivity than chromia or through reduction in operating temperatures and, therefore, thinner oxidation scales. Furthermore, with chromiaprotected alloys for the bipolar plate chromia volatilization needs to be contained to mitigate cell poisoning and reduction in cell stack performance.

2) Sulfur poisoning. Sulfur in the coal gas poses a threat to the stack life and performance. In this study, it is assumed that the coal gas has been desulfurized before entering the stack. In reality, some level of sulfur is most likely to be present. The sulfur content is suggested to be less than $0.1 \mathrm{ppm}$ [24] to avoid the poisoning and coating. A stack with better sulfur-resistance is preferred. Recent effort includes the assessment and characterization of sulfur poisoning of SOFCs focusing on the evaluation of long-term performance stability relative to the low hydrogen sulfide concentrations expected in fuels of the future [21].

3) Pressurization. Although pressurization helps on the stack efficiency only marginally [23], it can produce more power through the gas turbine. SOFC stack pressurization will require the development of more durable and reliable seal designs and materials for planar SOFC . Stack pressurization also requires a pressure vessel which complications for piping into and out of the vessel. 
The cost of the SOFC stack remains a barrier. SOFC produces majority of the power generation in the SOFC-TE system, approximately $70 \%$ in the optimized pressurized system and $90 \%$ in the optimized ambient pressure system. The cost of the stack needs to be approximately $\$ 140 / \mathrm{kW}$ to meet the $\$ 400 / \mathrm{kW}$ system cost target. Today's SOFC stack manufacturing cost is projected to be as low as $\$ 500 / \mathrm{kW}$ for a $5 \mathrm{~kW}$ SOFC stack [11] and, hence, substantial cost reduction is needed.

\subsubsection{Rotating machinery}

Rotating machineries in the pressurized SOFC-TE system include the turbine, the air compressor, anode recycle blower, cathode recycle blower and the TE cold air blower. The TE cold air blower can be a generic off-the-shelf air blower that generates small pressure head, i.e., of the order of a few hundred Pascal. The rest of the rotating machinery are specific to the pressurized SOFC systems and are not commercially available today.

The major technology gap lies in the anode and cathode recycle blowers, which re-circulate the exhaust to the anode and cathode inlet, respectively. The exhaust temperature range is $700-1000^{\circ} \mathrm{C}$. Some materials such as Ni-based superalloys can withstand such temperature, stainless steels become marginal even for static, i.e., walls, parts. There are industrial blowers that work at such temperature [22]. However, it is difficult to find generic blowers for the SOFC recycle.

Customization has to be made and reliability needs to be considered. An additional issue for the anode blower is that the recycle blowers work at small volume flow rates (290 CFM for the anode blower and 1300 CFM for the cathode blower in a 200kW of hybrid SOFC-TE system). These blowers may need some level of customization and lead to higher equipment cost, as well as system complexity and maintenance load. An alternative approach for exhaust recycle is to use ejectors in place of recycle blowers, which has been used in many hydrogen-driven fuel cells [23]. The advantage of the ejector is that it is simple and no moving parts. However, the level of recycle flow ratio is limited and fixed and cannot be adjusted for off-design operating conditions. Therefore, the ejector may not be ideal if the system needs to be operated often at off-design conditions. This trade-off should be evaluated in subsequent detailed design stages. If a bank of SOFC stacks is used in a power plant, we can use one anode recycle blower to serve multiple stacks. This should lead to lower anode blower cost and is likely to increase the blower efficiency.

The turbine and the air compressor are usually mounted on the same shaft, and are available today for 300kW SOFC/GT system [23]. The turbo-compressor assembly tends to have lower efficiency and higher cost at small size as today. For utility power plant applications, the turbo assembly tends to be larger than today's size.

\subsubsection{Generic components}

Generic components in the SOFC denote air preheater or heat exchanger, gas valve, pressure vessel, insulation and fuel supply pipe, etc. Most of these components are commercially available today and do not constitute major technical barriers. A possible problem is the carbon formation on the fuel supply line because the coal gas with $\mathrm{H}_{2}, \mathrm{O}_{2}$ and $\mathrm{CO}$ is unstable. The issue will be more pronounced if the fuel supply line is long. However, copper piping and ceramic coatings on other alloys can resolve the carbon deposition issue. Another potential issue is that the air preheater is 
subject to the inlet hot gas at $700-1000^{\circ} \mathrm{C}$ and requires Ni-based alloys for long lifetimes, which may require some consideration of expansion and reliability. In general, the heat exchangers for high temperature are available in applications such as in a furnace, thus do not pose special difficulties.

\subsubsection{Cost challenges}

The goal for the SOFC-TE system is to achieve $\$ 400 / \mathrm{kWe}$, where the SOFC stack produces the majority of the power generation in the SOFC-TE system, approximately $70 \%$ in the optimized pressurized system and $90 \%$ in the optimized ambient pressure system. The SOFC and GT together produce more than $95 \%$ of the power in the optimal pressurized SOFC-TE system. GE's SOFC/GT today is approaching the manufacturing cost of $\$ 800 / \mathrm{kWe}$ [20]. There is still a significant cost gap to reach the targeted $\$ 400 / \mathrm{kWe}$.

At $5 \mathrm{~kW}$ scale, the ambient pressure SOFC stack is projected to be as low as $\$ 500 / \mathrm{kW}$ today [11]. Based on the modeling, the stack cost needs to be approximately $\$ 140 / \mathrm{kW}$. The cost reduction of $70 \%$ is needed to reach the cost target. Several factors may contribute to the cost reduction. First, material and fabrication technology is likely to be more mature in the future, leading to lower material cost. Second, in the power plant application, there is a potential to go to larger unit size. Larger units do not necessarily mean low overall cost for the devices like 400kW stack, which is composed of repeating SOFC cells, unless larger footprint cells and low cost materials and fabrication processes are used for the bipolar plates. However, a $100 \mathrm{~kW}$ turbine assembly is likely to be less expansive than $2 \times 50 \mathrm{~kW}$ units due to the reduced number of total units and the resulting less assembly time. Third, application of SOFC in other areas such as portable, auxiliary power unit (APU) or commercial applications may increase the total SOFC volume, thus driving the cost down.

The generic components like valves are not likely to drive the cost down. The cost for the SOFCTE system-specific components, such as the turbine-compressor and the high temperature heat exchanger, may go down with the volume increase of the installed systems.

\subsection{Thermoelectric Generator}

The potential of using thermoelectrics to generate power usefully has increased significantly in recent years. Advancements in new higher temperature materials with figure of merit (ZT) substantially greater than unity are under development at places such as Michigan State University [26] and Lincoln Laboratory at Massachusetts Institute of Technology (MIT) [27]. In addition, Jet Propulsion Laboratory (JPL) has had considerable success in developing material segmentation concepts [28]. Meanwhile, BSST has demonstrated the benefits of thermal isolation in the direction of flow $[29,30]$ that can improve coefficient of performance (COP) in heating and cooling, as well as high power density designs that require about $1 / 6^{\text {th }}$ the thermoelectric (TE) material usage of conventional TE-based power generator designs [31].

The thermoelectric generator design incorporates state-of-the-art material technology with proprietary BSST heat transfer innovations in combination with the thermal isolation thermodynamic cycle and high power density concepts previously described $[31,32]$. The device is 
constructed of a series of segmented elements comprised of up to three different materials. Figure 7-1 shows the choice TE materials available for use in devices today. Generally one chooses both $\mathrm{p}$ and n-type material systems with the best ZT for each temperature range. By segmenting the TE material, elements can be constructed to better achieve the highest average ZT over each particular temperature range. An example of a TE couple made of segmented elements is shown in Figure $7-2$.
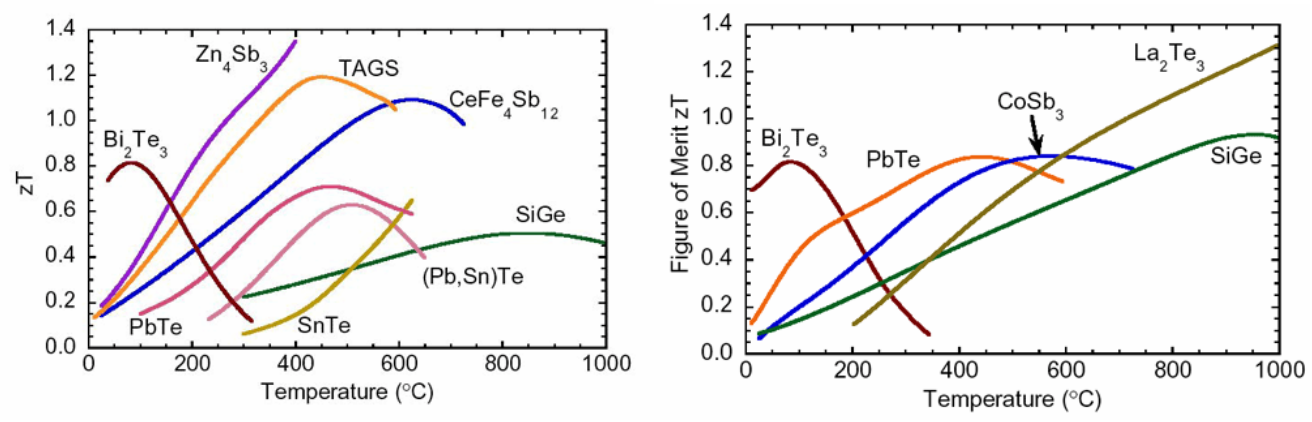

Figure 7-1: Figure of merit (ZT) for current TE material (p-type and n-type) [33]

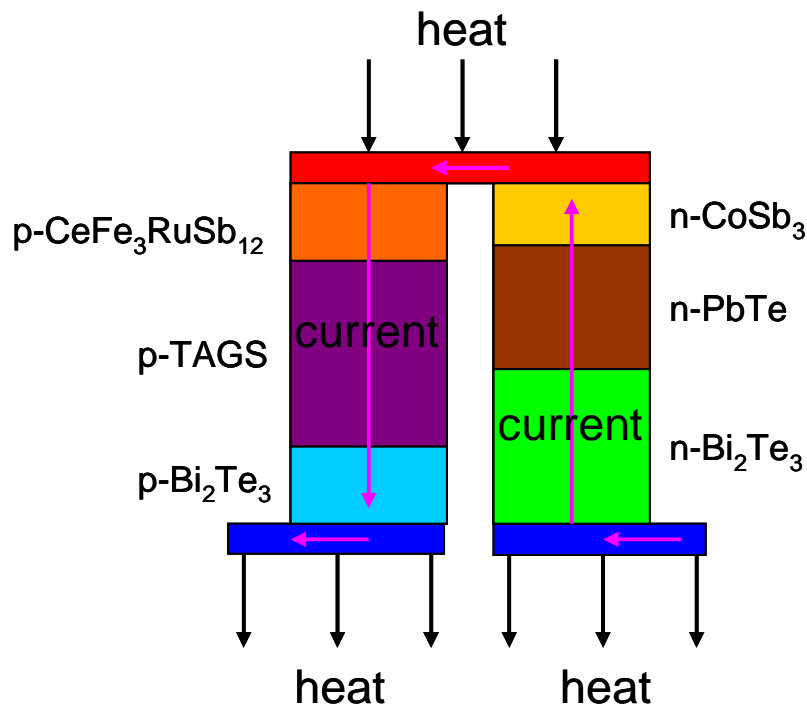

Figure 7-2: Traditional TE couple configuration using segmented elements

The material with the highest ZT at low temperatures $(<150 \mathrm{C})$ is $\mathrm{Bi}_{2} \mathrm{Te}_{3}$ for both p- and n-type elements. For intermediate temperatures $(150-500 \mathrm{C})$, TAGS $\left[\left(\mathrm{AgSbTe}_{2}\right)_{1-\mathrm{x}}(\mathrm{GeTe})_{\mathrm{x}}\right]$ is the optimal p-type material. Figure 7-1 shows that $\mathrm{Zn}_{4} \mathrm{Sb}_{3}$ is another option for approximately the same temperature range. TAGS was chosen by BSST since it has a longer history of use. PbTe has the highest ZT for this same temperature range in n-type material. Skutterudite (p-type $\mathrm{CeFe}_{4} \mathrm{Sb}_{12}$ and n-type $\left.\mathrm{CoSb}_{3}\right)$ has the highest ZT for the higher temperature ranges $(500-700 \mathrm{C})$. These six materials are our choice materials for the TPG design. 
In addition to selecting materials with the highest possible ZT, TE material compatibility must be taken into account. Typical segmented element performance can be reduced by the effects of TE compatibility mismatch, as described in detail by Snyder [34]. Figure 7-3 shows compatibility factors for both p- and n-type materials. Snyder's paper discusses the impact of compatibility mismatch on optimum power output when efficiency for different element segments occurs at significantly different current densities. Compatibility mismatch starts to play a role when the compatibility factor of different materials varies by more than a factor of two. Since thermoelectric power curves are parabolic with increasing current, with severe incompatibility some segments actually provide negative power outputs at an optimal current for other segments. To combat this effect, each material segment often has a different aspect ratio (cross-sectional area divided by thickness). Usually this is done by maintaining uniform cross-sectional area and varying the thickness of each layer to better match the current for optimal power output. However, this can also be accomplished by constructing a segmented element with non-uniform cross-sectional area. Similar concepts were described in some of BSST's patents $[35,36]$.
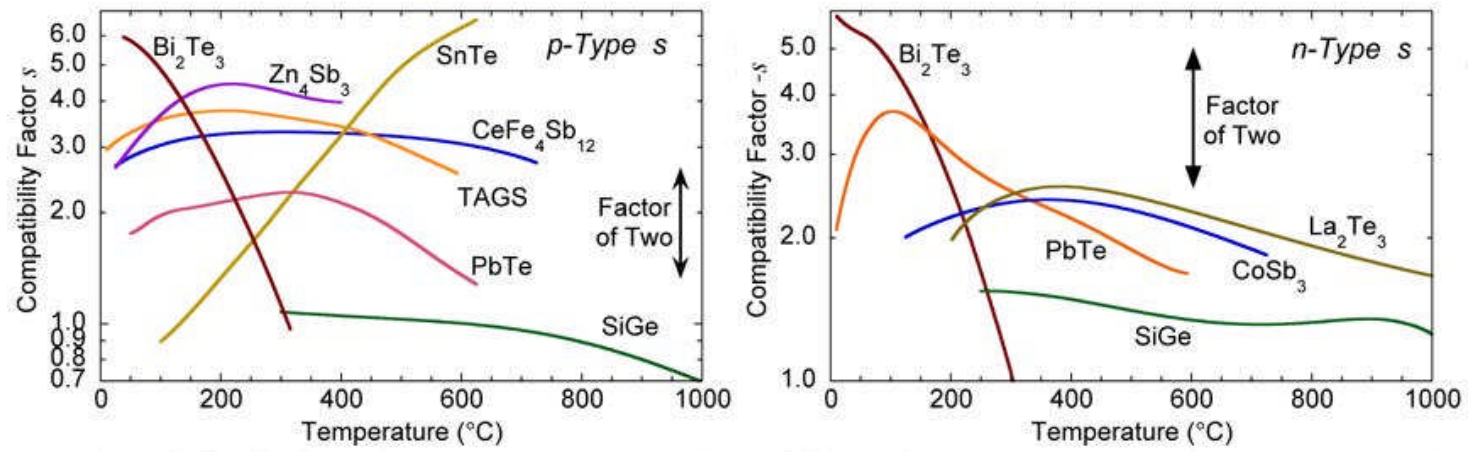

Figure 7-3: Compatibility factor for current p- and n-type materials [33]

Segmented thermoelectric pellets have been fabricated in limited quantity for BSST by Marlow Industries in support of other projects. They were not used for construction yet due to limited availability, however limited electrical testing of the pellets was performed. Figure 7-4 shows photographs of both $\mathrm{p}$ - and n-type pellets consisting of three segments each. The p-type pellets were built from skutterudite, TAGS and $\mathrm{Bi}_{2} \mathrm{Te}_{3}$ (counting from hot to cold side). The n-type pellets had $\mathrm{PbTe}$ instead of TAGS. The relative thickness of the segments was optimized based on simulations taking into account the properties of individual thermoelectric materials. 


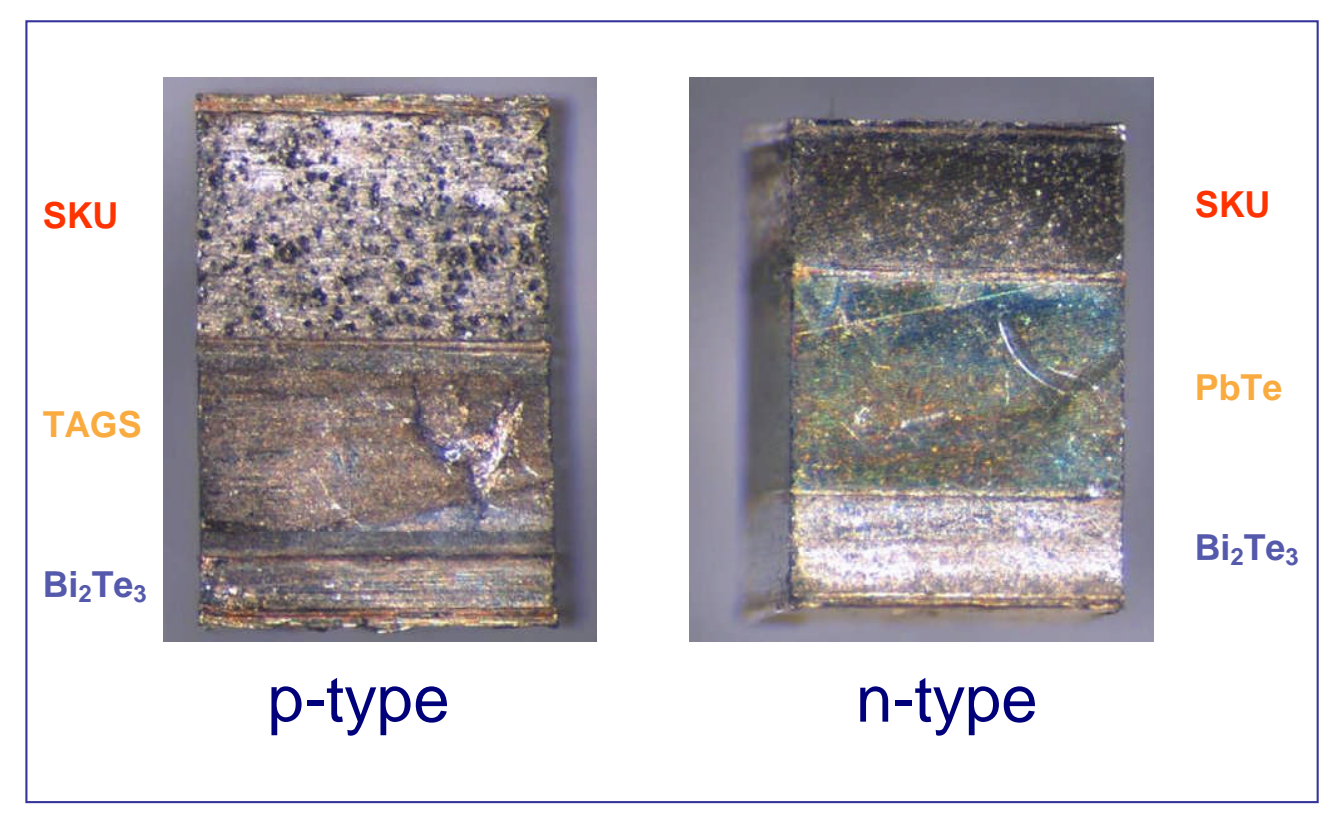

Figure 7-4: Photographs of the initial segmented pellets

Using segmented elements of this design in a high temperature generator would result in a significant performance improvement over homogenous thermoelectric elements.

\subsection{Power Conditioning System (PCS)}

The PCS requires a low-cost high efficient DC-to-AC power electronic converter. The simplest PCS would consist of a single-stage DC-to-AC converter, cooling, controls, protection, communication interface, grid interconnection switchgear, surge arrestors and required wiring. The single-stage design requires a high output voltage, providing a sufficiently high DC voltage to eliminate the otherwise required DC-to-DC booster conversion stage. The final trade-off between voltage levels and converter topologies, suitable for different power ratings is an issue for further study.

\subsubsection{PCS technology challenges}

Achieving low-cost with the chosen design has to focus on achieving a system where the PCS and the Power Plant (PP) controller share microprocessor resources, sensing devices as well as communication devices and interfaces. Combining processor and communication functions on a single board will reduce the number of components and associated costs. IGBT (Insulated Gate Bipolar Transistor) integrated power modules with gate drives and protections circuits are available in the power range between 5 and $50 \mathrm{~kW}$, and will be specified if they are the most cost effective solutions found from design studies. Cost reduction in the integrated system can be achieved by using custom power modules that include all power conditioner and PP controller circuit functions and optimal power semiconductor sizing.

Design considerations for hybrid-source power systems such as the SOFC-TE system include controller for optimal utilization of primary sources, simplifications of power circuits (low cost, high reliability), voltage ratios, isolation requirements, energy storage requirements, inverter DC 
bus requirements and cost targets. The final design can be cost effective if based on mass produced parts, e.g., from the automotive industry. PCS costs are strongly influenced by fixed overhead of the drive control processors and IGBT gate drives and power suppliers. Grid-connection of SOFC-TE systems requires protection circuits including sensing and control and imposes additional cost challenges. Integration of the grid interconnection functionality into the combined PCS/PP controller will further reduce component cost and work towards achieving a low-cost solution.

The electrical integration of the power generation from the SOFC and TE could be done in a number of topologies. The simplest is probably to use individual DC-to-DC and DC-to-AC converters and connect outputs to a common AC bus. A novel interleaved multiphase isolated soft switching DC-to-DC converter has been developed for low-voltage input and high-voltage output, which can be connected to a DC-to-AC converter. Alternative approaches include topologies with a common DC link for the SOFC and TE. A disadvantage with such DC distribution configuration is that Output DC voltage variations can result in circulating currents. Modular multilevel in inverter configurations and high frequency link direct DC-to-AC converters could also be studied.

In practice, the technical specifications for the PCS and PPM subsystems will be submitted to a prescreened list of vendors that have a proven capability of developing and manufacturing PCS. The final selection will be based on price as well as the vendor's strength in power section design and high volume manufacturing capability. The design study has to provide a specification for a costeffective fuel cell converter, which operates under a wide input voltage range and output load swings with high efficiency and improved reliability.

\subsubsection{PCS cost challenges}

Figure 7-5 below shows the PCS specific cost for PV systems decreases as the production quantity increases. The PCS cost for the SOFC-TE system is approximately $\$ 130 / \mathrm{kWe}$ based on the modeling. Even though the PCS units for SOFC-TE in large power plant is likely to have lower cost than the PCS cost of 1-10 kW solar PV, approaching the $\$ 130 / \mathrm{kW}$ PCS cost target is still a challenge.

One way to reduce the PCS cost is to adopt a DC bus in the power plant, as discussed in Section 2.2. Both the SOFC and the TE generate DC power, which can be sent to the DC bus without going through the DC/AC inverter. Not only the cost will be reduced, the efficiency of the PCS will also be increased. Such DC bus has not been used practically today and development is needed. The DC power supply system in the plant needs to have an AC to DC backup system, thus may partially counteract the PCS cost reduction. 


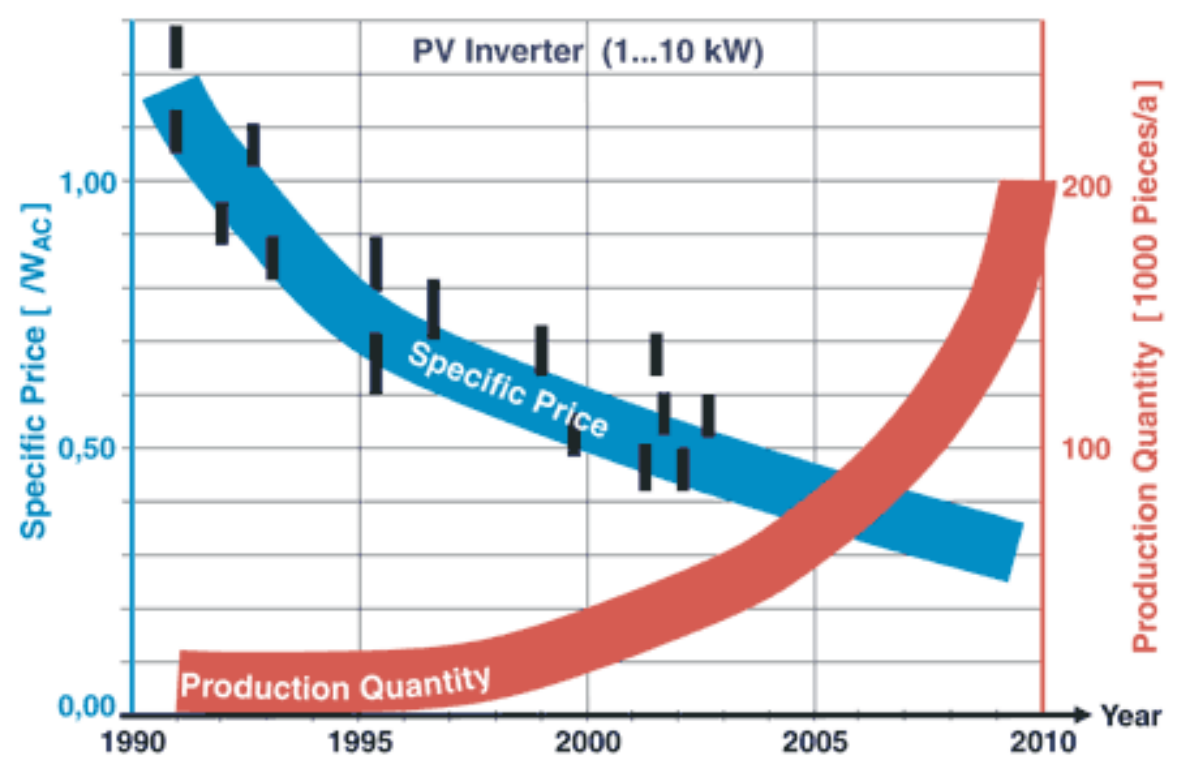

Figure 7-5: Development and prognoses of specific cost and production quantity for the PV inverter of nominal powers between 1 and $10 \mathrm{~kW}$ [37]

\subsection{System Integration and Control}

The successful operation of the hybrid SOFC-TE system requires the coordination of different subsystems, namely SOFC, turbine, TE and PCS. The integration and control are to serve three purposes: 1) to obtain the optimal system performance; 2) to increase the system reliability; and 3) to reduce the lifetime cost. The integration and control denote first the hardware installations. More broadly, they include the integration scheme or control algorithms.

In the system performance, SOFC stack is at the central position because it is at the upstream of the turbine and the TE and the stack has the greatest contribution in the system power generation. Model predictive control (MPC) has been widely used for the SOFC optimal performance [38]. Although a pressurized SOFC/Gas turbine prototype has been built [23], detailed information on the part-load optimal performance, is not available for, e.g., the optimal pressure ratio, air inlet and outlet temperature, exhaust recycle ratio, if present, at $70 \%$ of the load. The optimal performance analysis needs the iteration between modeling and validation through data collection in testing.

The system reliability can be increased through better integration and control. In the SOFC, turbine and the TE, the high temperature at different locations causes thermal expansion, which, if fast enough, could lead to fluid leakage, low performance or system failure. On the other hand, fast transient response is good for power management and application. The on-off cycle for the SOFCTE system is likely to have an impact on the SOFC and TE subsystem life. At the low demand time, whether it is better to turn off the system or run the system at low power still needs to be decided. As a matter of fact, this is not only a reliability issue, but also an integrated system performance and life cost issue. 
Finally, the optimal integration and control can be boiled down to the minimum lifetime cost. Better performance will reduce the fuel consumption, a major operation cost. Higher system reliability leads to low maintenance cost and possibly low replacement cost. From the design point of view, integration of certain parts, such as the inverters and controllers in the PCS for the SOFC and TE, leads to lower equipment cost. Another possibility is to feed a large turbine with the exhaust from multiple fuel cell stacks. A larger turbine tends to be more efficient and less costly than a group of small turbines. However, the stacks feeding the same turbine now have to coordinate in terms of power load and pressure. Proper system control has to be in place for this type of grouped connection.

Overall, the performance, reliability and cost issues are inter-related, and could only be addressed after sufficient data are collected.

\subsection{Summary}

The cost and performance barriers/enablers for the SOFC, TE, PCS and the system integration and control are discussed. The performance barriers are summarized below:

SOFC stack: $\quad$ using coal gas as the fuel, sulfur poisoning and pressurization

Rotating machinery: Blowers for anode and cathode recycle

Generic components: Carbon deposit on fuel supply line

TE: $\quad$ Material performance and heat transfer design

PCS: $\quad$ PCS and power plant controller combination, power plant DC bus

Integration and control: Optimal integration and control scheme considering performance, cost and reliability

The cost barriers are related to all the components. The cost of SOFC stack, PCS and the rest of the system each is about the one third of the system cost. Reduction of the cost is likely to be achieved through volume, combination of certain components and novel design such as power plant DC bus. 


\section{$8 \quad$ Phase II Planning}

After identifying the optimum configuration for the hybrid SOFC-TE system in Phase I, the Phase II work is intended to move onto technology maturation and risk reduction for the SOFC-TE system. This chapter presents the roadmap for the technology maturation, the rationale behind the approach and the work planned in Phase II.

\subsection{Roadmap for Technology Maturation}

While the best concept was identified to be a pressurized SOFC-TE system, several intermediate steps should be necessary for the technology maturation. A staged technology development approach is proposed, as shown in Figure 8-1. The ultimate goal is to deliver the SOFC-TE technology for coal based central power plants at multi-megawatt scale. From today's feasibility demonstration to the final application, the intermediate steps are proposed as:

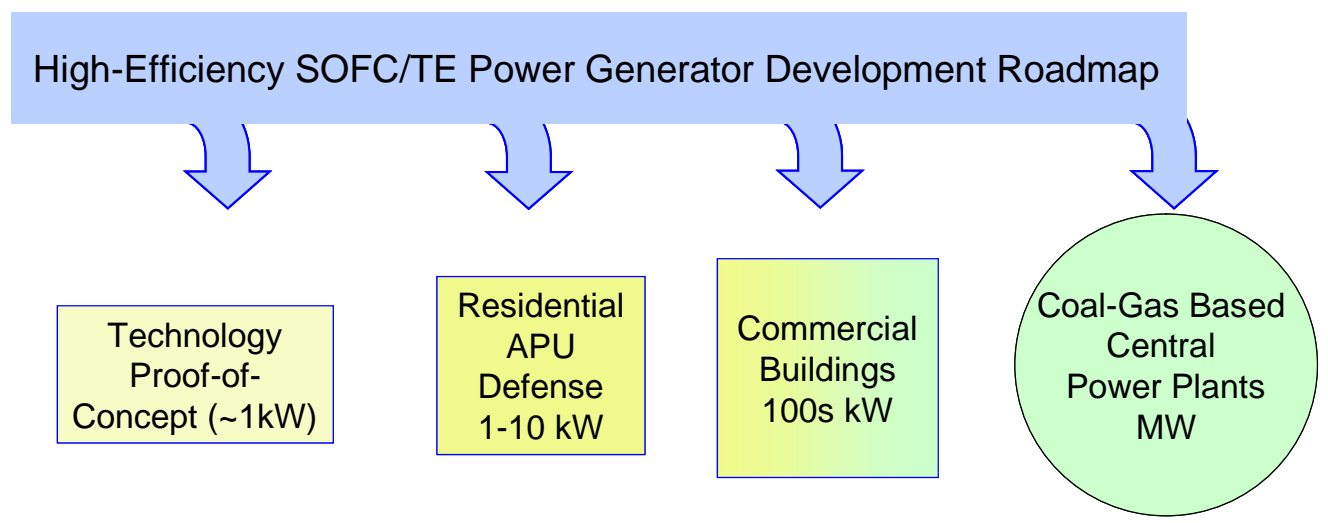

Figure 8-1: A staged development approach proposed for the SOFC-TE technology

Step 1: A proof-of-concept (POC) unit in the order of $1 \mathrm{~kW}$. The POC unit helps to screen and understand the potential technical risks regarding system thermal, chemical and electrical performance and controllability. These characteristics are common for all the aforementioned stages of development and are different from traditional power plants. The POC stage can serve as a valuable step in assessing the SOFC-TE system feasibility and in collecting decision-making information for further development stage work.

Step 2: Small capacity application in the order of 1-10 kW. This is the first commercial application of the SOFC-TE system. The SOFC-TE system at this scale can be used in residential, auxiliary power units and defense applications. At this stage, the reliability requirements should be considered but the efficiency requirement will be less stringent than the future larger applications. Step 3: Medium capacity applications in the order of $100 \mathrm{~kW}$. These applications can be commercial buildings or remote power generation units. In addition to the system durability and 
reliability, the economic value of the system has increased importance, which is related to the initial cost and the operational cost. For remote applications, low requirement on maintenance is also an important consideration. It is expected that the system reaches a sizeable volume to justify the development cost, and the SOFC cost has reduced to a level such that it can compete, at least with a smaller price gap, with other power generation technologies, such as reciprocating engines.

Step 4: Large capacity applications in the order of multi-MW. Such applications are mainly for utility power plant, either for steady power generation or for grid peak-shaving. The system efficiency is a major consideration for a power plant in choosing the technology. For peak-shaving application, the system dynamic response, e.g., how fast the system could provide the required power level when needed, is another major consideration. Note that it is desirable to use ambientpressure stacks for the first three steps because the integrated SOFC-Gas turbine is complex

The overall risk of the technology development can be reduced by building on preceding stage successes and simultaneously implementing early implementation, in other words, building and profiting from success while traveling the path to system capacities suitable for central power plants.

Another advantage of the aforementioned staged approach is that, the applications in the smaller units such as defense and commercial buildings help to boost the overall SOFC demand or sales volume. The current high cost of the SOFC stack will be reduced with the sales volume (cf: a cost reduction of about $20 \%$ per each doubling of production volume is typical in most processes) and will benefit the utility power plant application as well.

\subsection{Phase II Work Proposed}

Based on the Phase I contract, the Phase II work is to be mainly the analyses of the technologies, issues or solutions to be matured, including the underlying the technical risks and the likelihood of building a proof-of-concept unit.

In contrast to the above, we plan to go beyond the Phase I contract anticipation and to propose designing, building and testing a proof-of-concept (POC) unit in Phase II. This expanded effort will advance the understanding of system performance, integration, and provide the opportunity for unknown unknowns to emerge. UTRC and BSST can leverage several on-going projects funded by DOE or other agencies, such as the development of a "Power Dense SOFC System", which is funded by the Air Force Research Lab (AFRL).

Three possible POC configurations, all ambient-pressure systems, were considered, as shown in Table 8-1. The simple diagram, description, cost, integration complexity and the value are estimated for each option. In the first option, Option 1, the exhaust from the stack goes through a heat exchanger and then is sent to the TE. The SOFC and the TE are relatively independent. This system is simple, less costly and has moderate value, where the value is related to the information that the POC unit can provide. In the second option, Option 2, the TE is integrated into the SOFC by replacing the heat exchanger. Such integration imparts a higher level of complexity and is likely 
to be more expensive than the Option 1 system. However, the value of the system is not higher than the system in the first option, because as a POC unit, they offer similar insights in terms of technology maturation and risk reduction. The system in the third option, Option 3, combines the two TEs in the previous two options. It has higher value than the first two options considering that this configuration is the SOFC-TE integration scheme of the optimized ambient-pressure system, based on Chapter 5. However, the cost and the complexity of Option 3 are also higher. In a previous review, DOE showed the interest in the third option. However, the potentially available funds for Phase II development are deemed insufficient for building and testing an Option 3 system and, therefore, the Option 1 system will be proposed in the Phase II proposal.

Table 8-1: Configuration options for the Phase II proof-of-concept unit

\begin{tabular}{|c|c|c|c|c|}
\hline Options & Description & Cost & $\begin{array}{l}\text { Integration } \\
\text { Complexity }\end{array}$ & Value \\
\hline Option 1 & $\begin{array}{c}\text { SOFC is } \\
\text { independent of TE }\end{array}$ & * & * & * \\
\hline $\begin{array}{c}\text { Option } 2 \\
\qquad \rightarrow \text { stack }\end{array}$ & $\begin{array}{l}\text { TE integrated into } \\
\text { SOFC, affecting } \\
\text { SOFC performance }\end{array}$ & $* *$ & $* *$ & * \\
\hline Option 3 & Two TEs & $\star \star * *$ & $\star * *$ & $\star *$ \\
\hline
\end{tabular}

\subsection{Summary}

A staged roadmap is proposed to mature the SOFC-TE hybrid power generation system from today's feasibility analysis to the ultimate coal power plant applications. Using a staged process helps to reduce the overall development risk. It will promote the application of the system in other areas and the increased overall volume can lower the stack cost across different application, hence helpful for the power plant applications as well.

The first stage in the roadmap is the design, construction and testing of a proof-of-concept unit. The Option 1 among the three configuration options is being proposed, which uses an ambient pressure stack with a TE at the downstream. This proof-of-concept unit helps understand the hybrid system performance and risk reduction at the early stage of the SOFC-TE technology maturation process. 


\section{$9 \quad$ Summary and Conclusions}

In the context of growing concern over increasing energy consumption and pressure to mitigate environmental impact, the feasibility of hybrid SOFC-TE power generation systems has been assessed. The major conclusions are:

1. Power generation technologies with high efficiency and low environment impact are needed in the future to meet the increasing demand for electricity and more stringent emission requirement.

2. SOFC using coal gas as the fuel can serve as a valuable component to major power generation plants such as steam power system. SOFC can provide higher efficiency with coal gas that is usually available onsite. SOFC technology is clean without NOx or SOx generation. Thermoelectric (TE) power generation is a good addition to the SOFC technology, either through using the SOFC exhaust heat, or through integration with the existing SOFC heat recovery devices. TE is clean as a heat recovery unit. It has almost no moving part except the cold air blower or cold water pump, thus has low requirement for maintenance than other heat recovery power generation technology such as organic Rankine cycle (ORC) machines. The SOFC-TE hybrid system has the potential to be used in distributed generation as well as in utility power plants, for base loading and/or peakshaving modes.

3. A rich set of concepts has been generated for the SOFC-TE integration covering from systems integration to component design and improvement, from chemical/thermal issues to PCS. These concepts provided a framework for comparing and quantifying different systems through modeling analysis.

4. TE-material technologies in the marketplace and under development were benchmarked. The TE materials were classified into Low Temperature, Medium Temperature and High Temperature ranges. In particular, cost, performance, durability, manufacturing process, technology readiness level, time to market and ease of mass production have been considered.

5. System performance and cost modeling tool was built to evaluate the SOFC-TE concepts. The tool was based on UTRC's proprietary SOFC modeling library and BSST's TE model. Publicly available cost data and the proprietary performance data show that the model is valid.

6. Sensitivity analysis showed that rotating machine efficiency, air preheater effectiveness, PCS efficiency and cell voltage are among the key factors that affect the system performance most.

7. The best system configuration to meet the project target is a pressurized SOFC-TE system with one TE generator downstream of the SOFC air preheater. The optimal pressure ratio is around 4 and the system efficiency is $65.3 \%$ with TE having a figure of merit (ZT) of 2.5 . 
The system cost is $\$ 390 / \mathrm{kWe}$. To assist the technology development, an optimal ambientpressure SOFC with two TE generators was identified as the best system configuration. The system efficiency is $51 \%$ with ZT of the TE at 2.5 .

8. Major technology barriers for maturing the SOFC-TE system were identified. For the SOFC stack operating on coal gas to get to higher efficiency new, high-activity cathode materials and lower ohmic losses at interfaces will be needed. Elimination of sulfur and chromia poisoning and mitigation of carbon deposition will require further development, while stack pressurization will require improved seal designs and materials. The blowers for anode and cathode recycle are yet to be developed, which need to stand the high temperature from 700$1000{ }^{\circ} \mathrm{C}$. For the TE, the major challenges are material performance and heat transfer design. As a new hybrid system in which both the two subsystems produce DC power at different amount and voltage, the power conditioning systems (PCS) may require a novel design to achieve high efficiency and low cost. Similar is the system integration and control, which needs an optimal considering performance, cost and reliability.

9. The cost barriers are related to all the components. The cost of SOFC stack, PCS and the rest of the system each is about the one third of the system cost. Reduction of the cost is likely to be achieved through volume, combination of certain components, e.g., the inverter and the power plant controller in the PCS, and the novel design such as power plant DC bus.

10. For the technology and cost barriers, since an SOFC-TE hybrid system has never been built, data from proof-of-concept demonstration and pilot-scale test would be valuable. A staged process is proposed to mature the technology into one that can be used ultimately in the coal based power plants. A proof-of-concept unit is recommended for Phase II, which will be helpful in identifying the technical risks, such as system dynamic response during load change, and understanding the system performance. 


\section{List of Figures}

Figure 1-1: Diagram of a notional hybrid SOFC-TE system ...................................................5

Figure 2-1: Summary of concepts generated during the Concept Generation Sessions .....................9

Figure 2-2: A pressurized SOFC-TE system with two TE generators ...........................................10

Figure 2-3: Concept of TE integrated into SOFC stacks .......................................................... 11

Figure 2-4: SOFC-TE power in parallel, merged after DC/AC conversion ....................................13

Figure 2-5: SOFC-TE power in parallel, merged before DC/AC conversion................................. 13

Figure 2-6: SOFC-TE power in series connection .................................................................... 14

Figure 2-7: SOFC-TE power in parallel connection....................................................................... 14

Figure 4-1: Major equations and variables used in the turbine model .........................................24

Figure 5-1: Diagram of a simple ambient pressure SOFC-TE hybrid system .............................27

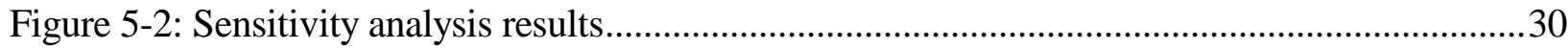

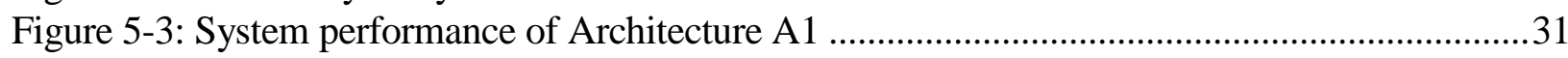

Figure 5-4: TE power and system power of Architecture A1 at different cold air split ratios ...........32

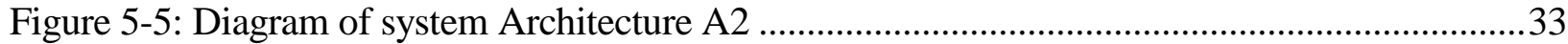

Figure 5-6: TE power and the power consumed by the shared air blower in Architecture A2 .........33

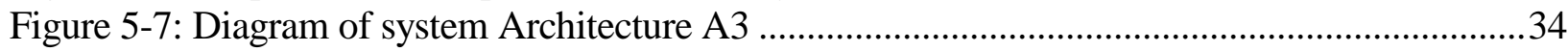

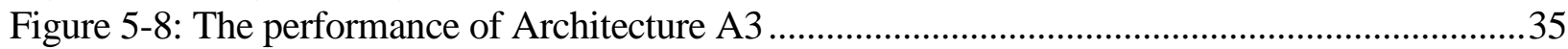

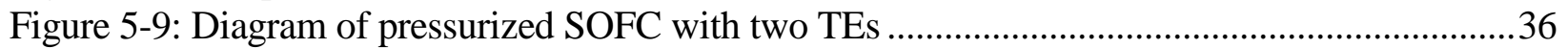

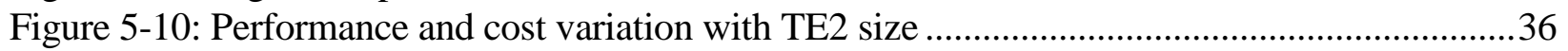

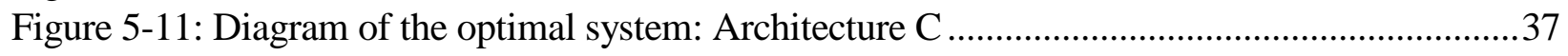

Figure 5-12: System efficiency as a function of turbine pressure ratio .........................................38

Figure 5-13: System efficiency as a function of the SOFC-TE interface temperature .....................39

Figure 5-14: TE efficiency as a function of the ZT and the cold flow rate for the TE ....................40

Figure 5-15: SOFC-TE system cost as a function of the system capacity in $\mathrm{kW}$............................42

Figure 6-1: Diagram for the parallel connection between SOFC and TE in PCS ..........................44

Figure 7-1: Figure of merit (ZT) for current TE material (p-type and n-type) [33] .........................54

Figure 7-2: Traditional TE couple configuration using segmented elements .................................54

Figure 7-3: Compatibility factor for current $\mathrm{p}$ - and n-type materials [33] ........................................55

Figure 7-4: Photographs of the initial segmented pellets ..........................................................56

Figure 7-5: Development and prognoses of specific cost and production quantity for the PV inverter

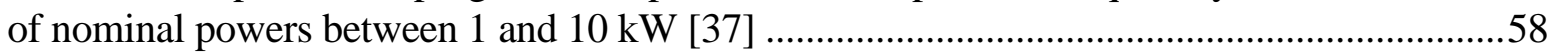

Figure 8-1: A staged development approach proposed for the SOFC-TE technology .....................60 


\section{List of Tables}

Table 2-1: Summary of the power conditioning system (PCS) concepts ......................................15

Table 3-1: Materials for applications with hot-side temperatures up to $250^{\circ} \mathrm{C}$.............................. 18

Table 3-2: Materials for applications with hot-side temperature between 250 and $500^{\circ} \mathrm{C} \mathrm{\ldots .............19}$

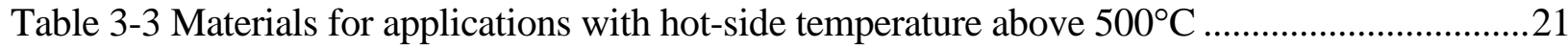

Table 4-1: Cost models in SOFC-TE modeling ...................................................................25

Table 4-2: Comparison of cost with the A. D. Little data (Unit: \$) ............................................26

Table 5-1: System sensitivity analysis variables and ranges .....................................................29

Table 5-2: Rotating machinery sensitivity analysis variables and ranges ...................................29

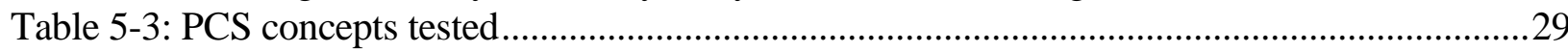

Table 6-1: Major design specifications for the 200kWe pressurized SOFC-TE system .................47

Table 6-2: Major design specifications for the 200kWe ambient pressure SOFC-TE system ..........47

Table 6-3: SOFC-TE component life and replacement schedule ................................................49

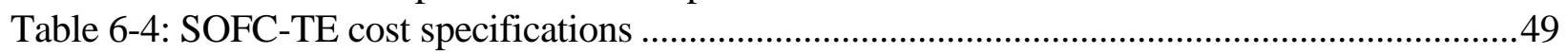

Table 8-1: Configuration options for the Phase II proof-of-concept unit .......................................62 


\section{References}

1. Energy Information Administration (EIA), 'International Energy Outlook 2006', Office of Integrated Analysis and Forecasting, U.S. Department of Energy, Washington, DC, June 2006, www.eia.doe.gov/oiaf/ieo/index.html

2. Energy Information Administration (EIA), 'International Energy Outlook 2006', Office of Integrated Analysis and Forecasting, U.S. Department of Energy, Washington, DC, February 2006, www.eia.doe.gov/oiaf/ieo/index.html

3. GridWorks, 'Overview of the Electric Grid, Office of Electricity Delivery \& Energy Reliability', U.S. Department of Energy, web information, http://www.energetics.com/gridworkds/grid.html

4. International Energy Agency (IEA), 'Roadmapping Coal's Future - Zero Emission Technologies for Fossil Fuels', OECD/IEA, France, 2005, http://www.iea.org/textbase/papers/2005/roadmapping.pdf

5. W.A. Surdoval, U.S. DOE Fossil Energy Fuel Cell Program, U.S. Department of Energy, National Energy Technology Laboratory, 'Fuel Cells for a Sustainable World', July 2005, http://www.efcf.com/e/past/2005_fcw_program.pdf

6. Crane, Douglas T., 'Potential Thermoelectric Applications In Diesel Vehicles,' Proceedings of the 9th Diesel Engine Emissions Reduction (DEER) Conference, Newport, Rhode Island, August 2003.

7. Intersociety Energy Conversion Engineering Conference (paper 20076) - 'Systems-Level Optimization of Low-Temperature Thermoelectric Waste Heat Recovery' (July 31, 2002) Authors: Douglas Crane and Gregory Jackson

8. U.S. Department of Energy, Solid State Energy Conversion Alliance (SECA), web information, http://www.netl.doe.gov/technologies/coalpower/fuelcells/seca/

9. $\quad$ Bilbro, J. W., "Technology Resources", 2001 NASA Training.

10. gPROMs webpage, http://www.psenterprise.com/gproms/

11. A. D. Little, Conceptual Design of POX/SOFC 5kW Net System, 2001, http://seca.doe.gov/technologies/coalpower/fuelcells/publications/conceptualdesignofpoxsof c5kwnetsystem.pdf

12. Robert J. Braun, Optimal Design and Operation of Solid Oxide Fuel Cell Systems for Small-scale Stationary Applications, Ph.D. dissertation, University of Wisconsin Madison, 2002

13. Compositional information supplied by the DOE in response to questions concerning Topic 3D of DEPS26-04NT42249-0, "DEVELOPMENT OF TECHNOLOGIES AND

CAPABILITIES FOR COAL ENERGY RESOURCES”, CFDA No. 81.089, Debra A.

Duncan, Contract Specialist, Tel. 412-386-5700, email: duncan@ netl.doe.gov 
MIT/Industry Consortium on Advanced Automotive Electrical/Electronic Components and Systems - 'The Potential of Thermoelectric Waste Heat Recovery for Automotive Electrical Systems' (Jan. 30, 2002)

14. Cummins Power Generation, $10 \mathrm{~kW}$ SOFC Power System Commercialization, SECA Semi-Annual Report 41244R02, February, 2003

15. A. Hagen, M. Menon, S. Ramousse, P.H. Larsen, R. Barfod, P.V. Hendriksen, in Sixth European Solid Oxide Fuel Cell Forum Proceedings, M. Mogensen (eds.), p. 930, European Fuel Cell Forum, Oberrohrdorf, Switzerland, 2004.

16. M. Mogensen, P.V. Hendriksen, in High Temperature Solid Oxide Fuel Cells, Fundamentals, Design, and Applications, S. C. Singhal,D. Kendall, Eds, Chaper 10, Elsevier Advanced Technology (2003).

17. GATE Forum - 'Towards Optimization of Automotive Waste Heat Recovery Using Thermoelectrics' (March 23, 2001)

18. SAE World Congress (paper 2001-01-1021) - 'Towards Optimization of Automotive Waste Heat Recovery Using Thermoelectrics' (March 7, 2001) Authors: Douglas Crane, Gregory Jackson, and David Holloway

19. GATE Symposium - 'Optimization of Automotive Waste Heat Recovery Using Thermoelectrics' (Oct. 7, 2000)

20. John Laumer, "GE Delivers Coal-Fueled, Solid Oxide Fuel Cell (SOFC) Prototype", http://www.treehugger.com/files/2006/10/ge_delivers_coa_1.php, 2007

21. http://www.netl.doe.gov/publications/press/2006/06032-SECA_Phase_II_Awards.html

22. http://greatlakesindustrialfansandblowers.com/

23. James Larminie and Andrew Dicks, Fuel Cell Systems Explained, $2^{\text {nd }}$ Ed, Wiley, 2003

24. R. Gupta, B.S. Turk, T.C. Merkel and A. Lopez-Ortiz, "Emerging technologies for he production of ultraclean IGCC syngas", 2001 Gasification Technologies Conference, http://www.gasification.org/Presentations/2001.htm, Oct 7-10, 2001,

25. http://www.apec-conf.org/2005/APEC_2005_SP1_3.pdf

26. Hsu, K. F. et al., "Cubic AgPbmSbTe2+m: Bulk Thermoelectric Materials with High Figure of Merit," Science, Vol. 303, No. Feb. 6, 2004 (2004), pp. 818-821.

27. Harman, T. C. et al., "Quantum Dot Superlattice Thermoelectric Materials and Devices," Science, Vol. 297,(2002), pp. 2229-2232.

28. Caillat, T. et al., "Development of High Efficiency Segmented Thermoelectric Unicouples," 20th International Conference on Thermoelectrics, Beijing, China. 2001, pp. 282-285.

29. Bell, L. E., "Use of Thermal Isolation to Improve Thermoelectric System Operating Efficiency," 21st International Conference on Thermoelectrics, Long Beach, CA. 2002, pp. 477-487.

30. Diller, R. W. et al., "Experimental Results Confirming Improved Performance of Systems Using Thermal Isolation," 21st International Conference on Thermoelectrics, Long Beach, CA. 2002, pp. 548-550. 
31. Bell, L. E., "High Power Density Thermoelectric Systems," 23rd International Conference on Thermoelectrics, Adelaide, AU. 2004.

32. Bell, L. E., "Alternate Thermoelectric Thermodynamic Cycles with Improved Power Generation Efficiencies," 22nd International Conference on Thermoelectrics, Hérault, France. 2003.

33. Snyder, G. J., http://www.its.caltech.edu/ jsnyder/thermoelectrics.

34. Snyder, G. J., "Thermoelectric Power Generation: Efficiency and Compatibility," in Thermoelectrics Handbook Macro To Nano, Rowe, D. M., Editor. CRC Press (Boca Raton, FL, 2006), pp. 9-1 - 9-26.

35. Bell, L. E., "Efficiency Thermoelectrics Utilizing Thermal Isolation " BSST LLC, Irwindale, CA (US), (USA, 2003), US 6,539,725 B2.

36. Bell, L. E., "Efficiency Thermoelectrics Utilizing Convective Heat Flow," BSST LLC, Irwindale, CA (US), (United States, 2004), 06672076.

37. Re-Focus.net, http://www.re-focus.net/features/archive/janfeb04/janfeb04_full_2.html, 2006

38. D. Gerogiorgis, K.Kouramas, N. Bozinis and E.N. Pistikopoulos, Design and Performance of an Explicit Parametric Controller for a Solid Oxide Fuel Cell (Sofc) System, AIChE Annual Meeting, San Francisco, CA, USA, 2006

39. EG\&G Technical Services, Inc., Fuel Cell Handbook, http://www.netl.doe.gov/technologies/coalpower/fuelcells/seca/pubs/FCHandbook7.pdf

40. Jason Lai et al, III.C.3 A Low-Cost Soft-Switched DC/DC Converter for Solid Oxide Fuel Cells, 2006 Office of Fossil Energy Fuel Cell Program Annual Report, Dept. of Energy, 2006 


\section{List of Acronyms and Abbreviations}

$\mathrm{AC}$

ADL

BSST

Btu

CGS

CHP

COP

DC

DOE

GT

GW

HHV

IGBT

IGCC

JPL

LAST

LHV

$\mathrm{MBE}$

MPC

MW

PCS

PP

PR

PSOFC

PV

QDSL

RTI

SECA

SOFC

TAGS

TE/TEG

UTC

UTRC

UWM

ZT alternate current

Arthur D. Little Inc.

BSST LLC

British thermal unit

concept generation session

cooling, heating and power

coefficient of performance

direct current

Department of Energy

gas turbine

gigawatt

high heating value

insulated gate bi-polar transistor

Integrated gas combustion cycle

Jet Propulsion Lab

thermoelectric material, chemical composition $\mathrm{AgPb}_{\mathrm{m}} \mathrm{SbTe}_{2+\mathrm{m}}$

low heating value

molecular beam epitaxy

model predictive control

megawatt

power conditioning system

power plant

pressure ratio

pressurized solid oxide fuel cell

photovoltaic

quantum dot superlattice

Research Triangle Institute

Solid-state e

solid oxide fuel cell

thermoelectric material, chemical composition $\left(\mathrm{AgSbTe}_{2}\right)_{1-\mathrm{x}}(\mathrm{GeTe})_{\mathrm{x}}$ thermoelectric (technology or hardware)/thermoelectric generator.

United Technologies Corporation

United Technologies Research Center

University of Wisconsin Madison

figure of merit for TE 